UNIVERSIDADE DE SÃO PAULO

INSTITUTO DE PSICOLOGIA

MARCIA KAMEYAMA

Variabilidade comportamental em ratos jovens e idosos expostos a diferentes contingências de reforçamento, com e sem exigência de variação ou repetição, e à extinção.

(Versão corrigida)

São Paulo 
Variabilidade comportamental em ratos jovens e idosos expostos a diferentes contingências de reforçamento, com e sem exigência de variação ou repetição, e à extinção.

(Versão corrigida)

Tese apresentada ao Instituto de Psicologia da Universidade de São Paulo, como parte dos requisitos para obtenção do grau de Doutora em Psicologia

Área de concentração: Psicologia Experimental

Orientadora: Profa. Dra. Maria Helena Leite Hunziker

São Paulo

2019 


\section{Kameyama, Marcia}

Variabilidade comportamental em ratos jovens e idosos expostos a diferentes contingências de reforçamento, com e sem exigência de variação ou repetição, e à extinção / Marcia Kameyama; orientadora Maria Helena Leite Hunziker. -- São Paulo, 2019.

$104 \mathrm{f}$.

Tese (Doutorado - Programa de Pós-Graduação em Psicologia Experimental) -Instituto de Psicologia, Universidade de São Paulo, 2019.

1. variabilidade operante. 2 . variabilidade induzida. 3. envelhecimento. 4. magnitude do reforço. I. Leite Hunziker, Maria Helena, orient. II. Título. 
Nome: Marcia Kameyama

Título: Variabilidade comportamental em ratos jovens e idosos expostos a diferentes contingências de reforçamento, com e sem exigência de variação ou repetição, e à extinção.

Tese apresentada ao Instituto de Psicologia da Universidade de São Paulo, como parte dos requisitos para obtenção do grau de Doutora em Psicologia Área de Concentração: Psicologia Experimental Orientadora: Profa. Dra. Maria Helena Leite Hunziker

Aprovada em :

Banca Examinadora:

Prof. Dr.

Instituição:

Assinatura:

Prof. Dr.

Instituição:

Assinatura:

Prof. Dr.

Instituição:

Assinatura:

Prof. Dr.

Instituição:

Assinatura:

Prof. Dr.

Instituição:

Assinatura:

Prof. Dr.

Instituição: Assinatura: 
Ao Felipe, meu melhor amigo, meu amor, meu marido. 


\section{AGRADECIMENTOS}

À Maria Helena Leite Hunziker, a Tatu, por ser muito incrível! Difícil achar as palavras para expressar minha admiração! Sei que aprendi que trabalhar com amor é essencial, e como eu precisava dessa lição! Estar perto da Tatu é estar em constante aprendizado, ser incentivado a ter um olhar curioso e crítico a todas as coisas a nossa volta; é também aprender a compartilhar os perrengues e pedir ajuda. É saber que você pode contar com um apoio para resolver os grandes pepinos da coleta, e também ter suporte nos assuntos de ordem pessoal. Vou ser sempre grata por ter sido sua aluna Tatu!

Ao Felipe, por ter sido companheiro tão dedicado desde o momento que eu decidi fazer o doutorado. Não houve esforços que você não fizesse para me ajudar, para acalmar minhas ansiedades, para me fazer sorrir, para me ver saudável! Obrigada por me ouvir falar incessantemente sobre o meu projeto, sobre meus ratos, sobre minhas angústias e conquistas. Obrigada por colocar a mão na massa, seja lendo meus textos, me acompanhando todo final de semana à USP, na formatação final da tese, e em tantas outras coisas. Sem você, essa jornada teria sido ainda mais dura. Você trouxe e traz leveza para minha vida e para minha alma! Te amo!

Ao meu pai que sem eu perceber muitas vezes foi a pessoa que sempre me concedeu amor incondicional, especialmente nos momentos mais difíceis. À minha irmã Silvana que cuidou de mim de diversas formas, sendo parte essencial da minha vida, meu porto seguro! Obrigada por me ensinar muitas matemáticas, e por me fazer companhia naqueles momentos em que só você poderia estar lá! Ao meu irmão Oswaldo, sempre disponível a me ajudar a entender massa molar, calorias e tantas coisas difíceis para eu poder entender os artigos que eu tinha que ler. Um amigão incrível, sempre ligando pra que eu pudesse ter contato com ele e minha sobrinha linda! Veve, a titia te ama, e espera poder passar mais tempo com você agora! À minha mãe que, mesmo em outro plano, foi minha base para tudo que sou hoje!!!

À Alessandra Villas-Bôas, que mesmo distante da Análise Experimental do Comportamento já há algum tempo, se dispôs a discutir minhas perguntas de pesquisa e metodologias, e a ouvir meus desabafos sempre com muito carinho. Obrigada por me ajudar a crescer tanto pessoal como profissionalmente (ajudando a preencher pontos importantes para me ajudar a me sentir completa durante o doutorado), e pela parceria de anos sendo a melhor amiga que eu poderia ter! E também à Lara por ser a afilhada mais linda do mundo, e por tantas alegrias nos últimos dois anos.

À Lígia Mosolino de Carvalho que foi presença constante nesses anos, me ajudando a lidar com as coisas que eu não conseguia sozinha. Por se tornar tão essencial que cabe no número 6! Por dividir interesses, por me socorrer em diversos momentos, pelas tagarelices cheias de risadas e assuntos estimulantes, por dividir planos e sonhos. Te admiro muito!

À Tauane Gehm por me incentivar e me apoiar a fazer o doutorado. Você foi para mim, desde o início, um modelo de paixão e competência. E por, em diversos momentos, ser extremamente sensível ao que eu precisava, quando eu nem mesmo sabia pedir. Este caminho eu não teria traçado sem você!!

Ao Amilcar R. Fonseca Jr. por tirar minhas dúvidas e por discutir muitas e muitas vezes meu projeto e meus resultados, mesmo me fazendo chorar! Aliás, obrigada por me chamar de Marcinha...rsrs! Obrigada pelas tantas risadas e até mesmo pelas brincadeiras no Mural da 
Vergonha. Pela parceria e pelos muitos bilhetes que faziam das coletas menos solitárias. Pela ajuda com equipamentos e por cada coisa que você me ensinou nesses anos! Você é de fato uma enciclopédia ambulante! E um grande amigo!

Ao Eduardo Souza por toda parceria de perrengues bioteirísticos!! Só nós sabemos como foi dureza, e você tornou as coisas mais fáceis (na medida que dava né amigo...rsrs). Obrigada pela companhia de bandejões, pelas conversas, por toda a ajuda com os ratos e com feedbacks nos meus textos, e por ser sempre a pessoa que eu podia contar!

Ao Labc, em especial Laís, Fernanda, Tauane, Lígia, Carol, Luana, Pedro, Amilcar, Eduardo, Angélica, Aline, e Artur, por toda a ajuda e companheirismo. Durante todos esses anos, não faltou parceria, dedicação e competência desse grupo, que semanalmente trabalhava junto, estando cada um empenhado pelo crescimento do colega. Vocês são demais! Queria agradecer ao Pedro Zuccolo por ser minha referência desde antes do doutorado de profissional na área do envelhecimento. Você me ensinou muito e sou muito grata por isso!!

Ao Marcos Yamada por toda a ajuda com meus passos iniciais no laboratório! Pela ajuda com equipamentos, programas e planilhas. Sua ajuda foi essencial!

À Erica Santarém por ser minha companheira e incentivadora no tema de envelhecimento. Sem ela eu não saberia o que queria estudar no doutorado. Por todas as conversas, todo o aprendizado e apoio que você me proporcionou!

Aos funcionários do Instituto de Psicologia -USP, em especial à Grazi Abe, à Édila e ao Celso por toda ajuda com os ratos e pela competência quanto ao funcionamento do Biotério; à Sonia Caetano por ser sempre solícita e eficiente no apoio dados aos alunos; aos porteiros do bloco A pela simpatia e apoio em todos os finais de semana de coleta.

Ao Lourenço Barba e à Natalia Aggio por todas as contribuições no exame de qualificação.

Aos colegas de laboratórios vizinhos, em especial Andeson Carneiro e William Patarroyo, pelo companheirismo e pela ajuda com questões referentes à metodologia e com o cuidado dos ratos. Andeson, obrigada pelo excelente trabalho como representante discente.

Ao Vinicius David por toda a ajuda com a estatística e não-estatística.

Ao Marcio Bandeira pela confecção dos softwares para coleta dos dados.

À Taninha, Adriana, Salete e Cida (em memória) pela companhia nesses anos, pelos cuidados com a minha alimentação (Taninha não me deixava comer mal) e pelas risadas!

Aos amigos por entenderem os sumiços e por serem sempre muito cuidadosos!

À Maíra, Verena e Débora, essas mulheres incríveis, pelo cuidado com minha saúde física e emocional.

À Coordenação de Aperfeiçoamento de Pessoal de Nível Superior (CAPES) pelo apoio financeiro a esta pesquisa. 


\section{RESUMO}

Kameyama, M. (2019). Variabilidade comportamental em ratos jovens e idosos expostos a diferentes contingências de reforçamento, com e sem exigência de variação ou repetição, e à extinção. Tese de Doutorado. Instituto de Psicologia, Universidade de São Paulo, São Paulo.

O presente estudo teve como objetivo comparar a variabilidade comportamental de ratos Wistar machos jovens (4 meses) e idosos (20 meses), tanto operante quanto induzida. No Experimento 1 , ratos jovens $(n=5)$ e idosos $(n=4)$ receberam reforço $($ SAC 10\%) contingente à emissão de sequências de quatro respostas de pressão a duas barras, em cinco fases: FR4 - VAR - ACO VAR - Extinção. Avaliou-se quantitativamente o nível de variabilidade pelos índices U e MetVAR, e qualitativamente pela distribuição das frequências relativas das 16 sequências possíveis. Os resultados mostraram que não foram encontradas diferenças entre jovens e idosos: sob FR4 houve pouca variabilidade, que aumentou sob VAR e declinou sob ACO; na condição de extinção, os animais variaram mais que nas condições anteriores. Porém, o reforço utilizado foi insuficiente para manter o responder dos animais idosos, sendo que apenas um chegou à última fase do experimento. Foi realizado o Experimento 2 utilizando maior magnitude de reforço: SAC 20\%. Ratos jovens $(n=5)$ e idosos $(n=4)$ foram submetidos às cinco fases experimentais descritas no Experimento 1, sendo acrescentado outros animais jovens $(n=5)$ e idosos $(n=5)$, expostos ao reforçamento da repetição (REP) nas fases em que os demais eram expostos à VAR. Todos os animais completaram o experimento, mostrando que sob VAR e REP não foram verificadas diferenças entre jovens e idosos (com alta e baixa variabilidade nessas condições, respectivamente). Contudo, os sujeitos idosos apresentaram menor variabilidade induzida pelas condições FR4 e ACO. A condição de extinção gerou altos índices de variação em todos os animais, porém mais acentuadamente nos animais anteriormente submetidos à REP. No seu todo, os resultados de ambos os experimentos indicaram que a idade dos sujeitos não interferiu nos padrões de variabilidade e repetição operantes. Contudo, os animais idosos mostraram comportamento menos variável frente a reforçamento não contingente à variação e necessitaram de maior magnitude do reforço (concentração da sacarose) para se manter respondendo na situação experimental. Tais resultados sugerem que as diferenças inicialmente observadas entre jovens e idosos, relativas à variabilidade do comportamento, podem ser minimizadas pela manipulação de contingências de reforçamento. Esses dados permitem que se questione se algumas das diferenças comportamentais atribuídas à idade (envelhecimento) podem ser decorrentes de diferentes contingências de reforçamento que atingem os indivíduos de ambos os grupos.

Palavras-chave: variabilidade operante; variabilidade induzida; envelhecimento; magnitude do reforço. 


\begin{abstract}
Kameyama, M. (2019). Behavioral variability in young and old rats exposed to contingencies of reinforcement, with and without variation or repetition requirement, and extinction. Doctoral Dissertation. Psychology Institute, São Paulo University, São Paulo.

The present study aimed to compare the behavioral variability - operant and induced - of young (4 months) and old (20 months) male Wistar rats. In Experiment 1, young $(\mathrm{n}=5)$ and old $(\mathrm{n}=$ 4) rats were exposed to positive reinforcement (10\% sucrose) of four-response sequences across two bars in five steps: FR4 - VAR - YOKE - VAR - Extinction. The level of variability was evaluated quantitatively by the U-value and MetVAR, and qualitatively by the distribution of the relative frequencies of the 16 possible sequences. The results showed that no differences were found between young and old animals: under FR4 there was little variability, which increased under VAR and declined under YOKE; under extinction, animals varied more than under the previous conditions. However, the reinforcement used was insufficient to maintain the response of old animals, with only one reaching the last phase of the experiment. Experiment 2 was performed using a larger reinforcement magnitude: $20 \%$ sucrose. Young ( $\mathrm{n}$ $=5)$ and old $(\mathrm{n}=4)$ rats were submitted to the same five experimental phases described in Experiment 1 , and more young animals $(n=5)$ and old $(n=5)$ rats were added to Experiment 2, submitted to the same five phases, except that VAR phases were replaced by REP phases (reinforcement was contingent to repetition of a single sequence). All animals completed the experiment. Under VAR and REP phases no differences were observed between young and old rats (with high and low variability under these conditions, respectively). However, old subjects had lower induced variability under FR4 and ACO contingencies. Extinction produced high rates of variation in all animals, but more markedly in animals previously submitted to REP. Results of both experiments indicated that subjects' ages did not interfere with operant variability and repetition patterns. However, the older animals showed less induced variable behavior under contingency of intermittent reinforcement, and required a greater magnitude of reinforcement (sucrose concentration) in order to keep lever-presses responses. These results suggest that the differences initially observed between young and old rats, related to behavior variability, can be minimized by the manipulation of reinforcement contingencies. These data allow us to question whether some of the behavioral differences attributed to age (aging) may be due to different reinforcement contingencies that affect individuals in both groups.
\end{abstract}

Keywords: operant variability; induced variability; aging; magnitude of reinforcement. 


\section{LISTA DE TABELAS}

Tabela 1 - Resumo do delineamento experimental, com a ordem de apresentação das contingências e número de sessões mínimas planejado para cada fase. Com exceção das fases sinalizadas $\left(* \mathrm{e}^{* *}\right)$, o experimento foi realizado tendo duas barras disponíveis na caixa experimental.

Tabela 2 - Número de sessões realizadas sob cada contingência e no total do experimento relativo a cada sujeito. Na linha inferior é reapresentado o número mínimo de sessões que haviam sido programadas. Com exceção das fases sinalizadas $\left(* \mathrm{e}^{* *}\right)$, o experimento foi realizado tendo duas barras disponíveis na caixa experimental.

Tabela 3 - Delineamento experimental, com a ordem de apresentação das contingências e números de sessões mínimas planejadas em cada fase. Com exceção das fases sinalizadas (* e **), todo o experimento foi conduzido tendo duas barras na caixa experimental.

Tabela 4 - Número de sessões realizadas sob cada contingência e no total do experimento pelos sujeitos VAR, idosos e jovens (I-VAR e J-VAR, respectivamente). Na linha inferior é reapresentado o número mínimo de sessões que haviam sido programadas. Com exceção das fases sinalizadas $\left(* \mathrm{e}^{* *}\right)$, todo o experimento foi conduzido tendo duas barras na caixa experimental.

Tabela 5 - Número de sessões realizadas sob cada contingência, e no total do experimento, pelos sujeitos REP, idosos e jovens (I-REP e J-REP, respectivamente). Na linha inferior é reapresentado o número mínimo de sessões que haviam sido programadas. Com exceção das fases sinalizadas $\left(* \mathrm{e}^{* *}\right)$, todo o experimento foi conduzido tendo duas barras na caixa experimental 


\section{LISTA DE FIGURAS}

Figura 1 - Valor U, MetVAR, porcentagem de reforço e taxa de resposta dos sujeitos idosos e jovens nas sessões válidas de cada fase experimental. São apresentados os dados individuais dos sujeitos, em que os gráficos à esquerda correspondem aos sujeitos idosos, e os gráficos à direita, aos sujeitos jovens

Figura 2 - Distribuição de sequências emitidas por sujeitos idosos e jovens em cada fase experimental. São apresentadas as frequências relativas das sequências emitidas na primeira e última sessão de cada contingência, tendo como universo 16 sequências possíveis. No eixo horizontal, estão ordenadas sequências agrupadas em função do número de alternações (entre barras exigido para sua emissão: mais à esquerda estão as sequencias com zero alternação, seguidas pelas que exigem uma, duas ou três alternações entre barras). As áreas cinza e branca delimitam os conjuntos de sequências por número de

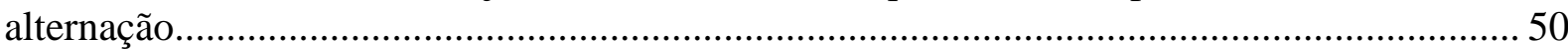

Figura 3 - Distribuição de sequências emitidas pelos sujeitos idosos e jovens em Lag 4' e EXT. São apresentadas as médias das frequências relativas das sequências emitidas nas cinco últimas sessões de Lag 4' e nas cinco sessões de EXT, tendo como universo 16 sequências possíveis. No eixo horizontal, estão ordenadas sequências agrupadas em função do número de alternações (entre barras exigido para sua emissão: mais à esquerda estão as sequencias com zero alternação, seguidas pelas que exigem uma, duas ou três alternações entre barras). As áreas cinza e branca delimitam os conjuntos de sequências por número de alternação.

Figura 4 - Valor U, MetVAR, porcentagem de reforço e taxa de resposta dos sujeitos VAR, idosos e jovens (I-VAR e J-VAR, respectivamente), nas sessões válidas de cada fase experimental. São apresentados os dados individuais dos sujeitos, em que os gráficos à esquerda correspondem aos sujeitos Idosos, e os gráficos à direita, aos sujeitos jovens.

Figura 5- Valor U, MetVAR, porcentagem de reforço e taxa de resposta dos sujeitos REP, idosos e jovens (I-REP e J-REP, respectivamente), nas sessões válidas de cada fase experimental. São apresentados os dados individuais dos sujeitos, em que os gráficos à esquerda correspondem aos sujeitos idosos, e os gráficos à direita, aos sujeitos jovens 71

Figura 6 - Porcentagem das sequências selecionadas para reforçamento sob REP nas sessões válidas de cada fase experimental. São apresentados os dados individuais dos sujeitos idosos e jovens submetidos à REP (I-REP e J-REP, respectivamente), em que o gráfico superior corresponde aos sujeitos idosos, e o gráfico inferior, aos sujeitos jovens. 73

Figura 7 - Distribuição de sequências emitidas por sujeitos VAR, idosos e jovens (I-VAR e JVAR, respectivamente), em cada fase experimental. São apresentadas as frequências relativas das sequências emitidas na primeira e última sessão de cada contingência, tendo como universo 16 sequências possíveis. No eixo horizontal, estão ordenadas sequências agrupadas em função do número de alternações (entre barras exigido para sua emissão: mais à esquerda estão as sequencias com zero alternação, seguidas pelas que exigem uma, duas ou três alternações entre barras). As áreas cinza e branca delimitam os conjuntos de sequências por número de alternação. 
Figura 8 - Distribuição de sequências emitidas por sujeitos dos Grupos I-REP e J-REP em cada fase experimental. São apresentadas as frequências relativas das sequências emitidas na primeira e última sessão de cada contingência, tendo como universo 16 sequências possíveis. No eixo horizontal, estão ordenadas sequências agrupadas em função do número de alternações (entre barras exigido para sua emissão: mais à esquerda estão as sequencias com zero alternação, seguidas pelas que exigem uma, duas ou três alternações entre barras). As áreas cinza e branca delimitam os conjuntos de sequências por número de

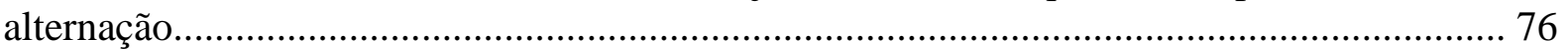

Figura 9 - Distribuição de sequências emitidas pelos sujeitos VAR, idosos e jovens (I-VAR e J-VAR, respectivamente), em Lag 4' e EXT. São apresentadas as médias das frequências relativas das sequências emitidas nas cinco últimas sessões de Lag 4' e nas cinco sessões de EXT, tendo como universo 16 sequências possíveis. No eixo horizontal, estão ordenadas sequências agrupadas em função do número de alternações (entre barras exigido para sua emissão: mais à esquerda estão as sequencias com zero alternação, seguidas pelas que exigem uma, duas ou três alternações entre barras). As áreas cinza e branca delimitam os conjuntos de

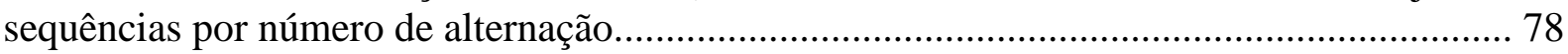

Figura 10 - Distribuição de sequências emitidas pelos sujeitos dos Grupos I-REP e J-REP em Lag 4' e EXT. São apresentadas as médias das frequências relativas das sequências emitidas nas cinco últimas sessões de Lag 4' e nas cinco sessões de EXT, tendo como universo 16 sequências possíveis. No eixo horizontal, estão ordenadas sequências agrupadas em função do número de alternações (entre barras exigido para sua emissão: mais à esquerda estão as sequencias com zero alternação, seguidas pelas que exigem uma, duas ou três alternações entre barras). As áreas cinza e branca delimitam os conjuntos de sequências por número de alternação 80 


\section{SUMÁRIO}

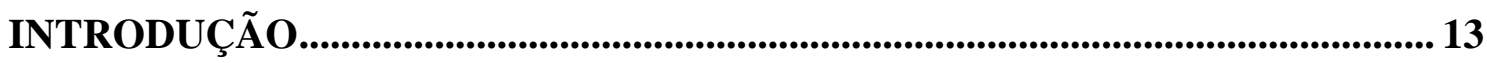

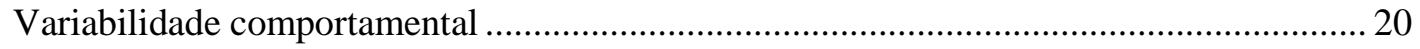

Variabilidade comportamental em idosos .......................................................................... 29

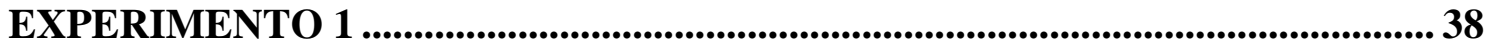

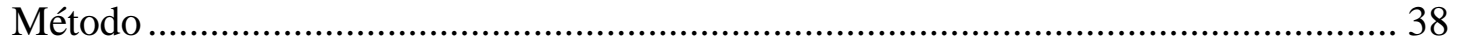

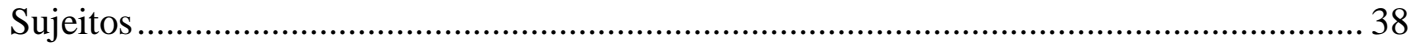

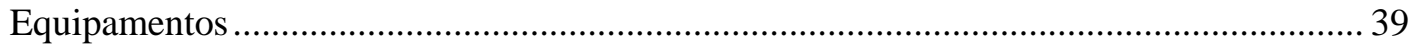

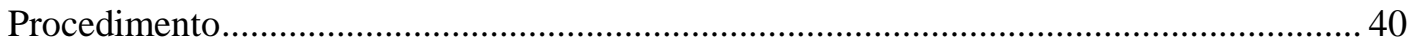

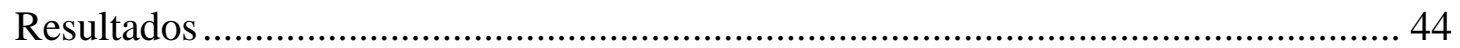

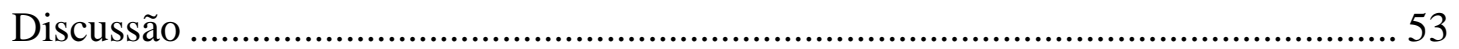

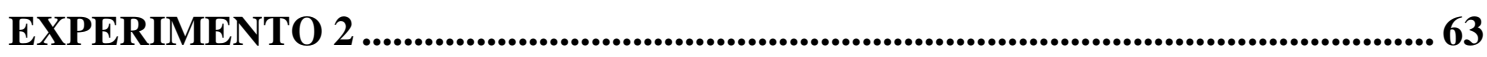

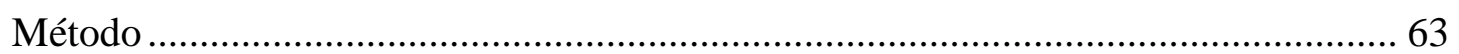

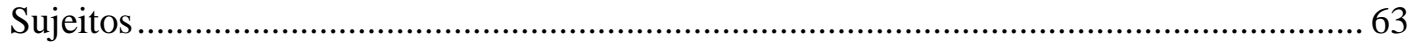

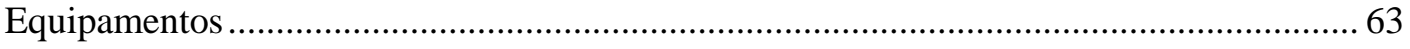

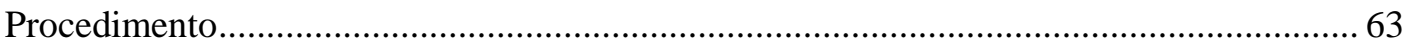

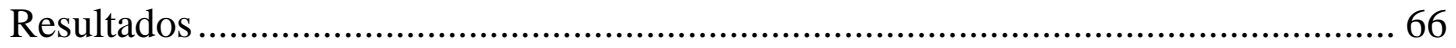

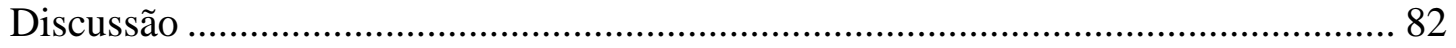

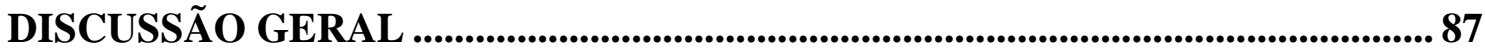

REFERÊNCIAS...............................................................................................94 


\section{INTRODUÇÃOO}

A população brasileira, nos últimos anos, tem vivido por mais tempo, sendo cada vez maior a parcela idosa no país. O envelhecimento populacional ${ }^{1}$ é um fenômeno mundial, já estabelecido em países desenvolvidos há algumas décadas, mas em ascensão nos países em desenvolvimento. No Brasil, nos anos de 1970, 1991 e 2010, a expectativa de vida era de 54, 67 e 74 anos, respectivamente. Espera-se que, em 2050, essa expectativa chegue a 81 anos. No que se refere à estrutura etária da população brasileira, em 2010, a parcela idosa (com idade $\geq 60$ anos) representava $10,8 \%$ do total da população. Em 2050, estima-se que essa parcela chegue a 22,71\% (Chaimowicz, 2009; IBGE, n.d.).

O envelhecimento é definido pela Organização Mundial de Saúde (OMS) como um

processo sequencial, individual, cumulativo, irreversível, universal, não patológico de deterioração de um organismo maduro, próprio a todos os membros de uma espécie, de maneira que o tempo o torne menos capaz de fazer frente ao estresse do meio ambiente e, portanto, aumente sua possibilidade de morte (Ciosak et al., 2011, pp. 1764).

Destaca-se desta definição de envelhecimento sua semelhança com definições analítico-comportamentais sobre o desenvolvimento do organismo. Bijou e Baer (1980) definem desenvolvimento como "mudanças progressivas na interação entre comportamento de um organismo com seu ambiente", não tendo o termo progressiva como sinônimo de melhoria, o que poderia descartar a fase da vida que inclui a velhice justamente por ser processo entendido como de deterioração do organismo (Gehm, 2013). Progressiva nesse sentido deve ser entendido sucessivo e cumulativo, como traz a definição de Ribes (1996) no que se refere às variáveis históricas também afetarem o comportamento do indivíduo, além daquelas imediatas no momento presente. Desse modo, para o estudo do envelhecimento é necessário compreendê-lo inserido numa perspectiva desenvolvimentista, uma vez que ocorrem mudanças constantes do comportamento dos indivíduos ao longo do curso da vida (ontogenia), da concepção à morte (Baltes, 1987) - logo, a velhice é a fase da vida mais próxima à morte, com o maior acúmulo de alterações orgânicas e comportamentais sucessivas.

\footnotetext{
${ }^{1}$ Pode-se classificar uma população de um país como envelhecida, quando a parcela acima de 80 anos ultrapassa os 14\% da população total (Chaimowicz, 2009).
} 
Ainda, apesar de universal, o envelhecimento é ao mesmo tempo um processo individual - por acontecer com todos, não significa que gerem processos iguais. $\mathrm{Na}$ área da Gerontologia/Geriatria, existem quatro classificações para o envelhecer: bemsucedido, normal, frágil e patológico (Moraes, 2008; Moraes, Marino, \& Santos, 2010). Essas classificações envolvem diferentes graus de saúde do idoso. Rowe e Kahn (1998) apresentam três indicadores para o envelhecimento bem-sucedido, que são: baixo risco de doenças e de incapacidades funcionais; funcionamento mental e físico excelentes; e envolvimento ativo com a vida. A capacidade funcional é definida por Moraes (2012) como "a capacidade de gerir a própria vida ou cuidar de si mesmo" (p. 10), ou seja, o indivíduo com a capacidade funcional preservada é aquele que consegue realizar suas atividades de modo independente (capacidade física de realizar algo por seus próprios meios) e autônomo (capacidade de tomar suas próprias decisões, estabelecendo e seguindo suas próprias regras). Neste sentido, as classificações citadas levarão em consideração esses aspectos, e em consonância com a definição de envelhecimento, que ponta ser este um processo não patológico, é possível perceber que não existe apenas um modo para o processo de envelhecimento acontecer. Como a pessoa irá envelhecer dependerá de fatores, que não serão apenas orgânicos/genéticos, mas também culturais e ontogenéticos.

Uma forma de medir a capacidade funcional de uma pessoa é por meio das atividades de vida diária (AVD), em que estas podem ser de dois tipos: atividades básicas de vida diária (ABVD) e atividades instrumentais de vida diária (AIVD). As primeiras envolvem atividades simples, como tomar banho, sentar-se e levantar-se e pentear o cabelo. As AIVD's são atividades mais complexas e que podem indicar declínio em habilidades como planejamento, antecipação, sequenciamento e monitoramento de tarefa complexas, além de serem as primeiras afetadas na Doença de Alzheimer, colaborando para seu diagnóstico. Alguns exemplos de AIVD’s são: usar o telefone, administrar o dinheiro, percorrer uma trajetória conhecida. (ver Moraes, 2008; Moraes et al., 2010).

Estudos correlacionais indicaram relações entre variáveis associadas a fatores sociodemográficos e a realização de atividades de vida diária (AVD) entre participantes com 60 anos ou mais (Santos, Lebrão, Duarte, \& Lima, 2008; Zuccolo et al., 2012). Nesses estudos, idade e escolaridade apresentaram correlação com a dificuldade apresentada pelos participantes na realização das AIVD's: quanto mais velho, maior a proporção de pessoas que relatavam dificuldades ou incapacidades de realizar tais atividades; e idosos com nenhuma ou baixa escolaridade também relataram ainda mais 
dificuldades ou incapacidades. No estudo de Santos et al. (2008), ainda, foi observado que gênero e renda também estavam associados a dificuldades nas AIVD's, em que mulheres idosas relataram mais dificuldades, assim como pessoas idosas com baixa renda.

Os fatores demográficos em si, apresentados nesses estudos, não seriam aqueles que afetariam as AVD's consideradas, mas sim, um conjunto de variáveis que os acompanham. Entre tais variáveis, estão: acesso e adesão a serviços de saúde; oportunidades de educação e quantidade de tempo dentro do sistema formal de ensino; condições e tipos de trabalho durante a vida; morar com cônjuge ou com mais membros da família; e atividades de lazer e culturais (Alexandre et al., 2014; Parahyba \& Veras, 2008; Zuccolo et al., 2012). Nesse sentido, gênero, renda e escolaridade, mais ou menos diretamente, podem sugerir influências da história de vida que podem estar correlacionadas com as dificuldades observadas. Entre as mulheres, por exemplo, a vulnerabilidade social, além da maior prevalência de doenças crônicas, estaria relacionada à maior incidência de incapacidade funcional neste grupo (Alexandre et al., 2014). Ainda, Parahyba e Veras (2008) argumentam a importância da escolha da renda familiar per capita como indicador de status socioeconômico, uma vez que é ela que possibilita acesso à boa educação, saúde e moradia de qualidade, transporte, entre outros bens, quando há insuficiência de suporte por parte do Estado, como ocorre no Brasil.

Numa perspectiva analítico-comportamental, é importante entender de que maneira o organismo envelhecido interage com o mundo, considerando o modo como esse organismo interfere na eficácia com que estímulos consequentes selecionam novas respostas e estabelecem a função dos estímulos antecedentes (Burgio \& Burgio, 1986). Neste sentido, alguns déficits comportamentais observados durante a velhice podem ser funções específicas de algumas contingências das quais o idoso está inserido, perda de reforçadores sociais, e de algumas alterações orgânicas próprias da idade, como surgimento e/ou aumento de dor e fadiga e diminuição de visão e audição, afetando a função de estímulos discriminativos (Baltes \& Barton, 1979).

Derenne e Baron (2002) argumentam que as técnicas comportamentais podem reabilitar um funcionamento deficiente e ser úteis nos fatores de riscos correlacionados à longevidade. Baltes e Barton (1979) e Burgio e Burgio (1986), por exemplo, realizaram um levantamento de estudos que demonstraram situações de idosos institucionalizados que recebiam maior quantidade de atenção e suporte contingentes a comportamentos classificados como dependentes e quase nenhuma atenção para comportamentos 
independentes. Quando esta atenção foi voltada para comportamentos mais independentes, estes aumentaram de frequência. Neste sentido, uma linha de pesquisa aplicada tem sido incluir programas comportamentais em instituições voltadas ao público idoso a fim de promover soluções para problemas de comportamento, como deambulação/agitação e as falas bizarras e paranoicas em pacientes institucionalizados e com demência, incontinência urinária, manejo da diabetes, falta de iniciativa em diálogos e baixa participação em atividades de idosos institucionalizados (Baltes \& Barton, 1979; Burgio \& Burgio, 1986; Burgio \& Kowalkowski, 2011; Goyos, Rossit, Elias, Escobal, \& Chereguini, 2009).

Já a pesquisa básica tem se voltado a buscar compreender se, e em que condições experimentais, sujeitos jovens e idosos apresentam diferenças fazendo uso das mais diversas tarefas comportamentais, assim como examinar se variáveis histórias podem afetar diferencialmente organismos jovens e idosos. Algeri, Biagini, Manfridi e Pitskas (1991), Winocur (1998) e Van Praag, Shubert, Zhao e Gage (2005) demonstraram com ratos jovens e idosos que fatores ambientais, como alimentação, atividade física e ambiente enriquecido, influenciaram o desempenho desses animais em teste de labirintos, que envolvem aprendizagem e memória espacial Testes de labirinto costumam ser usados na investigação do declínio em orientação espacial, sendo também um modelo animal para e alguns aspectos de enfermidades como a doença de Alzheimer.

Foram comparados grupos de ratos jovens e idosos que passaram por diferentes condições, nos quais os sujeitos tinham 3 e 19 meses no estudo de Van Praag et al. (2005) e 6-7 e 19-20 meses no estudo de Winocur (1998). No estudo de Algeri et al. (1991) foi realizado um estudo longitudinal, em que os animais foram pegos com 3 semanas de idade e divididos em grupos, já iniciando as alimentações diferenciadas, sendo submetidos aos testes experimentais aos 12, 24 e 30 meses. As condições pelas quais os grupos idosos passaram foram: no estudo de Algeri et al. (1991) os sujeitos grupos experimentais foram alimentados com ração hipocalórica e rica em fibras durante toda a sua vida, enquanto os dos grupos controle tiveram alimentação padrão; em Van Praag et al. (2005), os grupos experimentais tiveram acesso a roda de correr por 45 dias, enquanto o controle não; e em Winocur (1998), o grupo experimental foi alojado em habitação rica em estímulos (ambiente enriquecido) e o controle em habitação pobre em estímulos (ambiente empobrecido). Os sujeitos passaram por tais condições anteriormente aos testes de labirintos - labirinto aquático de Morris (Algeri et al., 1991; Van Praag et al., 2005), e labirinto de campo fechado Hebb-Williams (Winocur, 1998). 
Os resultados mostraram que os sujeitos dos grupos experimentais aprenderam melhor a tarefa, apresentando menor distância, latência de resposta e erros, quando comparados aos sujeitos do grupo controle. No que se refere à comparação dos grupos por idade, no trabalho de Algeri et al. (1991), os sujeitos do grupo experimental, que tiveram alimentação hipocalórica e rica em fibras, apresentaram melhores desempenhos na primeira vez que foram submetidos às condições experimentais, aos 12 meses, e embora ambos os grupos tenham aprendido rapidamente a tarefa, os animais do grupo experimental apresentaram índices melhores que os do grupo controle. Já aos 30 meses, os animais do grupo controle apresentaram piora no decorrer das sessões experimentais, enquanto que os do grupo experimental apresentou melhora. Nos estudos de Van Praag et al. (2005) e Winocur (1998) foi possível observar um melhor desempenho dos sujeitos jovens corredores e os que foram alojados em ambiente enriquecido em relação aos demais grupos. Em Van Praag et al. (2005), embora seja possível observar um melhor desempenho dos sujeitos jovens corredores em relação aos demais grupos, é importante ressaltar que, em alguns parâmetros, como a distância percorrida, o grupo idoso corredor não diferiu do grupo jovem sedentário, sendo que o grupo idoso sedentário sempre teve os piores desempenhos. Em Winocur (1998), os grupos idosos sempre apresentaram pior desempenho que os grupos jovens, embora o grupo idoso em ambiente enriquecido tenha sido melhor que o idoso ambiente empobrecido.

Esses estudos indicam que a idade não é o único fator para o déficit comportamental observado nos grupos idosos, mas que fatores como alimentação, realização ou não de exercício físico, tipo de ambiente de moradia, também podem estar associados aos declínios observados em sujeitos idosos. E assim como pode ser observado nos estudos correlacionais epidemiológicos descritos acima, fatores ambientais, sejam eles demográficos, sociais, econômicos, de estilo de vida, podem de modo direto ou indireto alterar o organismo ao longo de sua vida, fazendo com que esse ingresse na velhice de diferentes maneiras - podendo haver ou não uma vantagem inicial devido à sua história de vida -, e isso poderá influenciar o modo como o organismo responde ao que acontece com ele dali em diante.

Pesquisas básicas experimentais também demonstraram os efeitos do manejo de contingências e a exposição a uma tarefa para a melhora do desempenho de sujeitos idosos. Baron e Menich (1985) e Baron, Menich e Perone (1983) apresentaram o tempo de reação (TR) como uma propriedade do comportamento, e que deveria ser sensível aos eventos ambientais contingentes à resposta e utilizaram procedimentos de matching-to- 
sample com uma contingência de reforço que restringia o tempo de resposta na fase experimental. Comparou-se o desempenho de grupo jovem (18-23 anos) e idoso (63-79 anos no estudo de 1983, e 65-73 anos, no de 1985). Os autores observaram que o TR diminuía progressivamente na fase experimental para ambos os grupos, embora os TR's dos idosos se mantiveram maiores que dos jovens. Resultado semelhante foi encontrado no estudo de Myerson, Robertson e Hale (2007), que utilizou uma tarefa de julgamento igual-diferente de categorias de estímulos, sem a presença de uma contingência de reforço para que os participantes respondessem mais rapidamente, e comparou os TR's de grupos jovem (19-22 anos) e idoso (70-78 anos). Os autores entendem ser a maior lentidão dos participantes idosos uma característica desta faixa etária, mas que a exposição à tarefa auxiliou de maneira importante para que eles respondessem cada vez mais rápido (efeito do treino).

Quanto à acurácia (a escolha do estímulo correto de acordo com o modelo e o critério) das respostas dos participantes, Baron e Menich (1985) apontaram que, sendo reforçadas as tentativas corretas e as que estavam de acordo com o critério de tempo, a porcentagem de tentativas reforçadas diminuiu de acordo com a maior restrição de tempo, embora, o declínio tenha sido maior para os idosos. Dado semelhante foi encontrado por Baron et al. (1983), no sentido de que os resultados apontam para um aumento do número de erros na medida que a restrição de tempo se torna mais rigorosa. Contudo, eles não relatam diferenças entre os grupos. Da mesma forma, Myerson et al. (2007), que não manipularam a restrição de tempo, verificaram que a porcentagem de respostas corretas foi semelhante em ambos os grupos. Os fatores possíveis de estarem associados à diferença de resultados obtidos nos estudos de 1983 e 1985 seriam algumas variáveis alteradas na pesquisa de 1985: a composição dos estímulos, eram mais complexas, e a manipulação do atraso na apresentação dos estímulos de comparação após o surgimento do modelo. Os resultados sugerem, portanto, que em determinadas condições pode-se esperar que participante idoso possa ser tão eficiente quanto o jovem, ao menos no tipo de tarefa aqui considerada.

Em estudos com ratos e com o objetivo de comparar a aprendizagem e memória espaciais de grupos jovens (3-4 meses) e idosos (22-27 meses), Gage, Dunnett e Björklund (1984), Kobayashi, Kametani, Ugawa e Osanai (1987) e Pelleymounter, Smith e Gallagher (1987) utilizaram testes de labirinto, como o labirinto radial de oito braços e o labirinto aquático de Morris. Diferentemente dos animais jovens, foi verificado prejuízo na aprendizagem da tarefa por parte dos idosos, os quais exibiram estratégias menos 
efetivas, como visitar o terceiro braço seguinte do braço que tinham saído, e não o adjacente, como faziam os jovens, total de respostas maior para completar a tarefa, e maiores latências e distâncias percorridas que o grupo jovem para achar a plataforma, no caso do labirinto aquático. Entretanto, apesar disso, os animais idosos apresentaram melhora no desempenho em algumas medidas, como aumento de respostas corretas e diminuição gradual das latências de respostas, embora ainda assim tenham permanecido abaixo do grupo jovem.

É importante ressaltar, a partir dos estudos apresentados, que os efeitos das contingências de reforçamento no comportamento dos grupos idosos, sejam humanos ou não humanos, variou de acordo com o comportamento e os parâmetros mensurados e variáveis manipuladas. Nas tarefas que mediram TR e aprendizagem/memória espacial, as diferenças entre jovens e idosos se mantiveram, havendo assim um limite de efeito das variáveis ambientais no organismo idoso. Já quanto à acurácia na escolha do estímulo correto de acordo com o modelo nas tarefas de matching-to-sample e de julgamento de categorias de estímulos, os desempenhos sob algumas condições puderam ser equiparados com os dos jovens.

É possível, portanto, verificar a multidimensionalidade do processo de envelhecimento, em que as alterações observadas não ocorrem da mesma maneira no repertório comportamental do sujeito idoso como um todo, assim como não são da mesma maneira sensíveis aos efeitos das variáveis ambientais. Alterações em alguns comportamentos parecem de fato ocorrer com o avanço da idade, e elas devem ser consideradas no planejamento de uma pesquisa, ou mesmo, de uma intervenção comportamental. Ainda assim, algumas alterações podem não ser consequências inevitáveis do processo de envelhecimento, e com o estabelecimento de contingências específicas, os repertórios comportamentais de idosos podem ser aprimorados ou os déficits podem ser compensados.

Como apontado por Wells (1999), deve-se olhar esses déficits comportamentais no idoso com cautela, porque a tendência de se pensar que o envelhecimento de alguma maneira cria déficits se constitui como potencial problema, uma vez que cria conotações negativas à população idosa. Um dos problemas decorrentes desse tipo de visão, segundo a autora, estaria no tipo de pesquisa conduzida que espera que déficits aconteçam, podendo gerar vieses na formulação de hipóteses e a subsequente negligência de evidências que poderiam ser úteis, ou ainda levar a criação de tarefas que confirmem as expectativas anteriores. 
Nesse sentido, outro ponto importante de ser levado em consideração é como as variáveis ambientais parecem afetar diferentemente os sujeitos idosos inseridos num mesmo grupo, submetidos a mesmas condições, ou seja, a diversidade intragrupo. No estudo de Gage et al. (1984) sobre aprendizagem e memória espacial, citado anteriormente, e que utilizou o labirinto aquático de Morris, foi constatado uma diversidade notável entre os sujeitos do grupo idoso que não foi encontrada no grupo jovem. Os autores realizaram, além do teste de labirinto, testes de coordenação motora, de habilidades de nado, e medidas de atividade e exploração. Os animais apresentaram diversidade quanto aos testes em que apresentaram prejuízo, em que alguns exibiram prejuízos em apenas alguns deles, e outros em todos.

No trabalho de Baron et al. (1983), com humanos, também foi observado diversidade intragrupo. Nas medidas de TR, apesar de os participantes idosos responderem mais lentamente na média do grupo, uma proporção substancial de respostas emitidas por este grupo poderia ser encaixada na distribuição de respostas do grupo jovem. Também no estudo de Myerson et al. (2007) o grupo idoso tendeu a ser mais diversos que o grupo jovem. Assim, uma crítica metodológica que pode ser feita é que muitos estudos agruparam os indivíduos idosos com idades numa faixa muito abrangente (grupos de 60 até 82 anos, por exemplo), o que ocorreu em Baron et al. (1983), mas não em Myerson et al. (2007), o que torna a amostra ainda mais heterogênea. Os autores discutem esse tipo de agrupamento de participantes como sendo decorrente uma visão estereotipada de que idosos são todos semelhantes, não importando a idade que tenham (Nelson \& Dannefer, 1992).

De qualquer maneira, o desempenho de sujeitos idosos e a aparente manutenção das diferenças entre estes sujeitos e os jovens quando colocados para desempenhar determinadas tarefas deve ser considerada com cautela. É clara a grande heterogeneidade desta parcela da população, sendo importante, além de fazer uma boa seleção da amostra, incluir medidas de diversidade em pesquisas que envolvem a velhice, a fim de se ter uma melhor caracterização deste grupo.

\section{Variabilidade comportamental}

A variabilidade do comportamento é um fator importante para a seleção de comportamentos mais efetivos na vida do indivíduo; isto é, o surgimento de classes de respostas mais eficazes depende de que diferentes classes de respostas apareçam, até que 
uma delas seja selecionada (Skinner, 1966, 1981). Os níveis de variabilidade do comportamento de um indivíduo podem mudar a depender da contingência em vigor. Em determinadas situações o comportamento de um indivíduo pode ser bastante regular, repetitivo, enquanto em outras, ações criativas, de exploração e de resolução de problemas, variar o comportamento pode ocasionar uma maior obtenção de reforçadores (Neuringer, 2002, 2004, 2009).

Para Hunziker e Moreno (2000), a variabilidade comportamental deve ser entendida como a diferença ou mudança entre unidades comportamentais dentro de um universo previamente determinado. Por unidade comportamental entende-se cada instância ou elementos a serem comparados, em que o universo é a totalidade de unidades possíveis. A escolha das unidades e universos depende do ponto de vista ou decisão do pesquisador, podendo ser, por exemplo, a sequência de respostas de pressão a diferentes barras ou a resposta de bicar diferentes regiões de um painel, sendo que seus universos seriam todas as possibilidades de sequências dessas respostas, ou posições do painel, respectivamente (Hunziker \& Moreno, 2000; Rodrígues \& Hunziker, 2008).

Nos estudos sobre variabilidade comportamental, o modo como esta é conceituada influencia o modo como é mensurada (Hunziker \& Moreno, 2000). Segundo esses autores, a variabilidade pode ser conceituada, por exemplo, como dispersão ou equiprobabilidade. $\mathrm{Na}$ dispersão, o comportamento pode ser considerado mais variável quanto mais uma resposta se afasta de um valor central, como no estudo de Antonitis (1951) e Eckerman e Lanson (1969), que serão descritos adiante. Na dispersão tem-se como VD's adequadas a variância e o desvio padrão (Barba, 1997). Conceituada como equiprobabilidade, a variabilidade é tanto maior quanto mais as respostas se distribuem de forma equitativa entre as possibilidades existentes no universo comportamental. Este conceito tem como uma de suas formas de medidas mais usadas o índice (ou valor) U. O valor U é um índice de variabilidade comportamental que mede a distribuição das frequências de eventos possíveis dentro de um universo comportamental e que pode assumir valores entre 0 e 1 - quanto mais próximo do 1 , maior o grau de variabilidade, e quanto mais próximo do zero, maior o grau de repetição (Barba, 1997; Hunziker \& Moreno, 2000).

Barba (2006) aponta, ainda, para duas outras conceituações possíveis para a variabilidade: de recência e de dependência sequencial ou aleatoriedade. O conceito de recência define a variabilidade da seguinte forma: dada uma série de eventos, a variabilidade é avaliada a partir da "distância" entre a primeira ocorrência e sua segunda 
ocorrência de um evento. Quanto mais distante uma ocorrência for da outra, maior a variabilidade observada. Uma medida possível para este tipo de conceituação é o tempo de recorrência, que se refere ao número de eventos emitidos desde a sua última emissão (Yamada, 2012). A dependência sequencial ou aleatoriedade compreende que dois eventos são independentes se a ocorrência de um não afetar a probabilidade do outro. Neste sentido, haverá um maior grau de variabilidade quanto maior for o grau de independência entre os eventos, implicando também em um maior grau de imprevisibilidade (Barba, 1997). Uma VD possível para esse tipo de conceituação tratase da discrepância de índices U: dada uma sequência de eventos A-B-C-A-C-B-A, índices U serão calculados a partir de pares (AB, BC, CA, AC...), tercetos (ABC, BCA, CAC...) e quartetos (ABCA, BCAC...). A aleatoriedade dos eventos será medida se esses índices apresentarem valor $U$ semelhantes, indicando a independência entre os eventos considerados (para uma descrição e discussão mais detalhada, ver Barba, 2006).

No que se refere às conceituações que se pode ter a respeito da variabilidade, é importante que se deixe claro qual está sendo usada, ou que se realize a interpretação dos resultados por meio de mais de uma medida, uma vez que é possível encontrar diferentes níveis de variação a partir dos mesmos dados a depender da medida considerada. Por exemplo, na dispersão, as respostas podem se concentrar em poucos pontos distantes do ponto de referência e serem consideradas variáveis, mas ao empregar o critério de equiprobabilidade para esse mesmo caso, as respostas seriam repetidas por se concentrarem em poucos pontos (Hunziker e Moreno, 2000; Neuringer, 2002).

Um outro índice de variabilidade utilizado em algumas pesquisas (Maes, 2003; Neuringer et al., 2001; Souza, 2009) é o MetVAR, que corresponde à proporção de sequências que cumprem ou cumpririam um critério para reforçamento da variação selecionado pelo pesquisador. Quando o MetVAR é calculado nas fases em que a contingência de reforçamento da variação está em vigor, essa medida corresponde à proporção de reforços. O cálculo do MetVAR em fases em que variar não é critério para reforçamento, tem como objetivo mensurar a variabilidade induzida. Neste caso, usa-se, para o cálculo, um critério de variabilidade, sendo o mesmo empregado nas fases de variabilidade operantes, quando presente no estudo, para possibilitar a comparação entre elas. Diferentemente de outros índices, o MetVAR se mostra adequada para diferentes esquemas de reforçamento da variabilidade.

No entanto, independente do conceito e medidas de variabilidade usados empregados, considera-se que existam ao menos dois processos responsáveis pela 
variação do comportamento, sendo elas: a indução e seu reforçamento direto. Nas seções a seguir serão descritos cada um desses processos.

\section{Variabilidade induzida}

A variabilidade comportamental pode ser induzida por esquemas de reforçamento intermitente e pela extinção (Antonitis, 1951; Eckerman \& Lanson, 1969; Ferraro \& Branch, 1968; Herrick, 1965; Neuringer, 2002; Neuringer \& Jensen, 2012; Schaefer \& Steinhorst, 1959; Stebbins, 1962; Stebbins \& Lanson, 1962; Tremont, 1984; Villas-Bôas, 2006), podendo ser considerada um subproduto dessas contingências ambientais. Durante o reforço diferencial de uma resposta, a distribuição das respostas de um organismo passa a circunscrever predominantemente àquelas com dimensões (posição, topografia, força, etc.) que cumprem o critério estabelecido para reforçamento, reduzindo assim, a emissão de outras respostas emitidas antes de tal procedimento entrar em vigor (Catania, 1999). No caso da extinção, entende-se que ao deixar de apresentar o reforçador, que até então era apresentado contingente a uma resposta, ocorre um aumento na frequência de outras respostas que durante o reforçamento eram pouco prováveis de ocorrer, caracterizando a variabilidade.

No estudo de Antonitis (1951), por exemplo, seis ratos Wistar foram modelados a tocar com o focinho em um painel. Durante a fase de reforçamento contínuo (CRF), os sujeitos foram restringindo cada vez mais a localização de sua resposta a um ponto do painel, embora esse não fosse um critério para reforçamento. Na fase seguinte, o reforço deixou de ser apresentado, iniciando, assim, uma fase de extinção. Como resultado, obteve-se que os animais passaram a tocar com o focinho em locais variados do painel, até haver a redução da frequência da resposta própria da extinção. Dados semelhantes foram relatados por Eckerman e Lanson (1969, Experimento 1) e por Villas-Bôas (2006).

Eckerman e Lanson (1969, Experimento 1) treinaram três pombos a bicar um painel com 20 chaves. Uma vez modelada a resposta, os sujeitos passaram por uma fase de CRF em que a resposta de bicar em qualquer uma das 20 chaves era seguida por reforço. Em seguida, os sujeitos passaram por uma sessão de extinção, seguida por uma em CRF e outra de extinção. Durante as sessões em CRF, os sujeitos concentraram suas respostas aproximadamente nas chaves do centro do painel, enquanto que nas sessões de extinção, alteraram a localização de suas respostas bicando chaves diversas, o que caracterizou a maior variabilidade comportamental nesta fase. Villas-Bôas (2006) treinou 16 ratos Wistar a emitirem sequências de quatro respostas em duas barras (direita-D e 
esquerda- E). Após a extinção, foi possível observar um aumento da emissão de frequência de sequências não treinadas - além das sequências treinadas -, indicando um aumento da variabilidade comportamental.

Ferraro e Branch (1968) obtiveram relação semelhante entre variabilidade de intermitência do reforço. Eles treinaram quatro pombos a bicar em qualquer uma das oito chaves de um painel de respostas. Os animais foram submetidos a duas contingências diferentes: uma de CRF, outra de VI $1 \mathrm{~min}$, sendo repetida cada uma das fases intercaladamente. Para todos os sujeitos, a mudança do esquema de VI 1 min para o de CRF produziu uma diminuição da variabilidade relativa à localização das respostas, enquanto que a passagem do esquema de CRF para o de VI 1 min produziu seu aumento.

Schaefer e Steinhorst (1959) treinaram ratos Sprague-Dawley a pressionar uma barra, e sua VD era a duração em segundos que o rato mantinha a barra pressionada. A variabilidade foi mensurada comparando o tempo da resposta de pressão à barra entre as sessões ao longo de cada contingência. Entre outras condições, os autores submeteram os animais a três esquemas de reforçamento: CRF, razão fixa 5 (FR5), e FR 10. Dois animais passaram por 10 sessões em CRF, seguidas de 10 em FR5 e mais 10 em FR10. Dois outros sujeitos passaram por 10 sessões em CRF e 20 em FR10. Foi possível verificar que na mudança do esquema de CRF para o de FR5, a duração da pressão à barra variou nas primeiras sessões, mas se estabilizou nas sessões subsequentes. Posteriormente, na passagem de FR5 para FR10 as durações das respostas permaneceram estáveis. Já os animais que mudaram de CRF para FR10, apresentaram maior variação na duração das respostas de pressão à barra que as verificadas nos sujeitos anteriores em FR5, sem que as respostas se estabilizassem até o fim do experimento.

A indução de variabilidade por esquema de reforçamento intermitente é atribuída por Schoenfeld (1950) aos períodos de extinção existentes neles, que enfraquece a resposta anteriormente emitida, aumentando a variação dentro de uma mesma classe de respostas. Outras dimensões de repostas, tais como força, latência e deslocamento, também apresentaram resultados semelhantes aos acima descritos no que se refere à maior variabilidade comportamental induzida por esquema de reforçamento intermitente (Herrick, 1965; Stebbins, 1962; Stebbins \& Lanson, 1962; Tremont, 1984). Entretanto, é importante ressaltar que o aumento da variabilidade e sua manutenção pode depender de fatores como: um treino mais prolongado em um único esquema de reforçamento intermitente pode estabilizar os níveis de variabilidade, como ocorrido no estudo de Schaefer e Steinhorst (1959) - os autores não descartaram que a estabilidade da duração 
de resposta de pressão à barra também fosse encontrada em FR10 com um treino mais prolongado, uma vez que nesse esquema os níveis de variabilidade eram mais altos; e a natureza do esquema de reforçamento utilizado.

Boren, Moerschbaecher e Whyte (1978) treinaram dois macacos Rhesus a pressionarem seis barras. Inicialmente os animais foram submetidos a sessões sob o esquema FR100, seguidas por sessões sob FR200, FR 300, FR30, FR5 e CRF para um sujeito, e FR200, FR50, FR20, FR5, CRF e FR100 para o segundo sujeito. Posteriormente os sujeitos passaram por sessões de intervalo fixo (FI), nas seguintes ordens: FI 4, FI 0.5, FI 2, FI 1, FI 0.25, FI 0.06, e F I4 min para um sujeito, e FI 1, FI 2, FI 0.06, FI 0.25, FI 0.5, FI 4 e FI 1 min para o segundo sujeito. Os resultados mostraram que. em relação aos esquemas FR, a variabilidade diminuía à medida em que a razão aumentava. Quanto à variabilidade obtida nos esquemas FI, a relação foi direta, isto é, os níveis de variabilidade aumentavam à medida em que os intervalos também aumentavam. Os autores discutem que como o reforçamento, em FI, depende da emissão de uma resposta após a passagem de determinado tempo, a alternação entre barras se torna mais provável, uma vez que não altera a taxa de reforçamento. Já no esquema de FR, o animal tende a responder mais rapidamente, otimizando o ganho de reforços.

\section{Variabilidade reforçada}

Como dito anteriormente, o reforçamento organiza e fortalece uma classe de respostas, reduzindo a variação do comportamento de organismo em determinado contexto (Catania, 1999; Neuringer, 2002). Entretanto, na contramão de tal proposição, a variabilidade comportamental vem sendo estudada como uma dimensão operante do comportamento, isto é, passível de ser diretamente reforçada (Jensen, Miller, \& Neuringer, 2012; Neuringer, 2002, 2004). As evidências de que a variabilidade pode ser colocada sob controle operante demonstram que o responder variável aumenta de frequência quando o reforço é apresentado contingente a ele, e diminui quando o reforçamento ocorre de modo independente; a manipulação da exigência para reforçamento pode afetar os níveis de variação exibidas pelo organismo; além de ser possível colocar a variabilidade do comportamento sob controle de estímulos, o que é adaptativo para um organismo na medida em que ele discriminar quando variar e quando repetir produzirá maior reforçamento (Jensen et al., 2012; Page \& Neuringer, 1985; Neuringer, 2002, 2004). 
O estudo protótipo desse tipo de investigação foi o conduzido por Page e Neuringer (1985). Eles treinaram pombos a bicar duas chaves formando sequências de oito respostas distribuídas entre as chaves E e D. Em seu Experimento 3, o reforço era contingente à emissão de sequências variáveis segundo cinco critérios diferentes: as sequências deveriam diferir das últimas $5,10,15,25$ ou 50 sequências emitidas anteriormente pelo próprio sujeito (contingência $\operatorname{Lag} n$, na qual o $n$ corresponde ao número de sequências referentes para comparação da diferença com a atual). Sob Lag 5, as sequências tinham que diferir das cinco últimas para serem reforçadas; em Lag 10, diferir das dez últimas, e assim até Lag 50. A variabilidade foi calculada a partir da porcentagem de respostas que atingiram o critério de variabilidade, assim, como pelo cálculo do índice U. Foi observado, para ambos, que os pombos apresentaram sequências crescentemente variáveis na medida em que o critério Lag aumentou, tendo apenas uma leve queda sob Lag 50. Ainda assim, sob a contingência Lag 50 os sujeitos mantiveram níveis altos de variabilidade.

Outro procedimento muito usado para reforçamento do comportamento de variar é a contingência de limiar ou reforçamento dependente da frequência - RDF (Neuringer, 2002; Neuringer \& Jensen, 2012, 2013). Sob o RDF, o reforço é liberado contingente às sequências com frequência relativa abaixo de um limiar pré-determinado, isto é, as sequências reforçadas são aquelas menos emitidas pelo sujeito, sem ultrapassar um valor estabelecido pelo experimentador. Sob tal contingência é aplicado um coeficiente de amnésia, menor que 1,0, o qual é multiplicado às frequências das demais sequências - não reforçadas na tentativa -, o que diminui progressivamente suas frequências à medida em que se tornam menos recentes. Logo, a probabilidade de serem reforçadas se eleva. Diferentemente do que ocorre sob Lag, sequências repetidas podem ser reforçadas desde que atendam o critério estabelecido, além de ocasionar uma maior distribuição de respostas entre as sequências possíveis ao reforçar sequências menos frequentes e menos recentes.

Embora os resultados de Page e Neuringer (1985, Experimento 3) tenham fortalecido a ideia de que a variabilidade poderia ser reforçada, os autores conduziram um novo experimento (Experimento 5) que visou testar se a variabilidade encontrada sob a contingência Lag estava sob controle de fato do reforçamento, e não sendo induzida pela intermitência do reforço. Assim, submeteram os mesmos sujeitos do Experimento 3 a uma condição de acoplamento (ACO), em que os reforços eram liberados contingentes a uma sequência de oito respostas, mas independente da sua variação - quer fossem iguais 
ou diferentes das anteriores. As distribuições dos reforços foram as mesmas das sessões sob Lag 50, sendo que as seis primeiras sessões de ACO seguiram as distribuições das seis últimas sob Lag 50, isso se repetindo até o fim desta fase. Assim, se na sessão em Lag 50 os reforços ocorreram nas tentativas 4, 7 e 11, na sessão de ACO, os reforços também ocorreram nessas tentativas - cada tentativa corresponde a um período de delimitação da resposta, que era iniciada pelo acendimento das luzes da chave, momento no qual o sujeito deveria emitir a sequência de respostas de bicar as chaves; a tentativa era encerrada pelo reforçamento da sequência ou pelo time out, em que as luzes da chave se apagavam e nenhum reforço era liberado. Os autores verificaram que sob ACO os níveis de variabilidade das respostas dos sujeitos, mensurados pelo índice $U$, foram significantemente menores que na fase de Lag 50.

A contingência $\mathrm{ACO}$ foi adotada em outras pesquisas como forma de demonstrar o controle da variabilidade pela contingência de reforçamento (e.g., Barba \& Hunziker, 2002; Neuringer \& Huntley, 1991; Yamada, 2012), sendo possível programar o acoplamento também de uma segunda maneira: a distribuição dos reforços nas sessões dos sujeitos a serem expostos por ACO podem seguir a distribuição das sessões de VAR de outros sujeitos, da mesma maneira como descrito acima, porém o acoplamento se dá entre pares de sujeitos. Por exemplo, se um sujeito exposto à contingência em que o variar é reforçado, recebe reforços na tentativa 3, 7, 8 e 11, o sujeito acoplado a ele, receberá os reforços nas mesmas tentativas, independente da configuração da sequência emitida. Este procedimento de acoplamento ocorre quando se tem um delineamento de grupo, em que um grupo passa por VAR e outro por ACO, como em Yamada (2012), ou quando num delineamento $\mathrm{ABAB}$, a primeira fase consiste em $\mathrm{ACO}$, como em Hunziker, Caramori, da Silva e Barba (1998).

Em um último experimento, Page e Neuringer (1985, Experimento 6) demonstraram que a variabilidade pode ficar sob controle discriminativo, assim como outras dimensões do comportamento operante. Em um esquema de reforçamento múltiplo, com o componente de variabilidade (VAR) associado à luz azul e o componente de repetição (REP) associado à luz vermelha, sequências de seis respostas foram ref orçadas em VAR sob o critério Lag 10, enquanto que em REP foi reforçada apenas a sequência EDDEE. Posteriormente, foi feita a reversão da função dos estímulos luminosos associados a cada componente: azul passou a indicar REP e vermelho, VAR; além disso, o número de respostas requerido para formar uma sequência sob VAR diminuiu de seis para cinco, para igualar com REP. A precisão do responder em cada uma 
das contingências foi medida pela porcentagem de reforçamento, em que era necessário atingirem o critério de Lag 10 ou REP para serem reforçados. Durante a fase de aquisição, os sujeitos apresentaram altas porcentagens de reforçamento, sendo a aprendizagem sob REP mais lenta. Na fase de reversão, os desempenhos dos sujeitos tiveram uma piora imediata, mas logo recuperaram sua precisão. O controle discriminativo também foi demonstrado por Denney e Neuringer (1998), em que em um componente do esquema múltiplo vigorou a contingência VAR e no outro a contingência ACO.

Posteriormente, outros trabalhos utilizaram o esquema múltiplo com sucesso para estudar a resistência à mudança de comportamentos de variar e repetir (AbreuRodrigues, Hanna, Mello-Cruz, Matos, \& Delabrida, 2004; Cohen, Neuringer, \& Rhodes, 1990; Dougthy \& Lattal, 2001; Odum, Ward, Barnes, \& Burke, 2006; Ward, Bailey, \& Odum, 2006) e o efeito da magnitude do reforço na variação (Doughty, Giorno, \& Miller, 2013). Outras pesquisas têm explorado também a interação entre as variabilidades induzida e operante (Cherot, Jones, \& Neuringer, 1996), e os efeitos, na variabilidade operante, do atraso do reforço (Wagner \& Neuringer, 2006), da história de reforçamento (Hunziker et al., 1998; Hunziker, Lee, Ferreira, Silva, \& Caramori, 2002) e de instruções (Hunziker et al., 2002), além de que a variabilidade operante é igualmente controlada por reforçamento negativo (Cassado, 2009; Fonseca Júnior, 2015; Samelo, 2008, 2012).

Pesquisas têm demonstrado que determinadas alterações ambientais geram mais disrupções no desempenho de sujeitos que foram treinados a emitir sequências de respostas em REP do que em VAR, aumentando, assim, os níveis de variabilidade no primeiro, mas tendo pouco ou nenhum efeito nos níveis de variabilidade no segundo. Os fatores estudados que geram essas disrupções têm sido: o fornecimento de alimento antes da sessão ou durante a sessão, concorrentemente ao esquema de VAR ou REP em vigor, em pombos (Doughty \& Lattal, 2001); a administração i.p. de etanol anteriormente às sessões, em ratos (Cohen et al., 1990); e o atraso do reforço, em pombos (Odum et al., 2006); entre outros.

Neuringer, Kornell e Olufs (2001, Experimento 1), que submeteu ratos machos Long-Evans jovens à contingência RDF, seguida de EXT, demonstrou que os índices MetVAR apresentaram aumento sob EXT em comparação com a contingência RDF. No Experimento 3, Neuringer et al. (2001) reforçaram ratos Long-Evans de quatro meses a emitirem uma única sequência de três respostas a duas barras e uma chave (ECD) com probabilidade de reforçamento de $65 \%$. Sob EXT, os índices MetVAR aumentaram mais 
de duas vezes que os obtidos sob REP, enquanto que os sujeitos submetidos à VAR tiveram índices, sob EXT, até 1,4 vez maior que sob VAR.

Entretanto, Yamada (2007) obteve resultados diferentes de Neuringer et al. (2001). Yamada (2007) treinou ratos machos Wistar jovens a emitir sequências de respostas a duas barras, e verificou, que o aumento do índice $U$ dependia da contingência anterior de reforçamento da variabilidade, Lag 5 ou RDF, em que houve um pequeno aumento em Lag 5, e dados menos consistentes em RDF. Maes (2003) e Souza (2009), em que estudantes universitários foram solicitados a emitir sequências de respostas em três e duas teclas, respectivamente, encontraram um efeito diferencial da extinção nos níveis de variabilidade, após uma fase em que ela foi reforçada, dependendo da medida utilizada. Em ambos os trabalhos, os valores U tenderam a permanecer estáveis ou exibiram queda leve na extinção. Quanto ao MetVAR, Maes (2003) encontrou efeitos inconsistentes e Souza (2009) observou queda acentuada nessa medida.

Cabe ressaltar que os valores U obtidos no experimento de Yamada (2007) foram bastante altos (acima de 0,8), sendo que nas contingências RDF foram mais altos que os valores sob Lag 5, o que pode sugerir que a depender dos níveis de variabilidade alcançados durante a contingência em que o variar é reforçado, isso pode ter um efeito diferencial na extinção. Os participantes dos experimentos de Maes (2003) e Souza (2009) também tiveram altos níveis de variabilidade, em que o valor $U$ esteve acima de 0,8 nas condições em que variar foi reforçado. Os índices MetVAR, em Souza (2009) encontraram-se em ascensão, atingindo valores próximos de $75 \%$, na contingência de reforçamento do variar, e em Maes (2003) tiveram padrões mais assistemáticos.

\section{Variabilidade comportamental em idosos}

A velhice é vista como uma etapa da vida relacionada à redução da capacidade física e social do indivíduo: ocorrem perdas de papéis sociais, aposentadoria, morte de pessoas queridas, além da perda de agilidade motora, visão e audição e o aparecimento de doenças (Skinner \& Vaughan, 1985). Entretanto, algumas alterações que acompanham o processo de envelhecimento, incluindo as comportamentais, podem não ser consequências direta da idade, mas sim de contingências ambientais às quais o idoso está sujeito. Dessa maneira, é possível que alguns dos déficits comportamentais de idosos possam ser recuperados, aprimorados ou compensados se contingências ambientais adequadas forem estabelecidas. 
A variabilidade comportamental pode ser particularmente importante para o idoso, na sua adaptação a novos contextos decorrentes das mudanças que ocorrem nessa fase da vida. Ela está intimamente vinculada com a aquisição de novos comportamentos, resolução de problemas e exploração de novos interesses, entre outros. No senso comum considera-se que o idoso é propenso a poucas variações, preferindo o ambiente já conhecido e se comportando de maneira pouco variável. Será essa uma característica decorrente da idade avançada ou é apenas um exemplo de mudança de contingências que promovem essas mudanças comportamentais? Uma maneira de se responder a essa questão é pesquisar se organismos idosos têm a mesma "capacidade" de variar que organismos jovens, ou seja, se apresentam comportamentos variáveis frente a condições indutoras ou reforçadoras desse padrão comportamental. Os procedimentos experimentais anteriormente citados, empregados em estudos com humanos e não humanos, podem ser extremamente úteis nesse tipo de investigação.

Dois trabalhos foram realizados nessa linha, com humanos. No de Lopatto et al. (1998) foi comparada a variabilidade operante de pessoas jovens (19 a 24 anos) e idosos (64 a 98 anos). Esses participantes passaram por uma tarefa que consistia em completar uma matriz 6 × 6 e, para tal, deveriam emitir sequências de dez respostas de pressão a dois botões, sendo necessário pressionar cinco vezes cada um deles, para levar um cursor da parte superior esquerda para a parte inferior direita. No primeiro experimento deste estudo, os participantes passaram, primeiramente, pela contingência $\mathrm{CRF}$, seguida de reforçamento intermitente em razão variável 3 (VR3). Diferentes participantes passaram por um segundo experimento, no qual diferentes exigências de variação foram testadas: Lag 1, Lag 2 e Lag 3. A variabilidade foi medida por meio da frequência de sequências dominantes, em que quanto maior a dominância, menor a variação. Não foram obtidas diferenças entre os grupos.

Rangel (2010, Experimento 1), por sua vez, submeteu participantes jovens (18 a 30 anos) e idosos (60 a 75 anos) a um esquema múltiplo com um componente REP e outros três componentes VAR com diferentes níveis de variabilidade, apresentados em ordem crescente (Lag, 1, Lag 5 e Lag 25). A tarefa consistia em completar uma matriz 5 x 5, levando um cursor da parte superior esquerda para a parte inferior direita. $\mathrm{O}$ participante deveria emitir uma sequência de 8 respostas, sendo necessário ter quatro respostas em um botão e quatro em outro botão. Além do reforçamento contingente ao comportamento de variar (ganho de 10 pontos), foi incluída no procedimento a punição (perda de 5 pontos) às sequências que não atendiam ao critério estabelecido para variação. 
A escolha pelo uso da punição se deu para melhorar o desempenho dos participantes ao possibilitar uma maior discriminação entre as contingências em vigor e diminuir o número total de tentativas, o que, para a autora, poderia favorecer a adesão dos participantes à pesquisa.

Como resultado, observou-se que sob REP, todos os sujeitos apresentaram baixos índices de variabilidade, exceto por um sujeito idoso, que teve valor U próximo de 0,8 . Houve também aumento da variabilidade sob VAR em ambos os grupos à medida em que a exigência de variação crescia. A autora concluiu que os participantes jovens variaram mais do que os idosos, embora essa diferença não tenha sido confirmada por análises estatísticas. Os dados individuais indicaram que a maior diferença entre jovens e idosos se deu na contingência REP e Lag 1. Sob REP, quatro dos cinco participantes idosos obtiveram valor $U$ menor que 0,2 , enquanto que quatro de cinco participantes jovens tiveram índices de entre 0,2 e 0,4 . Sob $\operatorname{Lag} 1$, três de cinco participantes idosos apresentaram baixos índices $\mathrm{U}$ (cerca de 0,2 ), enquanto que apenas um sujeito jovem obteve baixo valor $\mathrm{U}$; os demais participantes, idosos e jovens, tiveram índices em torno de 0,8. Já sob Lag 5, as diferenças entre jovens e idosos diminuíram, em que apenas um participante idoso ainda apresentava índice $U$ mais baixo (cerca de 0,3), enquanto os demais participantes obtiveram índices próximos a 0,8. Sob Lag 15, sujeitos idosos e jovens exibiram índices $U$ semelhantes entre si, em torno de 0,8 .

Mais do que simplesmente apontar semelhanças e diferenças entre os comportamentos de jovens e idosos, os dados nos permitem fazer uma análise crítica sobre a funcionalidade desses resultados: 1) sob REP, pode-se considerar que os idosos foram mais adaptados à contingência que os jovens, dado que seus índices $U$ foram mais baixos; 2) sob Lag 1, contingência que exige baixíssima variação, os baixos índices U dos idosos foram perfeitamente funcionais, mais adaptados à contingência operante que os altos índices U dos jovens; 3) com alta exigência de variação para liberação do reforço (Lag 15), a idade não foi uma variável que produziu diferenças entre os sujeitos. Assim, ao menos no que diz respeito à variabilidade operante, esses dados sugerem que tanto idosos como jovens variaram ou repetiram igualmente. A variabilidade "espontânea" talvez ocorra diferencialmente entre jovens e idosos de forma que jovens variaram mais do que a contingência exigia (como sob $\operatorname{Lag} 1$, aqui descrito). Tal variabilidade não é controlada por antecedentes ou consequentes manipulados experimentalmente, mas, possivelmente induzida por fatores biológicos - como observado em outras condições, como em ratos hipertensos (SHR) que variam mais que ratos Wistar Kyoto (Mook, 
Jeffrey, \& Neuringer, 1993; Mook \& Neuringer, 1994), ou indivíduos autistas ou com depressão, que tendem a variar menos que aqueles sem esses diagnósticos (Hopkinson \& Neuringer, 2003; Miller \& Neuringer, 2000).

Rangel (2010, Experimento 3), ainda, procurou investigar se o atraso do reforço e a extinção afetariam diferentemente os desempenhos de participantes jovens e idosos sob as condições VAR e REP. Dessa maneira, submeteu novos participantes, jovens e idosos, a um esquema múltiplo com um componente de REP e outro VAR em Lag 5, nos mesmos parâmetros que no Experimento 1. Foram realizadas linhas de base (LB) REP e VAR, seguidas de outras fases com duas manipulações: primeiramente, atrasou em $5 \mathrm{~s} \mathrm{a}$ consequência de reforço ou punição; e, depois de retomada a LB, iniciou-se a extinção. O níveis de variabilidade sob REP foram mais afetados pelas manipulações que sob VAR. Comparando os grupos jovens e idosos, houve diferenças entre os grupos sob REP, mas dependendo da medida considerada: enquanto as porcentagens de sequências corretas do grupo idoso diminuíram com o atraso da consequência e com a extinção, os tempos de recorrência aumentaram; em relação ao grupo jovem, houve aumento no índice U, sem alterações na porcentagens de sequências corretas e nos tempos de recorrência. Observouse, assim, um efeito assistemático para ambos os grupos. Entretanto é importante ressaltar que houve pouca diferença nos tempos de recorrência e no índice $\mathrm{U}$ dos idosos em cada contingência - VAR e REP - durante as LB's, indicando dificuldade dos idosos em discriminar a mudança dos componentes do esquema múltiplo

Apesar da importância dos trabalhos de Lopatto et al. (1998) e Rangel (2010), alguns pontos referentes a aspectos metodológicos, desde a escolha dos sujeitos e da tarefa até parâmetros utilizados no procedimento, podem ser entendidos como problemáticos, afetando os resultados obtidos nesses estudos. Em Lopatto et al. (1998), os sujeitos idosos possuíam idade entre 64 e 98 anos, diferenças essas que comprometem a consideração de todos como pertencentes a um mesmo grupo: a amostra de participantes idosos com uma faixa etária tão ampla pode acarretar numa maior diversidade intragrupo. Nesta linha, foi constatado que os desvios padrão das médias das frequências dominantes nas contingências VR3, Lag 0, Lag 1 e Lag 2 e das porcentagens de reforçamento referentes às contingências Lag do grupo idoso foram maiores do que os do grupo jovem. Rangel (2010), por sua vez, apontou para uma possível falta de experiência com computadores por parte dos participantes idosos, que pode ter sido uma variável interveniente em seu estudo, o que também foi apontado por Lopatto et al. (1998) como 
um fator que poderia afetar a diversidade intragrupo verificada entre os participantes idosos.

Outro ponto importante em ambos os trabalhos foi a restrição à quantidade de respostas em cada botão para a formação das sequências: os participantes não podiam ultrapassar a quantidade de respostas em cada botão - cinco em Lopatto et al. (1998) para sequências de dez respostas, e quatro em Rangel (2010) para sequências de oito respostas -, que era encerrada a tentativa, contabilizada como erro. Foi demonstrado por Page e Neuringer (1985) que essa restrição é fonte de interpretações equivocadas a respeito do controle operante da variabilidade em estudos anteriores. Os autores avaliaram que essa restrição reduz os níveis de variabilidade, uma vez que a quantidade de sequências no universo comportamental diminui. Ainda, por haver dois tipos de erros - um que é repetir a sequência, e outro que é pressionar mais de cinco vezes um botão -, a porcentagem de reforçamento diminuiria, sendo que no segundo caso não estaria relacionada à variabilidade, VD do estudo.

Em relação aos dados referentes ao Experimento 3, que não mostrou discriminação entre componentes VAR e REP entre os sujeitos idosos, Rangel (2010) apontou que seria talvez necessário os participantes idosos permanecerem mais tempo expostos ao treino para que seus desempenhos melhorassem, o que estaria de acordo com a literatura da área de envelhecimento que indicam que ratos idosos necessitam maior quantidade de treino para aquisição de responder discriminado (Brushfield, Luu, Callahan, \& Gilbert, 2008; Schoembaum, Nugent, Saddoris, \& Gallagher, 2002; Stephens, Weidmann, Quartermain, \& Sarter, 1985). Além disso, considerou que uma possível diferença de valor reforçador dos pontos obtidos na tarefa pode ter afetado diferencialmente o desempenho dos dois grupos. Rangel (2010) entendeu que os pontos poderiam ser mais reforçadores para os jovens por estarem inseridos em um contexto mais competitivo e mais familiarizados com jogos que pontuam.

A questão se a idade poderia influenciar os níveis de variabilidade comportamental operante também foi trazida para a pesquisa com não humanos por Neuringer e Huntley (1991), que compararam grupos de ratos jovens (2 meses) e adultos (10 meses). Eles foram treinados a emitir sequências de quatro respostas em duas barras, sob esquema de reforçamento Lag 4 (VAR) e sob ACO, em um delineamento VAR ACO - VAR. Seus resultados indicaram que, na condição VAR, ratos jovens e adultos variaram em níveis semelhantes, mas na condição ACO, os ratos adultos variaram significantemente menos. 
Mais direcionado à velhice, Wells (1999, Experimento 1) comparou a variabilidade comportamental de ratos machos Long-Evans adultos (8 meses) e idosos (24 meses), com o mesmo delineamento experimental de Neuringer e Huntley (1991). Os resultados não mostraram diferença estatisticamente significante entre os dois grupos em nenhuma das duas condições. Um segundo experimento visou testar se a dificuldade da resposta poderia afetar os níveis de variabilidade dos ratos idosos. Dessa maneira, além da resposta de pressão à barra, acrescentou-se uma chave na parede oposta às barras. Os sujeitos deveriam responder nas duas barras e na chave para formar sequências de quatro respostas. Nesse experimento foi utilizado ao invés do critério $\operatorname{Lag} 4$, a contingência RDF que reforça as sequências menos frequentes e menos recentes. Os sujeitos foram submetidos a duas fases VAR e uma ACO, intercaladas. Novamente, não foram observadas diferenças nos níveis de variabilidade entre os ratos adultos e idosos, tanto em VAR quanto em ACO.

Um terceiro experimento foi conduzido por Wells (1999), baseado em Neuringer (1991), que identificou uma relação inversa entre a taxa de resposta e a variabilidade comportamental, manipulando os intervalos entre as respostas (IER) por meio do seu reforçamento diferencial. Os resultados de Neuringer (1991) indicaram que ao forçar o animal a responder mais pausadamente, o esquema gerava não apenas diminuição das taxas de resposta, mas também elevava os níveis de variabilidade. Uma das interpretações apresentada pelo autor foi que maiores pausas entre as respostas diminuem a taxa de reforçamento, o que pode aumentar a variabilidade por indução.

Assim, em seu um terceiro experimento, Wells (1999) aumentou sistematicamente os IER's a partir da segunda sessão na primeira condição VAR para os grupos jovens e idosos: os IER's iniciaram em 0,33s, passaram para 0,66s, chegando até a 1,5s, ao longo de nove sessões. Após atingir 1,5s, ele foi mantido constante e foram realizadas mais cinco sessões em VAR, seguidas de 15 sessões em ACO e cinco em VAR. Os dois grupos apresentaram índices de variabilidade semelhantes na condição VAR. Porém, em ACO, o grupo idoso apresentou porcentagem de variação significantemente maior que o grupo jovem, embora o índice U de dois grupos não tenha apresentado diferença estatisticamente. Nesse experimento, as taxas de resposta diminuíram em comparação aos demais experimentos para os dois grupos, mas a taxa de resposta do grupo idoso foi significantemente menor que a do adulto, o que, foi visto pela autora, como determinante para os maiores níveis de variabilidade obtidos pelos idosos. 
Embora nos trabalhos de Neuringer e Huntley (1991) e Wells (1999), os resultados relacionados aos níveis de variabilidade obtidos nas contingências em que o comportamento de variar foi reforçado tenham sido semelhantes entre jovens $\mathrm{e}$ adultos/idosos, os dois estudos diferiram em relação aos dados referentes à ACO. Uma possível explicação pode ser o fato dos animais de ambos os estudos apresentarem idades distintas. No estudo de Neuringer e Huntley (1991), os animais mais velhos possuíam 10 meses, enquanto no estudo de Wells (1999), o grupo idoso possuía 24 meses de idade. Além em disso, algumas questões metodológicas devem ser consideradas como passíveis de terem interferido nos resultados alcançados por Wells (1999). Uma delas foi a medida de variação empregada. Barba (1997) analisa que o valor U é um índice confiável apenas se seu cálculo for feito com uma quantidade mínima de tentativas, correspondente a 10 vezes o universo de possibilidades, que, em Wells (1999), era de 16 sequências, exigindo um mínimo de 160 sequências emitidas, o que na maior parte do tempo não ocorreu. A medida de porcentagem de variação possibilita, nesses casos, uma análise mais confiável, porém, os valores U e porcentagem de variação medem tipos de variabilidade diferentes, em que a primeira está associada ao conceito de equiprobabilidade e, a segunda, de recência. No caso, o estudo de Wells (1999) utilizou o valor U sem ter esse mínimo de sequencias emitidas pelos animais idosos.

É possível que a pequena taxa de resposta dos animais idosos de Wells (1999) se devesse ao reforço utilizado. No estudo com animais de diferentes idades, utilizandose reforço consumatório, é importante que seja avaliado se o mesmo montante de reforço tem propriedades reforçadoras equivalentes para jovens e idosos. O estudo de Everitt (1958) sugere que não. Ele mapeou o consumo de água e alimento de ratos machos Wistar, não privados, desde sua fase adulta (aos sete meses) até sua morte (a maioria dos animais sobreviveu até cerca de 25 meses, mas houve animais que viveram até os 33 meses). Este autor verificou que os animais apresentaram um decréscimo acentuado no consumo de água até mais ou menos os 18 meses, com estabilização do consumo até o $25^{\circ}$ mês de idade, e posterior aumento. $\mathrm{O}$ consumo de alimento teve queda acentuada até $18^{\circ}$ mês, com leve queda do consumo após este período até o $25^{\circ}$ mês, e posterior estabilização. Os resultados de todos os sujeitos da amostra apresentaram médias menores de consumo pelos sujeitos de 17 a 25 meses.

Tanto em Neuringer e Huntley (1991), como em Wells (1999), foram usados como reforçadores pelotas de alimento (pellets). O dado de Everitt (1958) tem maior implicação no trabalho de Wells (1999), uma vez que os animais utilizados tinham 
diferença de idade muito grande entre si, e logo, apresentavam necessidades calóricas muito diferentes. Assim, utilizar ração como reforçador para sujeitos idosos pode não ter a mesma eficácia em manter as taxas de resposta desses sujeitos comparativamente aos jovens. Nessa direção, Frutos et al. (2012) compararam a preferência entre ração e solução de sacarose (SAC) diluído à 16,2\% por ratos Fischer-344 machos de 3 e 18 meses, por meio de testes de preferência de escolha, verificando a preferência dos ratos idosos pela solução de SAC, em comparação à ração.

$\mathrm{Na}$ mesma linha, foi realizado pela pesquisadora do presente estudo, um experimento-piloto com ratos Wistar machos jovens (4 meses) e idosos (20 meses), treinados a emitir sequências de quatro respostas à duas barras. Foi constado que a maioria dos animais idosos emitiu menos que 110 sequências numa sessão de 45 min sob FR4 tendo água como reforçador. Havendo 16 sequências possíveis, essa quantidade é inferior ao número mínimo necessário para o cálculo de um índice U confiável. Diante disso, considerou-se que talvez a água não fosse o melhor reforçador a ser utilizado com animais idosos. Por isso, foi testada a solução de SAC a 10\% como reforçador. Optou-se pela concentração de $10 \%$, por esta ser bastante utilizada em estudos com animais jovens, entre 3 a 6 meses, de modo eficaz para manter altas taxas de respostas (Bernardes, 2008; Buczek, Wang, Steward, \& Shaham, 1999; Grimm, Fyall, \& Osincup, 2005; Grimm, Shaham, \& Hope, 2002; Shalev, Morales, Hope, Yap, \& Shaham, 2001). Após um período de adaptação, em que os sujeitos foram submetidos à CRF e à FR2, os animais idosos elevaram suas taxas de resposta, emitindo o número mínimo necessário para o cálculo do valor $U$.

Entende-se, portanto, ser importante alterar o reforçador utilizado, em comparação ao utilizado por Wells (1999), a fim de se ter um maior controle experimental no que se refere à manutenção do responder dos sujeitos idosos. Rangel (2010) também apontou que possíveis diferenças no valor reforçador dos pontos poderiam estar interferindo nos níveis de variabilidade exibida pelos participantes idosos, assim como na discriminação entre componentes VAR e REP em esquema de reforçamento múltiplo. Outros ajustes no procedimento parecem importantes a fim de se ter um maior rigor experimental, comparável ao obtido por Neuringer e Huntley (1991), entretanto, comparando sujeitos jovens e idosos, a fim de, mais do que avaliar o efeito da idade na variabilidade comportamental, comparar um organismo jovem, normalmente utilizado nas pesquisas experimentais, com um organismo idoso que já passou pelas alterações 
orgânicas comuns ao processo de envelhecimento (Baltes, 1987; Moraes, 2008; Rowe \& Kahn, 1998).

Dado o exposto, consideramos que ainda não está bem estabelecida a relação entre idade e variação operante e que, dado que a variabilidade induzida pode interferir na operante, é também necessário que essa indução seja avaliada com esses sujeitos. $\mathrm{O}$ presente estudo foi proposto levando-se em conta as considerações acima. Seu objetivo principal foi comparar ratos jovens (4 meses) e idosos (20 meses), no que diz respeito a variabilidade comportamental, operante e induzida. A variabilidade operante foi analisada utilizando-se o procedimento Lag "n", e a induzida avaliada nas condições de reforçamento intermitente não contingente à variação (FR4 e ACO), bem como frente à interrupção da relação de reforçamento (extinção). Buscando garantir uma frequência mínima de respostas pelos animais idosos, em todo o estudo foi utilizada a sacarose como evento reforçador da resposta de pressão à barra. 


\section{EXPERIMENTO 1}

O presente estudo teve por objetivos verificar se ratos jovens e idosos apresentam diferenças nos níveis de variabilidade comportamental quando expostos a contingências de reforçamento intermitente, com ou sem exigência de variação, e à extinção.

\section{MÉTODO}

A presente pesquisa foi aprovada pelo Comitê de Ética no Uso de Animais (CEUA) do IP-USP, de acordo com o protocolo n ${ }^{\circ} 4738281116$.

\section{Sujeitos}

Foram utilizados nove ratos machos Wistar, experimentalmente ingênuos, mantidos no biotério do Departamento de Psicologia Experimental do Instituto de Psicologia da USP (IP-USP) em condições de ventilação e temperatura controladas, ciclo de luz/escuro de 12 hr (8:00 - 20:00h) e livre acesso a água e alimento (ração balanceada). A partir do desmame, os sujeitos foram alojados em trios ou quartetos, em caixas ventiladas Alesco de polisulfona, com dimensões de 48,3 cm x 33,7 cm x 25,3 cm, contendo maravalha, e identificados com marcações na cauda com tinta permanente não tóxica. Os animais jovens $(n=5)$ iniciaram o experimento aos quatro meses de idade e os animais idosos $(n=4)$ aos 20 meses de idade $^{2}$.

A partir do segundo mês de idade, no caso dos sujeitos jovens, e do quarto mês no dos sujeitos idosos, os animais foram pesados quinzenalmente para verificação de suas condições gerais de saúde. Uma semana antes do início do experimento, os animais foram alojados em duplas ou trios, dando-se início ao sistema de privação de alimento, em que foram disponibilizados de 10 a $15 \mathrm{~g}$ de ração por dia para cada um deles ${ }^{3}$, a fim de mantê-

\footnotetext{
${ }^{2}$ Segundo Andreollo, Santos, Araújo e Lopes (2012) não há como comparar de forma fidedigna a idade humana com a de ratos. Contudo, sugere-se que os 60 anos humanos, que marcam o início da fase idosa, corresponderiam aproximadamente a 24 meses dos ratos. Dado que a fase de coleta de dados do presente estudo foi relativamente longa, optamos por utilizar, como animais idosos, ratos tendo 20 meses no início do experimento para evitar a perda de animais no meio da coleta por problemas da idade.

${ }^{3}$ A ração era disponibilizada em um único comedouro, proporcional ao número de sujeitos por caixa. Para verificar se um animal ingeria ração em maior quantidade que outro, alojado na mesma caixa, era feita a pesagem semanal. Se o peso de um animal subia e de outro caía, os animais eram separados para se alimentarem, e reagrupados quando terminavam.
} 
los com $80-85 \%$ do peso ad $\mathrm{lib}^{4}$. No dia que antecedia a pausa semanal do experimento (ver adiante), era feita suplementação alimentar, disponibilizando sementes de girassol e aveia $^{5}$ a cada animal. Durante o experimento, os animais foram pesados semanalmente para o controle do peso.

Um animal idoso (Sujeito $1 \mathrm{~b}$ ), no $36^{\circ}$ dia de coleta, foi afastado temporariamente do experimento por apresentar perda de peso acentuada. Após 23 dias, com suplementação alimentar de sementes de girassol e aveia, ele recuperou seu peso original e foi novamente introduzido no experimento, mantendo-se sua alimentação no mesmo padrão que os demais.

\section{Equipamentos}

Foram utilizadas cinco caixas experimentais de fabricação MED-PC, iguais entre si, com medidas interiores de 30,5 cm x 24,1 cm x 21,0 cm (comprimento x largura $\mathrm{x}$ altura), compostas por teto e paredes frontal e traseira de acrílico transparente e paredes laterais de alumínio. Cada caixa possuía em sua parede direita duas barras retráteis retangulares de alumínio, de 4,8 cm x 1,9 cm, a 6,0 cm do piso, posicionadas à direita (D) e esquerda (E) do sujeito, centralizadas e distando 11,5 cm entre si (medidas entre eixos). Uma pressão mínima de 35 gf (grama/força) produzia o rebaixamento da barra, sendo registrada automaticamente como uma resposta. Entre as barras e ao nível do piso, havia um bebedouro, o qual, quando acionado, podia disponibilizar ao sujeito uma gota de 0,05 cc de solução de sacarose (SAC) diluída a 10\% (reforço). O piso das caixas era composto por hastes cilíndricas de metal, com $0,3 \mathrm{~cm}$ de diâmetro e distantes $1,3 \mathrm{~cm}$ entre si. $\mathrm{Na}$ parte superior e central da parede lateral esquerda estava localizada uma lâmpada de 28 $\mathrm{V}$ que fornecia iluminação ao ambiente.

As caixas experimentais estavam dispostas dentro de câmaras de madeira que propiciavam isolamento acústico e visual. O controle e registro das sessões foram

\footnotetext{
${ }^{4}$ Os animais com 120 dias (Grupo Jovem) iniciaram o experimento em fase de crescimento corporal. Como o experimento teve duração média de quatro meses, mantê-los com $80-85 \%$ do peso ad lib. até o final do estudo poderia representar aumento gradual no nível de privação com o passar do tempo. Por esse motivo, ao longo do estudo foram feitas adaptações do peso, mensalmente, de acordo com a tabela de evolução dos pesos por idade de ratos machos Wistar privados de alimentos (Tomanari, Pine, \& Araújo Silva, 2003). ${ }_{5}^{5}$ As sementes de girassol e a aveia eram oferecidas aos animais como forma de suplementação alimentar, de modo a aumentar a probabilidade de manter os sujeitos saudáveis, em especial os idosos, até o final da coleta. O tipo de suplementação, a quantidade e frequência em que as sementes eram disponibilizadas foi uma recomendação da veterinária responsável pelo biotério do IP-USP na época em que os primeiros animais foram adquiridos.
} 
realizados por computador equipado com software desenvolvido para essa pesquisa em linguagem MED-PC.

\section{Procedimento}

Foram realizadas sessões diárias, de segunda a sábado, sempre no mesmo horário dentro da fase de luz do ciclo mantido no biotério. Aos domingos, os animais permaneciam no biotério sem qualquer manipulação. Os animais foram submetidos ao treino preliminar para modelagem e fortalecimento de resposta de pressão a duas barras (D e E), seguido da fase experimental, composta por seis fases.

\section{Treino Preliminar}

O treino preliminar correspondeu a quatro etapas, com sessões com duração máxima de $1 \mathrm{~h}$ ou a obtenção do número de reforços previamente determinados, o que ocorresse primeiro. No caso de o sujeito não receber o número de reforços estabelecidos, nova sessão era realizada até que esse critério fosse atingido.

$\mathrm{Na}$ primeira etapa foi realizado treino de bebedouro seguido de modelagem da resposta de pressão à barra, feito manualmente, pelo método de aproximações sucessivas. Nessa etapa, havia apenas uma das barras presente na caixa: entre os sujeitos idosos ( $\mathrm{n}=$ 4), metade teve a resposta modelada na barra D e a outra metade na barra E; entre os sujeitos jovens $(n=5)$, três tiveram a resposta modelada na barra $\mathrm{D}$ e dois na barra $\mathrm{E}$. $\mathrm{O}$ critério de aprendizagem, na modelagem, foi a liberação de dez reforços consecutivos para a resposta de pressão à barra, que quando atingido, a contingência passava imediatamente a CRF, com liberação automática de 100 reforços. A partir dessa etapa, todos os reforços foram liberados automaticamente.

$\mathrm{Na}$ segunda etapa, foi disponibilizada apenas a barra alternativa que não esteve presente previamente, sendo liberados 100 reforços em CRF. No caso de algum sujeito emitir poucas respostas de pressão à barra no começo da sessão, e não mais emiti-las da metade da sessão para o final, foi feita nova modelagem dessa resposta na barra alternativa, seguida da liberação de 100 reforços em CRF.

A partir da terceira etapa, as duas barras estiveram disponíveis em todo o experimento. Nessa etapa, os sujeitos receberam 100 reforços em CRF para a resposta de pressão a qualquer das barras. Na etapa seguinte, foram exigidas duas respostas em 
qualquer das barras para a liberação do reforço (FR2), sendo disponibilizados 200 reforços na sessão. Em seguida, deu-se início à Fase Experimental.

\section{Fase Experimental}

O início de cada sessão era marcado pelo acendimento da luz ambiente e pela inserção, na caixa, de ambas as barras. Ao término da sessão, a luz era apagada e as barras retiradas. Em todas as fases, quando era atingido o critério para reforçamento, o bebedouro era acionado. Quando o critério para reforçamento não era atingido, havia um período de $1 \mathrm{~s}$ em que a luz da caixa se apagava (time out), durante o qual, as respostas de pressão à barra não tinham consequência programada e não eram registradas. Encerrado o período de time out, a luz da caixa se acendia e a contingência em vigor voltava a operar.

Ao longo do experimento, os animais foram expostos às contingências denominadas FR4, variação (VAR), acoplado (ACO), e extinção (EXT).

Sob FR4, o reforço foi liberado contingente à emissão de quatro respostas de pressão em qualquer das barras. Esta fase se encerrou quando os sujeitos completaram um mínimo de cinco sessões com pelo menos 150 reforços por sessão, tendo-se um limite máximo de 15 sessões se este critério não fosse atingido.

Nas fases seguintes, a unidade comportamental foi uma sequência de quatro respostas de pressão a qualquer das barras. A emissão de uma sequência caracterizou uma tentativa, tendo cada sessão 200 tentativas ou a duração de 1h, o que ocorresse primeiro. A combinação de quatro respostas em duas barras permitia a emissão de 16 sequências diferentes, sendo a diferença entre elas relativa à localização, dentro da sequência, das respostas nas barras D e E. Ou seja, podiam ser formadas sequências tais como DDED, EEEE, EDDD, EDED, e assim sucessivamente. Semelhanças ou diferenças entre as sequências foram sempre consideradas em função da distribuição das respostas D e E dentro de cada uma delas. Por exemplo, as sequências EDDE e EDDE eram iguais entre si, mas diferentes de EEDD.

Sob a contingência VAR, foi exigido para reforçamento que os sujeitos variassem suas sequências, isto é, o reforço era liberado contingente a emissão de uma sequência apenas se ela fosse diferente das $n$ últimas sequências emitidas ( $\operatorname{Lag} n)$. A depender da fase do estudo, o valor de $n$ foi igual a 1, 2 ou 4 (Lag 1, Lag 2 e Lag 4, respectivamente). Por exemplo, após o animal emitir as sequências EDED, EEDE, DDEE e DDDD, em Lag 1, o reforço seria liberado contingente à emissão de qualquer nova 
sequência, exceto DDDD; em Lag 2, contingente a qualquer nova sequência que não fosse DDEE ou DDDD; e em $\operatorname{Lag} 4$, qualquer sequência que diferisse dessas quatro recém emitidas.

Sob ACO, os reforços foram liberados contingentes à emissão de uma sequência, porém independentemente da sua configuração: a ordem de distribuição de reforços foi a mesma obtida em sessões anteriores sob reforçamento em $\operatorname{Lag} 4$, às quais essa fase estava acoplada. Desta maneira, se na sessão de Lag 4 ocorressem reforços nas tentativas 1, 3, 7 e 9, os reforços em ACO eram liberados após a emissão da sequência nas tentativas 1, 3, 7 e 9, independente da distribuição de E ou D dentro dessa sequência. Para o acoplamento foram utilizadas as duas últimas sessões das condições Lag 4 realizadas pelo sujeito, que se alternaram a cada sessão de ACO.

Sob EXT, nenhuma sequência foi reforçada, sendo cada tentativa seguida pelo time out. Nessa fase, a sessão teve duração fixa de $1 \mathrm{~h}$.

A mudança de contingência era feita com base no número de sessões válidas realizadas em cada fase (ver na Tabela 1 o número mínimo previsto de sessões para cada fase). Foram consideradas válidas as sessões em que era completado um mínimo de 150 tentativas. Se o sujeito não atingisse esse mínimo, a sessão era descartada e o sujeito realizava uma nova sessão. A exceção foi em EXT, em que cada sessão teve duração de $1 \mathrm{~h}$, sem exigência de um mínimo de tentativas.

Todos os sujeitos foram expostos a cinco fases experimentais, em que as Fases 1,3 e 5, corresponderam às contingências FR4, ACO e EXT, respectivamente. A contingência VAR - Lag 1, Lag 2 e Lag 4 -, correspondeu à Fase 2. Na Fase 4, repetiu-se a contingência VAR Lag 4 (denominada VAR Lag 4' para se diferenciar da anterior).

A Tabela 1 apresenta, resumidamente, o delineamento experimental, incluindo a ordem de apresentação das contingências e número de sessões mínimas planejado para cada fase. 
Tabela 1 - Resumo do delineamento experimental, com a ordem de apresentação das contingências e número de sessões mínimas planejado para cada fase. Com exceção das fases sinalizadas (* $\left.\mathbf{e}^{* *}\right)$, o experimento foi realizado tendo duas barras disponíveis na caixa experimental.

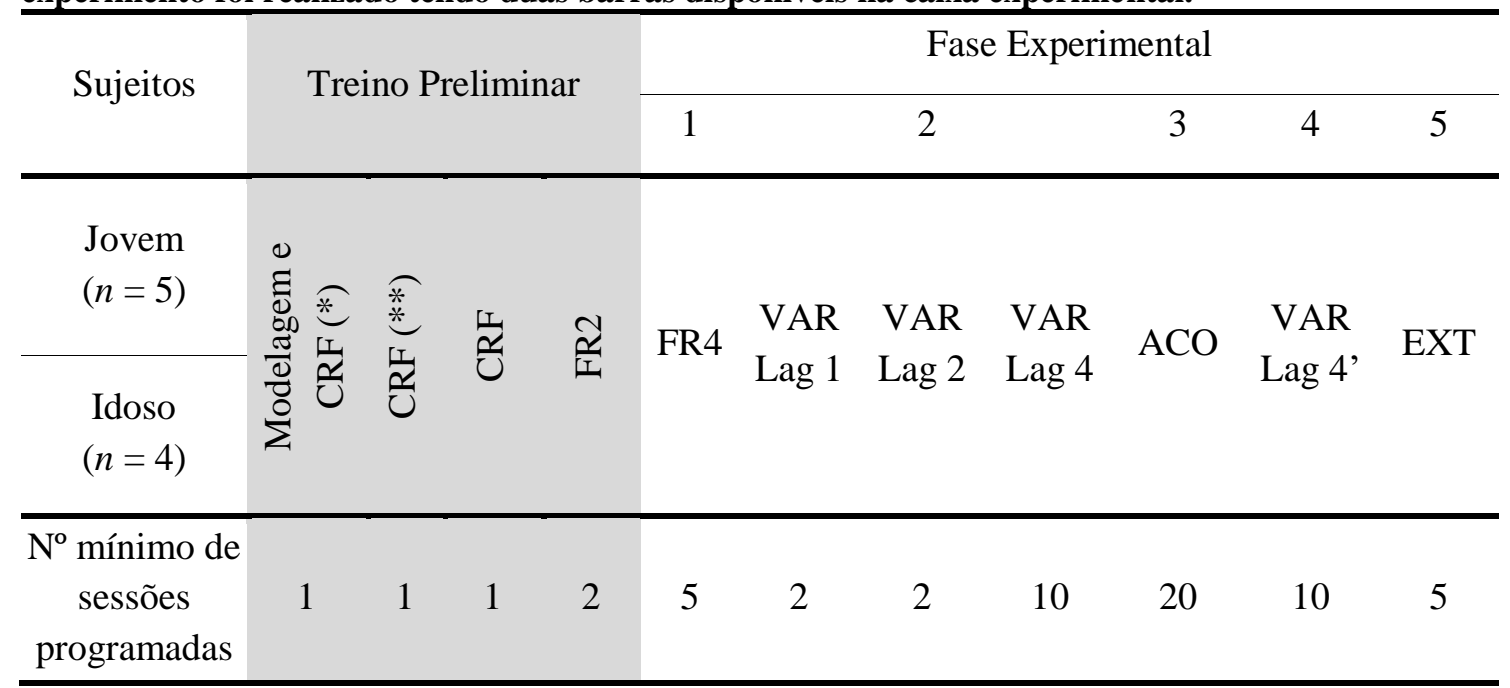

(*) uma barra $(* *)$ barra alternativa 


\section{RESULTADOS}

A Tabela 2 mostra que os animais diferiram entre si quanto ao número de sessões realizadas comparativamente à quantidade mínima de sessões programadas. Os animais idosos necessitaram de maior número de sessões que os jovens, em todas as fases e com grande diversidade entre si: dentre quatro sujeitos, apenas um completou todas as fases previstas $^{6}$. O Sujeito 8 b não chegou a completar a modelagem da resposta de pressão à barra alternativa após 12 sessões e, por isso, foi retirado do experimento. O Sujeito $1 \mathrm{~b}$ foi afastado do experimento por 24 dias por ter tido perda de peso acentuada na $36^{\mathrm{a}}$ sessão, em Lag 4. Quando retornou ao experimento, precisou ser novamente submetido a sessões de FR4, Lag 1, e Lag 2 para recuperar o padrão de resposta mostrado anteriormente, bem como algumas sessões adicionais em Lag 4 para atingir taxa de resposta suficiente para que as sessões fossem consideradas válidas. Assim, não houve tempo hábil para realizar as duas últimas fases. Já o Sujeito 2 b precisou de mais sessões que a maioria dos animais para completar todas as fases a que foi submetido, excedendo em $76 \%$ o mínimo de sessões programadas sem atingir o critério para chegar na fase final do experimento. $\mathrm{O}$ Sujeito $2 b$ teve a fase FR4 encerrada em função de atingir o número máximo de sessões estabelecido (15 sessões), tendo atingido o critério de validade da sessão em apenas três delas. O Sujeito $9 \mathrm{~b}$ foi trocado de caixa experimental (nenhum outro animal estava trabalhando na mesma caixa neste período) na fase de Lag 4 após oito sessões sem atingir o critério de mudança de fase. Após essa mudança, seu desempenho melhorou tendo completado todas as fases. Portanto, apenas esse sujeito pode ser comparado com os ratos jovens quanto ao número de sessões necessárias para completar o estudo: 87 sessões, bem acima da quantidade de sessões da maioria dos sujeitos idosos, e no mínimo programado. Apenas um único animal jovem se assemelhou ao idoso, necessitando de 86 sessões para finalizar todas as fases.

\footnotetext{
${ }^{6}$ Por questões operacionais do laboratório, e a idade avançada dos animais idosos, foi estipulada uma data limite para encerramento do estudo. Por esse motivo, animais que haviam sido expostos a um grande número de sessões, sem atingir os critérios de mudança de fase, tiveram sua participação encerrada sem concluir todo o delineamento experimental.
} 
Tabela 2 - Número de sessões realizadas sob cada contingência e no total do experimento relativo a cada sujeito. Na linha inferior é reapresentado o número mínimo de sessões que haviam sido programadas. Com exceção das fases sinalizadas $(* \mathbf{e} * *)$, o experimento foi realizado tendo duas barras disponíveis na caixa experimental.

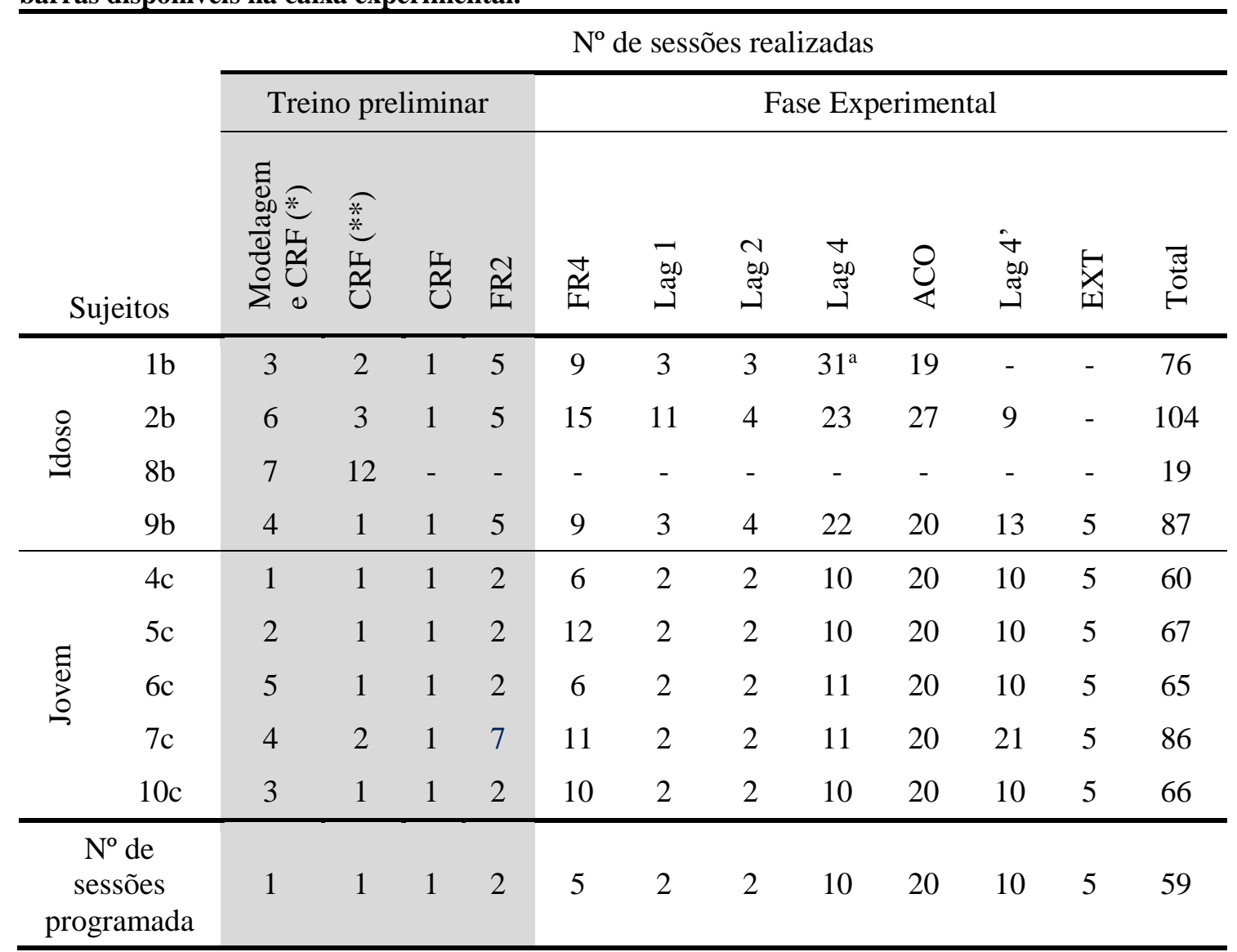

(*) uma barra $(* *)$ barra alternativa

a O Sujeito 1b, nesta fase, foi afastado temporariamente do experimento por apresentar perda de peso acentuada, como descrito na seção Sujeitos.

Dentre os animais jovens, todos completaram todas as fases do delineamento experimental, sendo que eles não apenas necessitaram de menos sessões para atingir o critério de mudança de fase do que os animais idosos, como mostraram pouca dispersão intragrupo: as maiores diferenças intragrupo se deram no Treino Preliminar e na primeira fase experimental quando expostos ao FR4; nas demais fases eles mantiveram o número de sessões próximo ao mínimo planejado, com exceção do Sujeito 7c, que necessitou de maior número de sessões em Lag 4'.

A análise da variabilidade comportamental dos sujeitos foi feita utilizando-se diversas medidas. A primeira delas foi o valor $U$, que mede a distribuição das frequências das sequências possíveis, utilizando a equação $\mathrm{U}=-\sum_{i}^{n}\left[p_{i} * \log _{2}\left(p_{i}\right)\right] / \log _{2}(n)$, no qual $n$ indica o universo de sequências possíveis (16 neste estudo), e $p_{i}$ as probabilidades dessas sequências. Esse índice pode assumir valores entre 0 e 1. Quanto mais próximo do 
1, maior o grau de variabilidade, e quanto mais próximo do zero, maior o grau de repetição.

Na parte superior da Figura 1 estão plotados os índices U individuais dos sujeitos idosos e jovens, nas sessões válidas, sob as diferentes contingências, exceto EXT. Esses dados mostram que a idade dos animais não produziu diferenças quanto à variabilidade comportamental nas diferentes fases do experimento, sendo as diferenças obtidas função das contingências manipuladas. Em FR4, os sujeitos, tanto idosos como jovens, apresentaram queda dos valores U no decorrer das sessões, com exceção apenas de um sujeito idoso, que apresentou estabilização em níveis baixos, e um jovem, que exibiu leve aumento dos índices. A partir da introdução da exigência de variação (Lag), os sujeitos mostraram índices U compatíveis com a contingência em vigor: maior variação quanto maior o "n" do Lag, queda quando submetidos à contingência $\mathrm{ACO}$ e aumento novamente desse índice quando do retorno da exigência de variação para obtenção do reforço ( Lag 4') em níveis um pouco abaixo dos obtidos sob Lag 4. É possível também verificar que os valores U, sob ACO, foram maiores que em FR4, exceto para o Sujeito 10c (jovem).

É relevante destacar que os valores $\mathrm{U}$ de todos os sujeitos nas contingências Lag mostraram-se consistentes entre si, havendo maior dispersão dos índices $U$ nas contingências em que a variabilidade não era critério para reforçamento, ou seja, em FR4 e ACO. Sob FR4, a diversidade dos índices dos sujeitos jovens foi maior que a dos idosos, diferentemente do ocorrido sob ACO, em que os índices dos sujeitos de ambas as faixas etárias apresentaram dispersões relativamente semelhantes. Na comparação entre fases, a dispersão dos índices U foi maior sob FR4 que sob ACO entre os sujeitos jovens, sendo que sob ACO apenas os índices de um sujeito desviaram dos demais, exibindo queda mais acentuada. Entre os idosos, embora em diferentes patamares, os sujeitos mostraram relativamente pouca dispersão entre si tanto sob FR4 como ACO. 

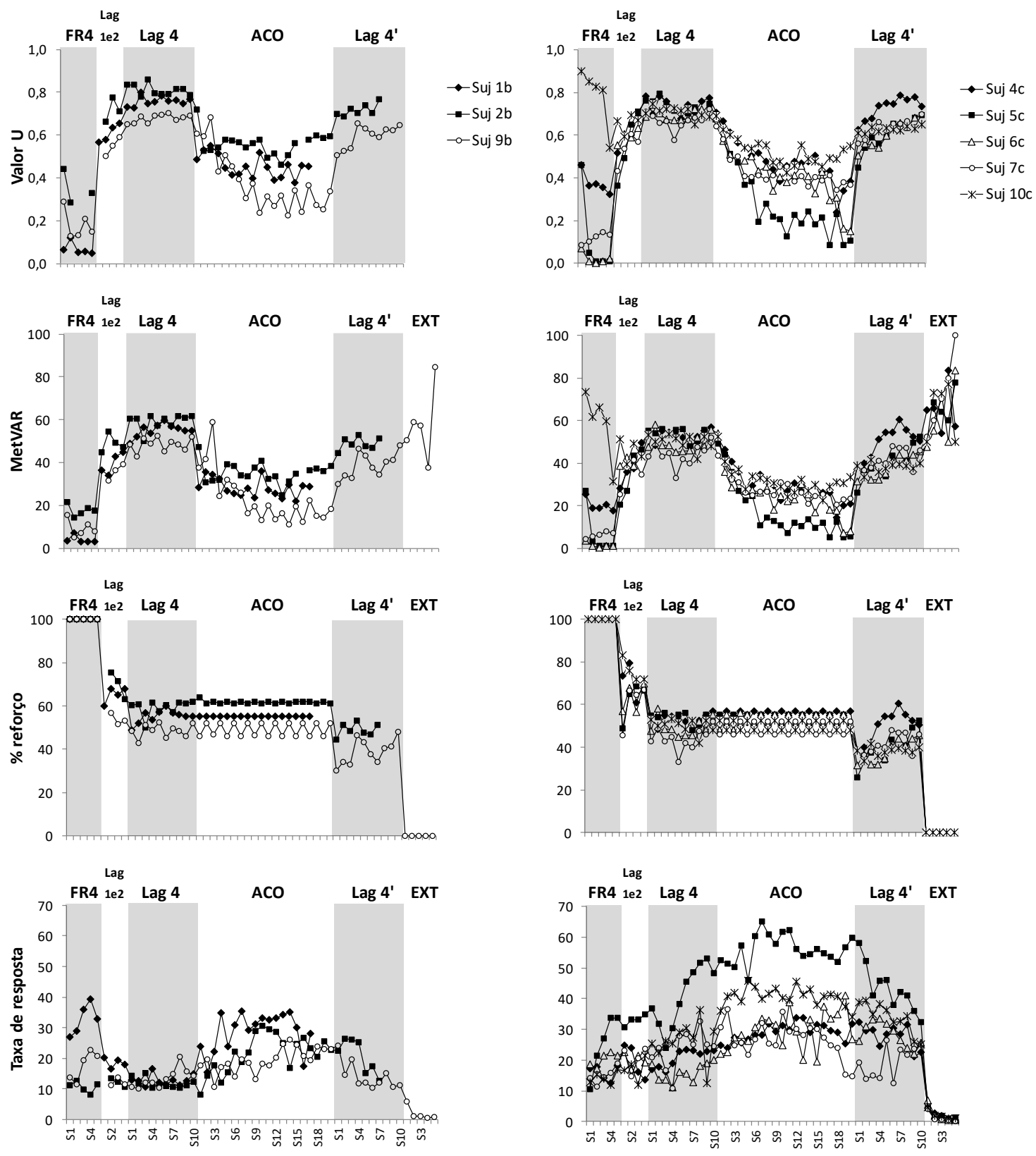

Idoso

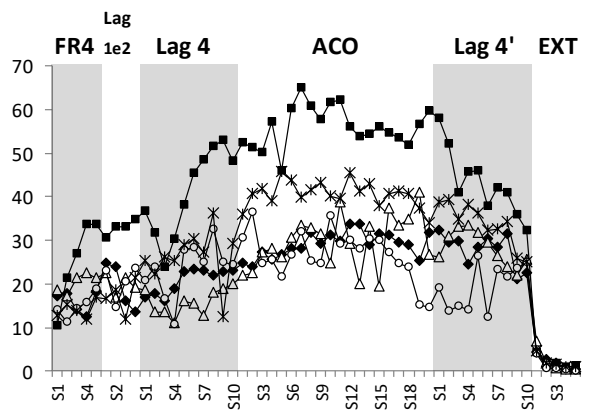

Jovem

Figura 1 - Valor U, MetVAR, porcentagem de reforço e taxa de resposta dos sujeitos idosos e jovens nas sessões válidas de cada fase experimental. São apresentados os dados individuais dos sujeitos, em que os gráficos à esquerda correspondem aos sujeitos idosos, e os gráficos à direita, aos sujeitos jovens.

Não foi possível calcular o valor U nas sessões de EXT devido ao baixo número de sequências emitidas. Segundo Barba (1997), o cálculo do U é confiável apenas a partir de um número mínimo de sequências emitidas, correspondente a 10 vezes o universo de possibilidades. No caso do presente estudo, em que o universo de possibilidades era de 16 sequências, o mínimo necessário para a confiabilidade dessa medida seria haver 160 sequências emitidas, número esse não atingido na condição de EXT. Portanto, para 
análise da variabilidade nesta fase, foi usado o índice MetVAR, outra medida de variabilidade, apresentada na literatura (Neuringer et al., 2001). Ela corresponde ao número de sequências que atingiriam o critério para reforçamento em $\operatorname{Lag} 4$, se essa contingência estivesse em vigor, dividido pelo número total de sequências emitidas na sessão, multiplicado por 100. Portanto, nas fases Lag 4 e Lag 4', essa medida corresponde à porcentagem de reforço, e, nas demais fases, ela mostra se o desempenho do animal seria ou não reforçado pelo critério de $\operatorname{Lag} 4$.

Os índices MetVAR são apresentados na segunda linha da Figura 1. A fim de possibilitar a comparação dos níveis de variabilidade sob EXT com os obtidos sob as demais contingências, esse índice foi calculado para todas as fases. Essa medida reproduz com grande semelhança o que havia sido mostrado pelo índice $U$ nas diferentes contingências analisadas, não sendo verificadas diferenças nos níveis de variabilidade entre sujeitos idosos e jovens. Durante Lag 4, MetVAR permaneceu estável e em níveis mais elevados que nas demais contingências. Sob Lag 4', os índices estiveram em elevação durante as primeiras sessões da fase, estabilizando, posteriormente, em níveis mais elevados, porém um pouco abaixo do observado sob Lag 4.

Em FR4 e ACO, em que o reforço não era contingente a variar, os índices MetVAR tiveram queda no decorrer das sessões. A maior dispersão intragrupo ocorreu sob as contingências FR4 e ACO, e a menor sob as contingências VAR, sendo, no geral, maior a dispersão entre os animais jovens. Na condição de EXT, todos os animais apresentaram aumento dos índices MetVAR desde a mudança de contingência (de Lag 4' para EXT) até a última sessão dessa fase. Apenas um sujeito idoso atingiu esta fase, mostrando desempenho semelhante aos jovens, ou seja, aumento do índice MetVAR.

As porcentagens de reforço são apresentadas na terceira linha da Figura 1, em que novamente não foram observadas diferenças entre idosos e jovens. Por características das contingências, essas porcentagens se situaram nos extremos superior e inferior dessa medida nas sessões de FR4 e EXT, respectivamente. Também, por característica do procedimento aqui adotado, sob ACO elas repetiram as duas últimas medidas obtidas na fase Lag 4. Portanto, são passíveis de maior análise os dados obtidos sob VAR, que mostram que as porcentagens de reforçamento diminuíram à medida que a contingência passou a ficar mais exigente. A maior queda se deu ao ser estabelecida a contingência de Lag 1, passando de $100 \%$ para algo em torno de $60 \%$ de reforçamento, na condição Lag 1, ocorrendo nova redução ao ser estabelecido o Lag 4 (cerca de 50\%, em média). Na 
condição Lag 4', a porcentagem de reforçamento foi ainda mais baixa, girando em torno de $40 \%$.

Na última linha da Figura 1 são apresentadas as taxas de respostas nas sessões válidas. Os sujeitos idosos e jovens apresentaram taxas de respostas bastante semelhantes enquanto submetidos à FR4, com tendência crescente a cada sessão. Ao serem submetidos às contingências VAR, padrões de resposta foram apresentados: os animais idosos inverteram a tendência anteriormente crescente, mostrando queda nas taxas de resposta entre FR4 e $\operatorname{Lag} 1$ 1; durante Lag 4 estabilizaram essas taxas, as quais aumentaram novamente sob ACO, quando não havia exigência de variação. Os animais jovens mantiveram estáveis as taxas durante Lag 1, houve aumento das mesmas a partir da metade de Lag 4, e posterior estabilização em ACO. Em Lag 4', os sujeitos idosos e jovens voltaram a ter padrão de resposta semelhantes com queda das taxas de resposta. Em EXT, as taxas de resposta dos animais jovens, e do único sujeito idoso a chegar a essa fase, caíram praticamente a zero. É possível afirmar, apesar das diferenças observadas entre as taxas de resposta dos sujeitos idosos e jovens nas primeiras contingências VAR, que as taxas de resposta dos sujeitos de ambas as faixas etárias foi sensível à contingência em vigor: as taxas de respostas foram mais altas durante ACO, mais baixas durante as contingências VAR, com redução ainda maior sob EXT.

As frequências relativas de cada uma das 16 sequências possíveis na primeira e na última sessões válidas de FR4, Lag 4, ACO e Lag 4' foram calculadas - a partir do número de emissões de cada sequência, dividido pelo total de sequências emitidas na sessão -, a fim de completar as informações oferecidas pelo valor U. Na Figura 2 estão demonstradas as distribuições das sequências emitidas pelos sujeitos idosos e jovens, em que, no eixo horizontal, as sequências estão ordenadas a começar com as de menor para as de maior número de alternação. Alternações consistem nas mudanças de uma barra à outra que o animal realiza para formar as sequências de quatro respostas de pressão à barra, exigidas para reforçamento. Dentre as sequências possíveis nesse estudo, há duas com nenhuma alternação (0 alt - EEEE e DDDD), seis com uma alternação (1 alt - EDDD, EEDD, EEED, DEEE, DDEE e DDDE), seis com duas alternações (2 alt - EDEE, EEDE, EDDE, DEDD, DDED e DEED) e duas com três alternações (3 alt - EDED e DEDE). Não foram exibidas as frequências de EXT, porque elas serão analisadas mais detalhadamente posteriormente. Também não foi apresentado o gráfico referente à Lag 4' do Sujeito 1b, uma vez que este não chegou a passar por esta contingência. 

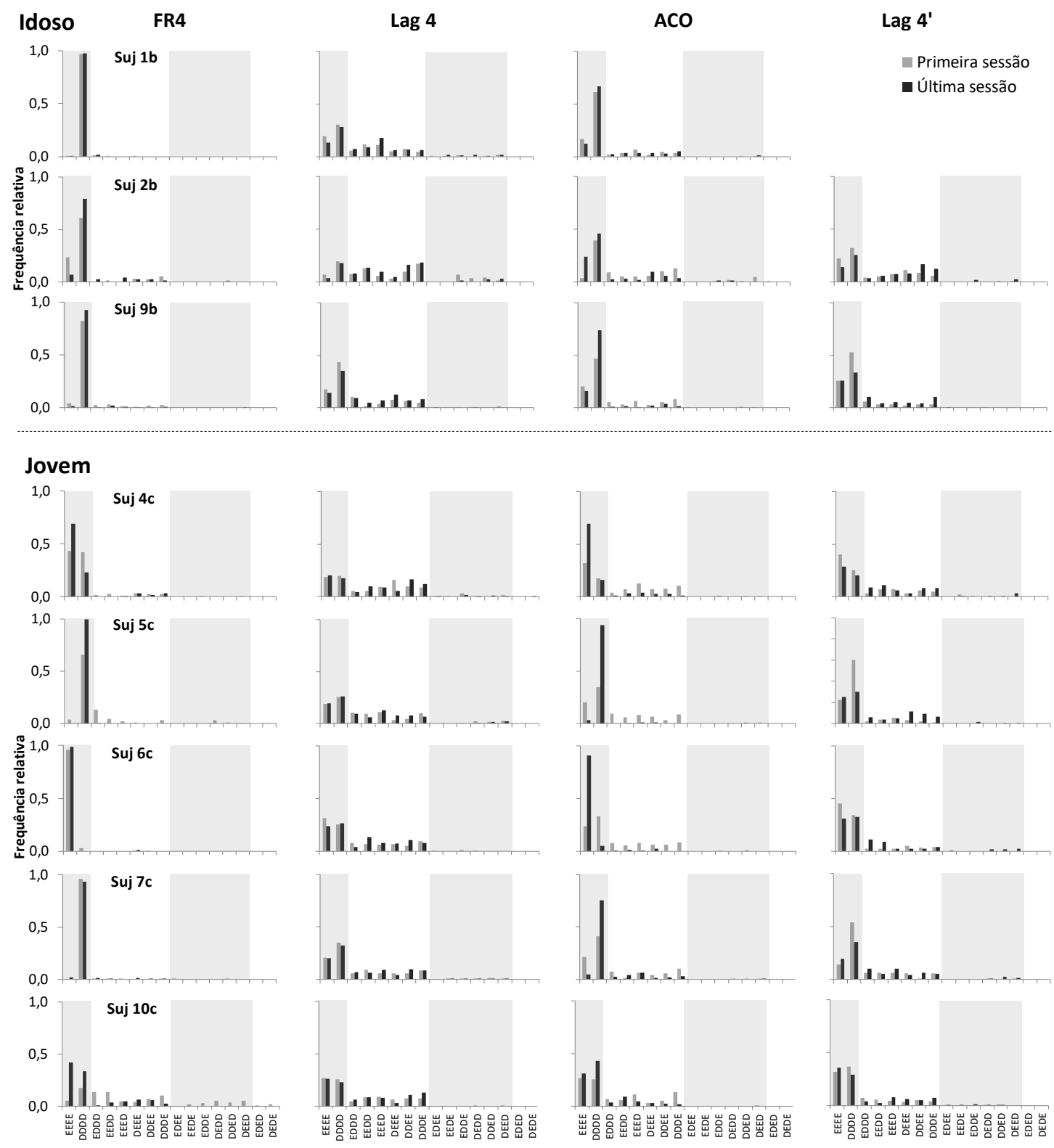

Figura 2 - Distribuição de sequências emitidas por sujeitos idosos e jovens em cada fase experimental. São apresentadas as frequências relativas das sequências emitidas na primeira e última sessão de cada contingência, tendo como universo 16 sequências possíveis. No eixo horizontal, estão ordenadas sequências agrupadas em função do número de alternações (entre barras exigido para sua emissão: mais à esquerda estão as sequencias com zero alternação, seguidas pelas que exigem uma, duas ou três alternações entre barras). As áreas cinza e branca delimitam os conjuntos de sequências por número de alternação.

A Figura 2 mostra que o padrão de distribuição das sequências foi semelhante entre os sujeitos idosos e jovens, diferindo apenas em função da contingência em vigor. Sob FR4, a maioria dos sujeitos concentrou suas respostas em uma única barra, compondo sequências com zero alternação (0 alt). E embora o Sujeito 10c tenha apresentado emissões de sequências bastante variadas na primeira sessão de FR4, na quinta sessão, as respostas concentraram-se nas duas sequências 0 alt. Sob $\operatorname{Lag} 4$, todos os sujeitos 
passaram a distribuir suas respostas em maior número de sequências que em FR4 desde a primeira sessão desta contingência. Isto é, as sequências 0 alt diminuíram de frequência e as de uma alternação (1 alt) passaram a ser muito emitidas, com algumas emissões de sequências com duas alternações (2 alt) e bem raras as de três alternações (3alt).

Quando se passou para ACO, as sequências 0 alt voltaram a ser as mais emitidas por todos os sujeitos, principalmente na última sessão desta contingência, embora, na primeira sessão de ACO ainda tenha sido possível observar uma maior distribuição das respostas entre as sequências 0 alt e 1 alt. Cabe ressaltar que os sujeitos idosos e a maioria dos sujeitos jovens, apresentaram, sob ACO, maior distribuição das diferentes sequências que na última sessão de FR4. Sob Lag 4', novamente, os sujeitos distribuíram suas respostas em um maior número de sequências, principalmente nas sequências 0 alt e 1 alt.

Os dados de distribuições das sequências ilustram os comportamentos que geraram os valores U mostrados na Figura 1, destacando-se que sob as contingências Lag 4 e Lag 4' estes valores foram os mais altos em comparação às demais contingências, como decorrência da maior variação das sequencias emitidas. Ainda assim, os índices U obtidos não excederam valores superiores a 0,8 - com exceção do Sujeito 2 b -, o que também é coerente com as distribuições observadas: as sequências se concentraram entre as 0 alt e 1 alt, enquanto as sequências 2 alt e 3 alt foram pouco emitidas. Sob FR4 e $\mathrm{ACO}$, os valores $\mathrm{U}$ foram mais baixos e apresentaram queda no decorrer das sessões, da mesma maneira que as distribuições das sequências se concentraram crescentemente nas de 0 alt, principalmente na última sessão. Assim como os valores U, sob ACO foram maiores que sob FR4, obteve-se maior distribuições das sequências emitidas sob a primeira contingência que a segunda.

A Figura 3 exibe as frequências relativas médias das sequências emitidas nas cinco últimas sessões válidas de Lag 4' e nas cinco sessões de EXT de cada sujeito que completou ambas as contingências. No eixo horizontal, assim como na figura anterior, as sequências estão dispostas desde as de 0 alt até as de 3 alt. Embora com frequência de resposta reduzida, o notável é que sob extinção os animais mantiveram a distribuição verificada quando a frequência de respostas foi mais elevada, sob reforçamento em Lag 4: mais emissão de sequências 0 alt e 1 alt. Destaque-se que sob a condição EXT houve mais emissão de sequências com maior número de alternações do que sob a condição Lag 4. Esse dado pode ser cruzado com o apresentado na Figura 1, relativos aos índices MetVAR que aumentaram a partir da primeira sessão, em comparação com Lag 4'. Assim, o aumento da variabilidade observada em EXT por meio da medida MetVAR, 
deveu-se ao aumento da emissão de sequências com maior número de alternações. Não houve diferenças nos padrões observados entre o sujeito idoso e os jovens, mas uma comparação mais confiável requereria maior número de sujeitos idosos.
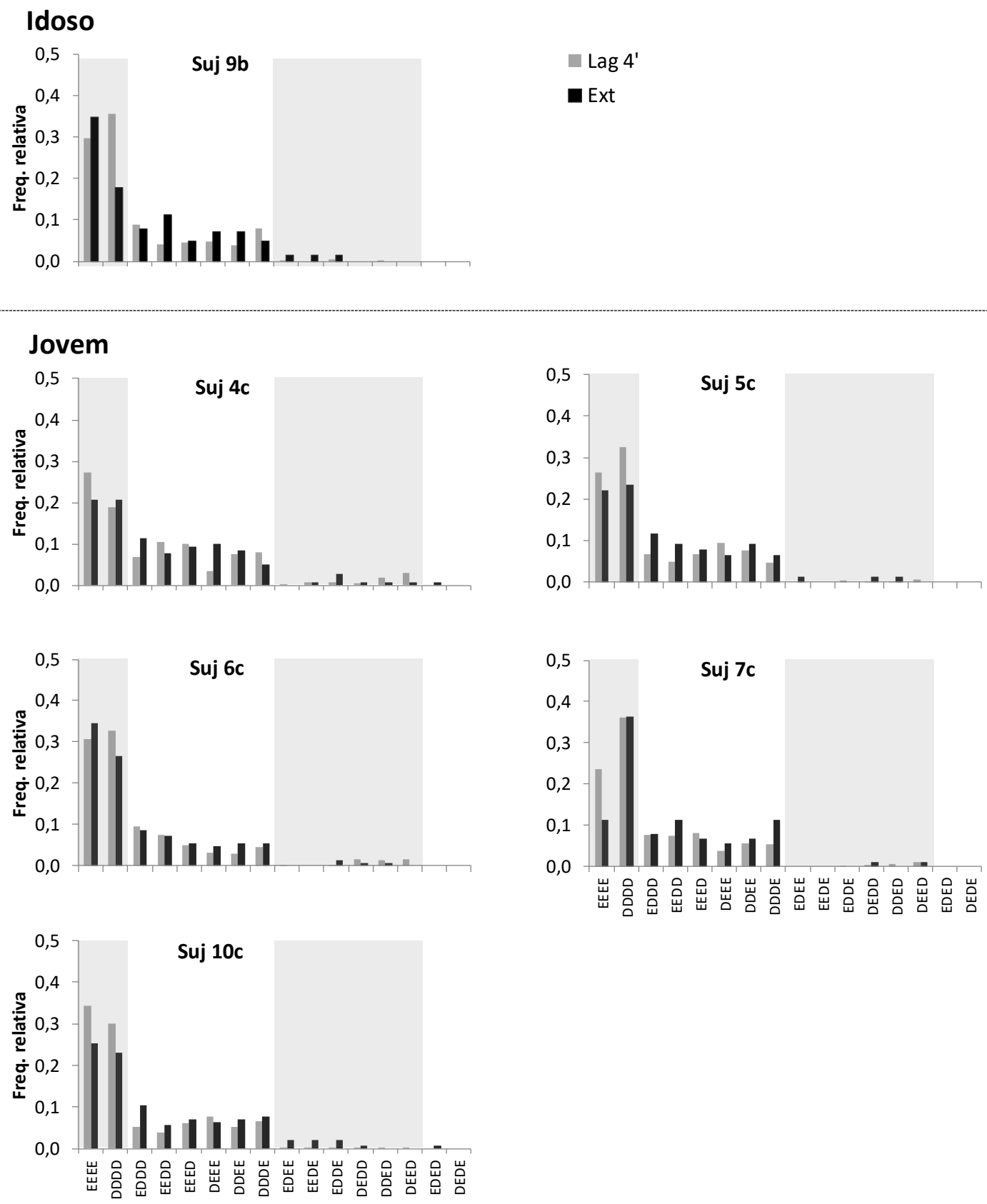

Figura 3 - Distribuição de sequências emitidas pelos sujeitos idosos e jovens em Lag 4' e EXT. São apresentadas as médias das frequências relativas das sequências emitidas nas cinco últimas sessões de Lag 4' e nas cinco sessões de EXT, tendo como universo 16 sequências possíveis. No eixo horizontal, estão ordenadas sequências agrupadas em função do número de alternações (entre barras exigido para sua emissão: mais à esquerda estão as sequencias com zero alternação, seguidas pelas que exigem uma, duas ou três alternações entre barras). As áreas cinza e branca delimitam os conjuntos de sequências por número de alternação. 


\section{DISCUSSÃO}

Quando exigida para reforçamento, a variabilidade comportamental foi alta, com aumento progressivo durante as contingências Lag 1 e Lag 2 e estabilidade em níveis mais elevados sob Lag 4. Em relação às contingências sem exigência de variação como critério para reforçamento, os resultados mostraram que na condição em que toda e qualquer sequência emitida era reforçada (FR4), foram apresentados os menores índices de variabilidade comportamental - medidos tanto pelo valor U ou MetVAR - em comparação com as demais contingências. Apenas um sujeito exibiu índices mais altos sob FR4 que sob as demais contingências, mas isso se deu nas primeiras sessões sob FR4, sendo esse valor decrescente na medida em que a contingência foi repetida nas sessões seguintes. Portanto, pode-se supor que era uma variabilidade "exploratória", que não foi mantida ao longo da contingência. Da mesma forma, em ACO, os índices de variabilidade declinaram progressivamente em comparação aos apresentados em Lag 4, embora tenham se mantido mais elevados que os obtidos em FR4. Padrão semelhante foi encontrado tanto entre os animais jovens como o idoso que chegou até o final do estudo, o que sugere que a idade do sujeito não interferiu na sua sensibilidade às contingências aqui manipuladas.

$\mathrm{Na}$ comparação entre sujeitos idosos - a comparação pode ser feita até a $17^{\mathrm{a}}$ sessão de ACO, ponto até onde todos os sujeitos idosos chegaram no experimento - e jovens, a única diferença observada foi no grau de dispersão dos índices de variabilidade em FR4 que foi maior entre os sujeitos jovens. Esses dados podem sugerir que, na ausência de qualquer histórico de reforçamento contingente ao variar, os sujeitos jovens são "naturalmente" mais variáveis no seu responder que os idosos. Contudo, dado o pequeno número de sujeitos aqui testados novas verificações precisariam ser conduzidas para confirmar, ou não, essa sugestão. Houve também maior dispersão dos índices de variabilidade dos sujeitos idosos e jovens nas contingências FR4 e ACO, e menor nas contingências Lag. Isso sugere que quando o variar era critério para reforçamento, os sujeitos foram igualmente sensíveis à contingência. Sob FR4 e ACO, como o variar não era exigido, os animais podiam apresentar níveis de variabilidade distintos, sem que isso produzisse diminuição do reforço.

Quanto às contingências Lag 4 e ACO, o padrão obtido no presente estudo foi similar ao obtido por Wells (1999, Experimento 1), que comparou a variabilidade comportamental entre ratos jovens e idosos, em condições relativamente semelhantes às nossas. Wells (1999) utilizou os mesmos índices de variabilidade utilizados no presente 
estudo, o valor U e o MetVAR (embora esta última com a denominação de porcentagem de variação): seus sujeitos apresentaram altos índices nas contingências $L a g$ 4, e índices progressivamente decrescentes sob ACO. Na segunda condição Lag 4, após ACO, os níveis de variabilidade foram um pouco mais baixos, assim como no presente estudo. Cabe ressaltar que a contingência Lag 4 não exige muita variação: a rigor, bastaria o sujeito emitir alternadamente cinco das 16 sequências possíveis para ter $100 \%$ de reforço. Contudo, os animais frequentemente variam mais do que esse mínimo exigido, o que, no presente estudo, elevou os valores $U$ em torno de 0,8 , obtendo distribuição ampliada das sequências. Ainda assim, os índices U, no presente estudo, foram menores que os obtidos por Wells (1999, Experimento 1), que ficaram em torno de 0,9.

Comparando-se as porcentagens de reforço e os índices de variabilidade, foi possível observar que, ao passar pela exposição a cada uma das condições VAR, as proporções de reforços caíram, enquanto os índices de variabilidade aumentaram. Este dado poderia sugerir que o aumento nos índices de variabilidade seria decorrente de indução pela menor porcentagem de reforços liberados descaracterizando essa variabilidade como operante. Contudo, os dados obtidos na condição ACO mostram que, ao menos em parte, o controle dessa variabilidade sob Lag era operante: em ACO as porcentagens de reforços permaneceram as mesmas em relação às duas últimas sessões de Lag 4, mas os índices de variabilidade diminuíram com o decorrer das sessões. Ou seja, embora a intermitência do reforço fosse semelhante entre Lag 4 e ACO, ao ser suspensa a exigência de variar, os valores U e MetVAR sofreram queda progressiva no decorrer das sessões de ACO. Quando a contingência para variar foi retomada em Lag 4', os índices voltaram a subir. Novamente, nenhuma diferença entre os sujeitos idosos e jovens foi observada, indicando que a idade não foi um fator determinante para os níveis de variabilidade, quer reforçada ou induzida, e sim, as contingências as quais os animais foram submetidos.

Durante FR4, os índices de variabilidade dos sujeitos, tanto idosos quantos jovens, tenderam a cair, enquanto as porcentagens de reforços se mantiveram constantes. Embora FR4 seja um esquema intermitente para respostas singulares de pressão à barra e, portanto, poder-se-ia esperar a manutenção dos níveis de variabilidade em níveis moderados ou altos (Boren et al., 1978; Schaefer \& Steinhorst, 1959) -, no presente estudo, a unidade comportamental era uma sequência de quatro respostas de pressão à barra. Logo, nessa fase o reforçamento pode ser considerado contínuo (CRF), pois toda e 
qualquer sequência emitida foi reforçada. Tal procedimento também foi utilizado por Schwartz (1980) e por Vogel e Annau (1973) que, utilizando pombos, reforçaram, respectivamente, sequências de oito e seis respostas de bicar a duas chaves, independentemente de sua configuração, havendo como única restrição que metade das respostas deveriam ocorrer na chave $\mathrm{E}$ e a outra metade, na chave D. Em ambos os trabalhos, os autores verificaram que, após algumas sessões, a quantidade de emissões de sequências diversas diminuía, aumentando concomitantemente a frequência de uma sequência dominante.

Os resultados de tais trabalhos, assim como os do presente experimento, estão de acordo com os obtidos no experimento de Antonitis (1951) e Eckerman e Lanson (1969, Experimento 1) que, ao reforçar a resposta a um painel, independentemente de sua localização, os animais passaram a concentrar suas respostas em um ponto após um período de tempo sob CRF, o que demonstra o fortalecimento de uma classe de resposta. É possível sugerir, portanto, que o mesmo processo possa ter ocorrido no presente trabalho: após um período na contingência FR4, uma mesma sequência passou a ser emitida cada vez mais frequentemente, diminuindo, assim, os níveis de variabilidade previamente existentes, sem alterar a porcentagem de reforçamento.

Sobre a diferença nos níveis de variabilidade observadas entre FR4 e ACO, elas podem ser atribuídas a dois fatores. Um deles está, justamente, no fato de que em ACO o reforçamento da sequência de quatro respostas de pressão à barra era intermitente e em FR4 era contínuo. Como segundo determinante tem-se a história recente de reforçamento do variar sob Lag 4: como variar em ACO não altera a probabilidade do reforço, inicialmente o sujeito se mantém sob controle do reforçamento recente que exigia essa variação, ou seja, sob influência da história recente; porém, não sendo exigida a variação, ela vai se tornando menos frequente, voltando o padrão de emissão de poucas sequências com pouca ou nenhuma alternação.

Estudos usando ratos Wistar e estudantes universitários (Hunziker et al., 1998; Hunziker et al., 2002, respectivamente) verificaram que os sujeitos expostos à ACO, sem histórico de reforçamento por variar, mostraram índices muito baixos de variabilidade. Em contraposição, aqueles que haviam sido expostos à contingência VAR e posteriormente à ACO, exibiram níveis de variabilidade mais altos em ACO do que aqueles que não tiveram esta história de reforçamento. O mesmo ocorreu com a contingência FR4, em que os sujeitos que tiveram exposição prévia à contingência em que o variar foi reforçado, apresentaram maiores níveis de variabilidade do que aqueles 
que não tiveram essa história de reforçamento (Hunziker et al., 1998). Os autores justificaram os resultados observados levando em conta dois pontos: (1) após o reforçamento contingente à variação, há maior probabilidade de os sujeitos emitirem sequências variáveis; (2) esquemas de reforçamento de FR4 e ACO não punem a variação, portanto, embora ela não seja exigida, o comportamento de variar não implica em diminuição da probabilidade de reforçamento. Ainda assim, verificou-se em ACO que os níveis de variabilidade caíram no decorrer das sessões, indicando um possível processo de extinção do comportamento de variar, uma vez que não havia reforçamento contingente a ele.

Além disso, a queda da variabilidade sob ACO pode ter se dado também em função da topografia das diferentes sequências que aparentemente implica em diferentes “dificuldades” em função do número de alternações envolvido. Alguns estudos já analisaram a importância da alternação entre manipulanda como elemento de controle da probabilidade de emissão da sequência, sendo tanto menor essa probabilidade quanto mais alternações envolver a sequência (Barba, 1997; Machado, 1997). Isso se dá porque alternar é uma resposta que envolve esforço físico e toma tempo. Por exemplo, comparando-se as sequências EDED e EEEE teremos que a primeira envolve sete respostas (quatro de pressão à barra e três de mudança de barra) e a última apenas quatro respostas. Logo, se ambas forem igualmente consequenciadas por reforço, é esperado que o sujeito escolha a segunda, poupando esforços e otimizando o ganho de reforços (sobre otimização ver Catania, 1999).

Nesta linha, os dados aqui apresentados mostraram que, não só sob ACO, mas também sob FR4, que houve a predominância das sequências com zero alternação, enquanto que nas contingências Lag, na medida em que o " $n$ " aumentou, ocorreu maior distribuição de sequências: maior emissão das sequências com zero e uma alternação, baixa emissão de sequências com duas alternações, e a nenhuma emissão de sequências com três alternações, efeitos consistentes com as análises anteriores. Ou seja, na medida em que variar era reforçado, sequências com maiores quantidades de alternações passaram a ser mais prováveis de serem emitidas. Todavia, pela exigência de Lag 4 ser baixa, as sequências com duas e três alternações ainda foram emitidas em baixa frequência pelo seu maior custo de resposta ${ }^{7}$. Ainda, no presente estudo, foi possível

\footnotetext{
${ }^{7}$ No presente trabalho está sendo considerado como definidor do custo de resposta o aumento do esforço físico para a emissão de uma resposta (como no caso de sequências com mais alternações) ou a alteração nos parâmetros da contingência que envolvem aumento da exigência para que o reforço seja liberado,
} 
verificar que não houve diferença entre os sujeitos idosos e jovens no que se refere à emissão de sequências com diferentes alternações. Isto é, a idade aparentemente não interagiu diferencialmente com o fator custo de resposta, o que confirma os resultados de Wells (1999, Experimento 2): ao aumentar a dificuldade da tarefa não encontrou diferenças na variabilidade entre os grupos jovens e idosos.

Foi possível também verificar o aumento dos níveis de variabilidade comportamental induzida pela extinção dos sujeitos jovens, medida pelo MetVAR, em comparação ao esquema de reforçamento da variabilidade Lag 4. Os resultados obtidos foram semelhantes aos de Neuringer et al. (2001, Experimento 1), que submeteu ratos machos Long-Evans jovens à contingência RDF, seguida de EXT, e observou que os índices MetVAR apresentaram aumento sob EXT em comparação com a contingência RDF. Os níveis de variabilidade obtidos no presente experimento, sob a contingência em que o variar era reforçado, foram semelhantes aos exibidos por Neuringer et al. (2001), os quais foram mais baixos que os verificados em Maes (2003), Souza (2009) e Yamada (2007). Estes dados podem corroborar a hipótese de que pode haver um efeito diferencial da extinção a depender dos níveis de variabilidade sob controle operante.

Apesar disso, semelhante aos resultados obtidos por Neuringer et al. (2001, Experimento 1) e Yamada (2007), verificou-se, no presente estudo, que a estrutura hierárquica de emissão das sequências obtida em Lag 4' foi mantida em EXT. Apesar dessa manutenção, sequências menos prováveis de serem emitidas em Lag 4' apresentaram aumento em sua frequência relativa nessa condição. Este resultado está de acordo com os obtidos por Maes (2003), Neuringer et al. (2001, Experimento 1) e Souza (2009). Neuringer et al. (2001) discutiu a possibilidade de existir uma combinação de estratégias durante a extinção, uma conservadora, uma vez que o sujeito repete comportamentos que já deram certo no passado, e outra mais arriscada, na medida que o sujeito emite repertórios pouco prováveis em condições anteriores. Villas-Bôas (2006), na mesma linha, avaliou a existência de dois fenômenos na extinção: a ressurgência e a variabilidade comportamentais. Após ensinar quatro sequências de quatro respostas em duas barras a ratos machos Wistar, e subsequentemente submetê-los à extinção, verificou que os sujeitos emitiam sequências que nunca haviam sido treinadas, ao mesmo tempo também que emitiam as sequências anteriormente treinadas. Além disso, as sequências novas, emitidas na extinção, assemelhavam-se, em seu início, àquelas aprendidas em 
fases anteriores. Deste modo, levantou a hipótese da ressurgência e a variação serem fenômenos atrelados.

A distribuição de sequência é de especial importância para a fase de extinção por apresentar um dado preciso sobre o comportamento dos sujeitos, uma vez que os índices de variabilidade devem ser considerados com ressalvas, especialmente o valor U, que necessita de um mínimo de sequências em seu cálculo para que seja confiável. Durante a extinção, as taxas de respostas diminuem, sendo que, por exemplo, no presente estudo, atingiram nas últimas sessões valores próximos do zero. O MetVAR, embora não tenha o mesmo problema de confiabilidade do valor $U$, e por ser uma medida proporcional, é obtido de sessões com poucas sequências emitidas. Assim, um valor alto de MetVAR pode ser sobrevalorizado, uma vez que se o sujeito emitir três sequências diferentes entre si em uma sessão, o índice seria de 100\%. Ainda assim, é um dado importante, por indicar de maneira simples, a proporção de tentativas que cumpriria a contingência de variabilidade.

Quanto ao grupo idoso, apenas um sujeito passou pela contingência EXT. Este sujeito também apresentou aumento dos índices MetVAR em comparação aos obtidos em Lag 4'. Apenas em uma sessão apresentou índice mais baixo, mas na sessão seguinte apresentou novamente aumento. Como replicação entre sujeitos é importante para demonstrar a fidedignidade dos resultados (Sidman, 1976; Perone, 2018), o fato de esse estudo ter ficado reduzido a apenas um sujeito idoso exposto à extinção impede que sejam feitas comparações dos resultados dessa fase levando-se em conta o fator etário.

No nosso estudo, apesar de não ter ocorrido diferenças entre ratos jovens e idosos no que se refere à emissão de sequências com diferentes custos, foi necessário incluir fases intermediárias e progressivas entre as contingências CRF e FR4, e FR4 e Lag 4, a fim de evitar que os animais idosos parassem de responder como obtido em estudo-piloto, no qual as mudanças de fases foram mais exigentes que as aqui implementadas. Outras pesquisas na área de variabilidade comportamental, que utilizaram ratos jovens, tiveram delineamentos envolvendo diversas mudanças de contingências sem que os animais tivessem problemas em se adaptar a cada mudança (Hunziker, Saldana, \& Neuringer 1996; Mook et al., 1993; Mook \& Neuringer, 1994, Yamada, 2007, 2012). Assim, é possível que a idade seja um fator que interfere na adaptação à mudança de contingência, sendo, então, acrescentadas as contingências FR2, entre CRF e FR4, Lag 1 e Lag 2, entre FR4 e Lag 4, no delineamento experimental dos sujeitos de ambas as idades - a fim de 
controlar possíveis interferências devido à história de reforçamento, os sujeitos jovens e idosos passaram pelas mesmas fases, embora, para manutenção das respostas de pressão à barra dos jovens, tais fases intermediárias não fossem necessárias.

Stephens, Weidmann, Quartermain e Sarter (1985) verificaram que ratos idosos apresentaram maior dificuldade na reversão de fases quando animais jovens e idosos eram reforçados a pressionar uma barra numa fase e outra na fase seguinte. Os autores atribuíram essa dificuldade a menor probabilidade de os ratos idosos emitirem uma nova resposta na primeira sessão de reversão. Além disso, observaram que os animais idosos necessitavam de maior treino para a modelagem da resposta de pressão à barra, havendo animais que falharam em aprender a resposta. Tais dados coincidem com o que obtivemos no presente estudo. Além disso, Goodrick (1969), Samson, Venkatesh, Patel, Lipa e Barnes (2014) e Stephens et al. (1985) verificaram que ratos idosos extinguiam mais rapidamente a resposta de pressão à barra que os jovens. Tais fatores combinados podem sugerir que, em uma mudança de fase, ao se exigir uma nova resposta ou aumentar a exigência da resposta para que esta seja reforçada, se a exigência for muito alta para os sujeitos idosos, pode haver maior probabilidade de que estes animais extingam o responder. Portanto, isso parece explicar a necessidade de fases intermediárias para adaptar os animais idosos às novas contingencias.

Os sujeitos idosos também excederam o mínimo de sessões programadas em maior número de sessões e em mais contingências que os sujeitos jovens. Esse excedente deveu-se a necessidade de atingir um número de sessões válidas para o cálculo do valor $\mathrm{U}$, e baixas taxas de resposta emitidas pelos sujeitos idosos. Assim, os animais idosos foram submetidos a um maior número de sessões para atingir o critério de sessões válidas. Outros estudos também constataram a necessidade de maior quantidade de treino para que ratos idosos atingissem critérios de aprendizagem estipulados em diferentes tarefas: treino discriminativo tendo como resposta cavar e deslocar um objeto (Brushfield et al., 2008); permanecer por determinado tempo no quadrante os a plataforma estava durante treino no labirinto aquático de Morris (Gallagher \& Burwell, 1989); velocidade de resposta em resposta de atravessar uma ponte (Frutos, Pistell, Ingram, \& Berthoud, 2012); tarefa de go/ no-go (Schoembaum et al., 2002); e labirinto T e resposta de pressão à barra (Stephens et al., 1985).

Diferentemente do que ocorreu na presente pesquisa, não foi possível observar diferenças de número de sessões entre os animais jovens e idosos em cada fase no trabalho de Wells (1999) devido ao fato de que o critério para mudança de fase foi apenas a 
quantidade de sessões previamente estabelecido. Contudo, os animais do experimento de Wells (1999) tiveram, tanto com idosos quanto com os jovens, baixas taxas de resposta, abaixo do que seria necessário para a confiabilidade do valor $\mathrm{U}$.

No que se refere às taxas de respostas obtidas, verificou-se, no presente experimento, que as taxas de resposta foram mais baixas entre os animais idosos que os jovens. Alguns estudos indicam uma diminuição na atividade motora (comportamentos de locomoção/ambulação) em ratos, na medida em que eles envelhecem (Gage et al., 1984; Goodrick, 1966; Hodge, Peacock, \& Hoff, 1967). Gage et al. (1984) realizaram medidas de atividade em campo aberto em ratos Sprague-Dawley machos jovens (3 meses) e idosos (24 meses), com livre acesso à água e comida. Já Goodrick (1966) e Hodge et al. (1967), utilizando ratos machos Sprague-Dawley/Wistar e Dahl salresistentes (DR), respectivamente, realizaram medidas de atividade motora, comparando grupos de sujeitos de diferentes idades em duas condições: com comida ad lib e privados. Goodrick (1966) utilizou animais com 9-11 meses e 19 meses, em campo aberto, e Hodge et al. (1967) com 30, 40, 60 e 365 dias, em suas gaiolas-viveiro. Todos os trabalhos verificaram que a atividade motora dos animais não privados diminuiu em função do aumento da idade. Quando privados, Goodrick (1966) e Hodge et al. (1967) constataram que os animais mais velhos tiveram sua atividade motora aumentada, embora Hodge et al. (1967) tenha observado que este aumento foi menor para o grupo mais velho em comparação aos grupos mais jovens.

Como os resultados aqui apresentados mostraram, a concentração de $10 \%$ de SAC não se mostrou eficaz para manter as respostas dos sujeitos idosos nas diferentes contingências, de forma que apenas um deles completou todas as fases programadas. Num extremo, um dos sujeitos idosos não aprendeu a resposta de pressão à barra alternativa mesmo após 12 sessões de modelagem. Assim, apesar da tentativa de utilizar um reforçador de maior magnitude que água ou comida, a solução de SAC 10\% parece não ter sido reforçadora o suficiente para os animais idosos, ao contrário do obtido com ratos jovens. Essa pode ter sido a maior diferença obtida no presente estudo como função da idade dos sujeitos. Tendo isso em vista, pode ser que a concentração de sacarose utilizada no presente estudo tenha interferido na verificação dos objetivos incialmente propostos. Se nossa meta é avaliar se a idade pode ser um fator de interação com as contingências que exigem ou não a variabilidade comportamental, então devemos utilizar reforçador com magnitude suficiente para manter os comportamentos tanto dos animais jovens como dos idosos. 
Diante do exposto, um novo experimento foi conduzido, alterando a concentração da solução de SAC de $10 \%$ para $20 \%$, na tentativa de que, com o novo reforçador, as taxas de respostas dos sujeitos idosos se elevassem, a fim de que: (a) mais sujeitos idosos completassem o experimento, possibilitando comparações intragrupo e entre grupos; e (b) o critério de passagem de fases pudesse ser atingido mais rapidamente, mantendo um maior controle experimental na medida que os sujeitos idosos e jovens possam ter uma quantidade de treino similar. Portanto, esse segundo estudo nos permitiu explorar se com o uso da solução de SAC $20 \%$ como reforço seria possível identificar diferenças sobre os níveis de variabilidade comportamental entre ratos jovens e idosos comparativamente às mesmas condições testadas nesse primeiro estudo.

Além disso, foram também acrescidos grupos submetidos à contingência de repetição a fim de verificar semelhanças ou diferenças nos níveis de variabilidade comportamental entre os ratos jovens e idosos. Pesquisas demonstraram que organismos com diferenças em suas constituições biológicas apresentaram diferenças tanto no comportamento de variar como no de repetir. Um exemplo são os estudos realizados com diferentes linhagens de ratos, espontaneamente hipertensos (SHR, do inglês spontaneously hypertensive rats) e Wistar Kyoto (WKY), que são normotensos (Mook et al., 1993; Mook \& Neuringer, 1994). Os SHR são utilizados em pesquisas sobre Transtorno de Déficit de Atenção e Hiperatividade (TDAH), por suas características em comum com a doença, como maiores níveis de atividade motora e exploração do ambiente, além de necessitarem maior treino para aprender determinadas tarefas. Mook et al. (1993, Experimento 2) submeterem os ratos SHR e WKY a um delineamento de reversão Lag 4 - ACO - $\operatorname{Lag} 4$, e verificaram que os animais SHR apresentaram maiores níveis de variabilidade durante a fase ACO e a segunda condição Lag 4.

Em experimento seguinte (Mook et al., 1993, Experimento 4), quando exigido que os sujeitos emitissem, dentre as 16 possibilidades existentes, um conjunto reduzido de apenas quatro sequências, devendo ainda ela ser diferente da anterior ( $\operatorname{Lag} 1)$. Ou seja, havia uma combinação de exigência de repetir (ao selecionar quatro sequências para serem reforçadas) e de variação ( $\operatorname{Lag} 1)$. Os animais SHR apresentaram menores porcentagens de respostas reforçadas em comparação aos WKY, sendo que estes últimos concentraram suas respostas em apenas duas das quatro sequências possíveis de serem reforçadas. Estes resultados foram replicados por Mook e Neuringer (1994). Assim, embora sensíveis às contingências experimentais, cada linhagem apresentou maior ou menor tendência para o comportamento de variar ou repetir. Outros exemplos são 
pesquisas nas quais participantes humanos com depressão ou autismo, comparados com seus controles, apresentam níveis mais baixos de variabilidade nas tarefas usadas, e níveis mais altos de repetição (Hopkinson \& Neuringer, 2003; Miller \& Neuringer, 2000).

Assim, a contingência de repetição foi incluída como um controle adicional à de variação, entendendo que se houvesse uma tendência de os sujeitos idosos e jovens diferirem entre si quanto à variabilidade, eles podem apresentar também diferenças no comportamento de repetir. Por fim, essa mudança permitiu que se avaliassem os níveis de variabilidade induzida pela extinção, tendo como linha de base a repetição. 


\section{EXPERIMENTO 2}

O presente estudo teve por objetivos verificar se com o uso de sacarose na concentração de $20 \%$ (SAC 20\%), como reforço positivo, ocorrem diferenças no comportamento de ratos jovens e idosos no que diz respeito aos níveis de variabilidade comportamental quando expostos a contingências de reforçamento intermitente (com e sem exigência de variação/repetição), e à extinção.

\section{MÉTODO}

\section{Sujeitos}

Foram utilizados 19 ratos machos Wistar, experimentalmente ingênuos, mantidos sob as mesmas condições de alojamento, manipulação e privação que os sujeitos do Experimento 1.

\section{Equipamentos}

Os mesmos do Experimento 1, exceto pelo reforçador, que consistiu em solução de sacarose diluída à 20\% (SAC 20\%).

\section{Procedimento}

Semelhante ao Experimento 1, com a diferença de que foram acrescidos animais expostos à contingência de repetição (REP), a qual será detalhada adiante.

\section{Treino Preliminar}

Igual ao Experimento 1.

\section{Fase Experimental}

Nove animais, cinco jovens e quatro idosos, foram expostos às cinco fases experimentais conforme descrito no Experimento 1: FR4, VAR, ACO, VAR e EXT. Esses animais serão doravante tratados como VAR, idosos ou jovens. Outros 10 sujeitos, metade jovens e metade idosos, foram expostos também a cinco fases experimentais 
acima listadas, com a diferença de que as fases VAR foram substituídas por fases sob a contingência de repetição (REP). Esses sujeitos serão nomeados como REP, idosos ou jovens.

Na contingência REP, apenas uma das 16 sequências possíveis era reforçada. Para cada sujeito foi escolhido o reforçamento de uma sequência que não envolvia alternação entre barras (EEEE ou DDDD). O critério de escolha entre ambas as sequências foi aquela que havia sido emitida com menor frequência, pelo sujeito, na fase de FR4. Nas duas primeiras sessões da fase REP, a probabilidade de reforçamento da sequência selecionada foi de $100 \%$ e, posteriormente, passou para $50 \%^{8}$.

Sob ACO, precedido de REP, os reforços foram liberados da mesma maneira que em ACO, precedido de VAR. Isto é, os reforços foram contingentes à emissão de uma sequência, independentemente da sua configuração, sendo que para o acoplamento foram usadas as duas últimas sessões de REP realizadas pelo sujeito, que se alternaram a cada sessão de ACO.

Todos os parâmetros das sessões e unidades foram os mesmos do Experimento 1. O critério de encerramento da contingência foi o mesmo usado no Experimento 1, tendo como base o cumprimento de determinado número de sessões válidas - sendo consideradas válidas as sessões em que era completado um mínimo de 150 tentativas. Assim também como no Experimento 1, em EXT, o critério de encerramento da fase foi o número de sessões programadas, em que todas constituíam sessões válidas, independentemente do número de tentativas. A Tabela 3 apresenta resumidamente o delineamento experimental, incluindo a ordem de apresentação das contingências e números de sessões planejadas em cada fase. As segundas fases de VAR Lag 4 e REP serão indicadas como VAR Lag 4' e REP' para diferenciar das primeiras fases em que essas contingências vigoraram.

\footnotetext{
${ }^{8}$ A sigla REP se refere a 50\% de probabilidade de reforçamento de uma determinada sequência. Na fase em que essa probabilidade foi de $100 \%$ a sigla é REP $100 \%$.
} 
Tabela 3 - Delineamento experimental, com a ordem de apresentação das contingências e números de sessões mínimas planejadas em cada fase. Com exceção das fases sinalizadas (* e ${ }^{* *}$ ), todo o experimento foi conduzido tendo duas barras na caixa experimental.

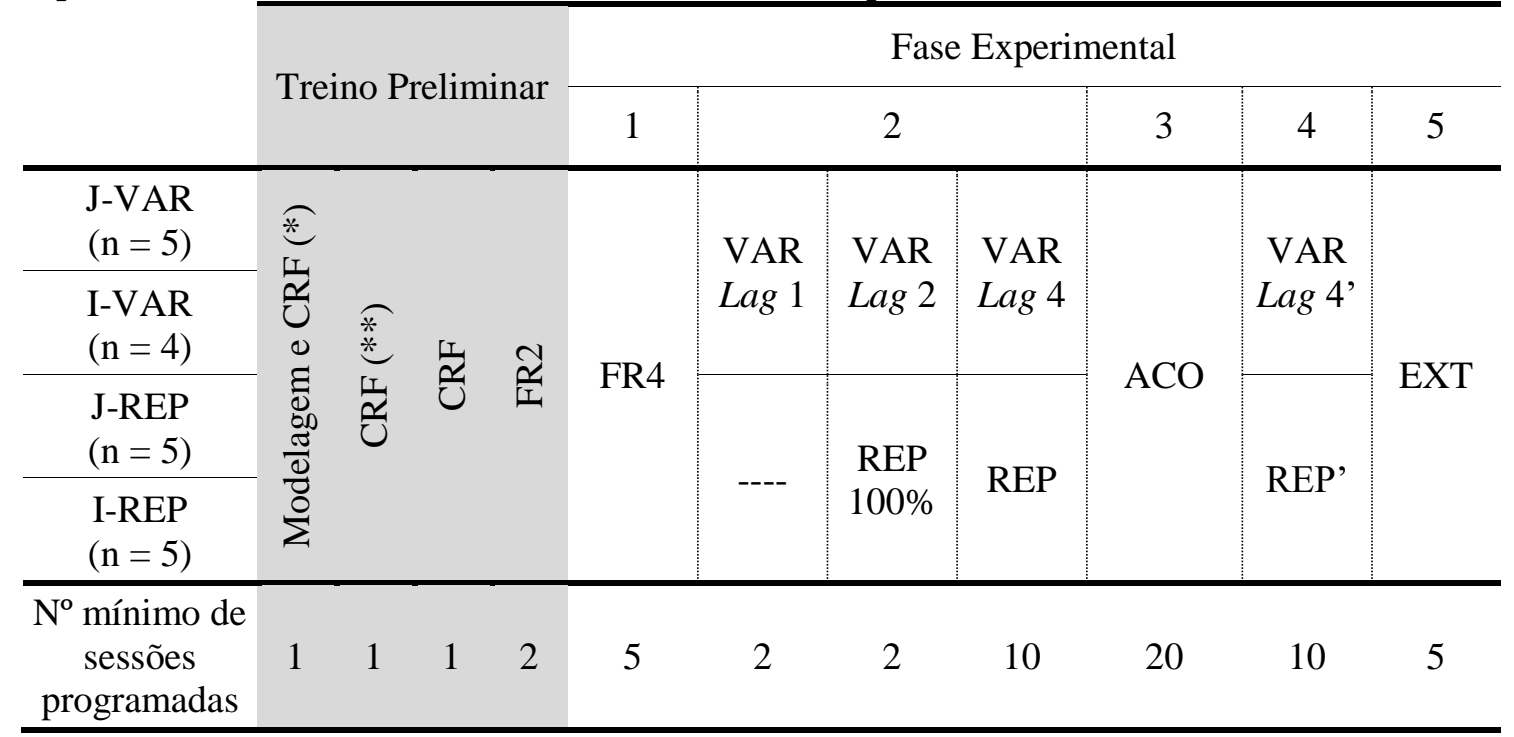

(*) uma barra $\quad(* *)$ barra alternativa 


\section{RESULTADOS}

Na Tabela 4 são apresentados o número de sessões realizadas pelos sujeitos VAR, idosos e jovens, nas diferentes fases do experimento. Todos os sujeitos completaram todas as fases programadas. Dentre os animais VAR, os idosos necessitaram de maior número de sessões para atingir os critérios mudança de fase, e embora todos tenham ultrapassado o mínimo de sessões programadas, os jovens apresentaram quantidade de sessões mais próxima ao mínimo programado. Apenas o Sujeito 9c necessitou mais sessões, aproximando-se dos sujeitos idosos.

Tabela 4 - Número de sessões realizadas sob cada contingência e no total do experimento pelos sujeitos VAR, idosos e jovens (I-VAR e J-VAR, respectivamente). Na linha inferior é reapresentado o número mínimo de sessões que haviam sido programadas. Com exceção das fases sinalizadas (* e **), todo o experimento foi conduzido tendo duas barras na caixa experimental.

$\mathrm{N}^{\mathrm{o}}$ de sessões realizadas

\begin{tabular}{|c|c|c|c|c|c|c|c|c|c|c|c|c|c|}
\hline & \multirow[b]{2}{*}{ 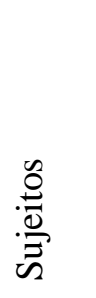 } & \multicolumn{4}{|c|}{ Treino preliminar } & & \multicolumn{7}{|c|}{ Fase Experimental } \\
\hline & & 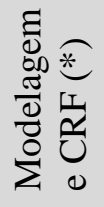 & 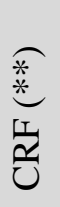 & 売 & $\frac{\tilde{x}}{x}$ & $\underset{\frac{d}{I}}{\frac{\Delta}{I}}$ & כ) & 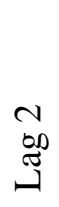 & 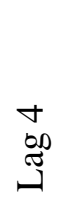 & 巳 & 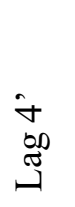 & 気 & $\stackrel{\pi}{0}$ \\
\hline \multirow{4}{*}{$\underset{1}{\stackrel{2}{d}}$} & $4 \mathrm{~b}$ & 2 & 1 & 9 & 10 & 13 & 3 & 3 & 12 & 21 & 10 & 5 & 89 \\
\hline & $5 b$ & 3 & 2 & 1 & 5 & 9 & 3 & 3 & 10 & 34 & 11 & 5 & 86 \\
\hline & $6 b$ & 2 & 1 & 1 & 5 & 12 & 3 & 3 & 10 & 20 & 15 & 5 & 77 \\
\hline & $7 \mathrm{~b}$ & 3 & 1 & 1 & 5 & 9 & 3 & 3 & 10 & 20 & 10 & 5 & 70 \\
\hline \multirow{5}{*}{$\underset{⿱}{\stackrel{2}{2}}$} & $11 \mathrm{c}$ & 3 & 1 & 1 & 2 & 9 & 2 & 2 & 10 & 20 & 11 & 5 & 66 \\
\hline & $2 \mathrm{c}$ & 1 & 1 & 1 & 2 & 6 & 2 & 2 & 10 & 20 & 10 & 5 & 60 \\
\hline & $3 \mathrm{c}$ & 1 & 1 & 1 & 2 & 6 & 2 & 2 & 10 & 20 & 10 & 5 & 60 \\
\hline & $8 \mathrm{c}$ & 6 & 2 & 1 & 3 & 7 & 2 & 2 & 10 & 20 & 10 & 5 & 68 \\
\hline & $9 \mathrm{c}$ & 5 & 2 & 1 & 2 & 9 & 2 & 2 & 13 & 20 & 17 & 5 & 78 \\
\hline \multicolumn{2}{|c|}{$\begin{array}{l}\mathrm{N}^{\mathrm{o}} \text { de sessões } \\
\text { programadas }\end{array}$} & 1 & 1 & 1 & 2 & 5 & 2 & 2 & 10 & 20 & 10 & 5 & 59 \\
\hline
\end{tabular}

No geral, foi na fase de treino que os sujeitos necessitaram de maior número de sessões do que o mínimo, tendo os sujeitos idosos apresentado maior diversidade entre si. Dois sujeitos jovens excederam em 4 e 5 sessões o mínimo programado. nas fases de Modelagem e CRF. O Sujeito 8c precisou ter a modelagem da resposta de pressão à barra 
suspensa temporariamente após a segunda sessão por apresentar respostas de freezing ${ }^{9}$. Já o Sujeito 9c foi o único animal a precisar ter a resposta de pressão a barra novamente modelada na barra alternativa.

Tabela 5 - Número de sessões realizadas sob cada contingência, e no total do experimento, pelos sujeitos REP, idosos e jovens (I-REP e J-REP, respectivamente). Na linha inferior é reapresentado o número mínimo de sessões que haviam sido programadas. Com exceção das fases sinalizadas (* $\mathbf{e} * *)$, todo o experimento foi conduzido tendo duas barras na caixa experimental.

\begin{tabular}{|c|c|c|c|c|c|c|c|c|c|c|c|c|}
\hline & \multirow[b]{3}{*}{$\frac{\mathscr{0}}{\stackrel{0}{0}}$} & \multicolumn{9}{|c|}{$\mathrm{N}^{\mathrm{o}}$ de sessões realizadas } & & \\
\hline & & \multicolumn{4}{|c|}{ Treino preliminar } & \multicolumn{7}{|c|}{ Fase Experimental } \\
\hline & & 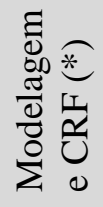 & 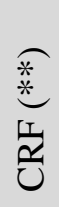 & 壳 & جָ & 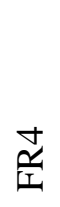 & $\begin{array}{l}80 \\
8 \\
\frac{1}{2} \\
\frac{1}{\alpha}\end{array}$ & $\frac{2}{\alpha}$ & O & $\frac{0}{x}$ & $\underset{x}{\bar{x}}$ & $\stackrel{\frac{\pi}{0}}{0}$ \\
\hline \multirow{5}{*}{$\frac{\frac{\pi}{\alpha}}{\frac{\pi}{1}}$} & $3 b$ & 2 & 2 & 1 & 5 & 9 & 2 & 11 & 20 & 10 & 5 & 68 \\
\hline & 10 & 2 & 1 & 1 & 5 & 9 & 2 & 11 & 20 & 10 & 5 & 67 \\
\hline & 11 & 4 & 2 & 1 & 5 & 9 & 2 & 11 & 20 & 10 & 5 & 69 \\
\hline & 12 & 3 & 1 & 3 & 9 & 8 & 14 & 12 & 20 & 10 & 5 & 85 \\
\hline & 13 & 2 & 2 & 1 & 5 & 9 & 17 & 14 & 20 & 11 & 5 & 86 \\
\hline \multirow{5}{*}{$\frac{\frac{a r}{\alpha}}{\frac{1}{1}}$} & $1 d$ & 2 & 1 & 1 & 3 & 7 & 3 & 10 & 21 & 10 & 5 & 63 \\
\hline & $2 d$ & 1 & 1 & 1 & 3 & 7 & 2 & 10 & 20 & 10 & 5 & 60 \\
\hline & $3 d$ & 1 & 1 & 1 & 3 & 11 & 8 & 10 & 20 & 11 & 5 & 71 \\
\hline & $4 d$ & 1 & 1 & 1 & 7 & 5 & 3 & 10 & 20 & 10 & 5 & 63 \\
\hline & $5 \mathrm{~d}$ & 2 & 1 & 1 & 3 & 7 & 2 & 10 & 20 & 10 & 5 & 61 \\
\hline \multicolumn{2}{|c|}{$\begin{array}{c}\mathrm{N}^{\mathrm{o}} \text { de sessões } \\
\text { programada }\end{array}$} & 1 & 1 & 1 & 2 & 5 & 2 & 10 & 20 & 10 & 5 & 57 \\
\hline
\end{tabular}

A Tabela 5 exibe a quantidade de sessões realizadas pelos sujeitos REP, idosos e jovens. Assim, como o descrito anteriormente, os sujeitos idosos necessitaram, no geral, de mais sessões para completar o experimento do que os jovens, e isso se deu principalmente nas fases iniciais. Cabe destacar que os Sujeitos 3b, 11 e 13, idosos, precisaram ter a resposta de pressão à barra alternativa modelada. Na mudança de REP

\footnotetext{
${ }^{9}$ Estas respostas provavelmente foram decorrentes de condicionamento respondente acidental, uma vez que na mesma caixa em que a primeira sessão de modelagem deste animal foi realizada, ocorreu, no dia anterior, procedimento com estimulação elétrica, de outra pesquisa. Embora limpa após o procedimento, talvez algum odor deixado pelo animal que recebeu estimulação elétrica tenha permanecido na caixa. O modo de limpeza da caixa foi aperfeiçoado, mas ainda foi necessário realizar a extinção respondente: o animal permaneceu na caixa por $1 \mathrm{~h}$, sem que as barras estivessem disponíveis e com a luz ambiente ligada. Portanto, três das sessões que na Tabela 5 aparecem atribuídas à modelagem e CRF foram usadas para este procedimento de extinção do freezing.
} 
100\% para REP, dois animais idosos (Sujeitos 12 e 13), excederam em 12 e 15 sessões, respectivamente, o número mínimo programado para esta fase. Por outro lado, sob FR4, o Sujeito 3d, jovem, foi o que mais precisou de sessões para atingir o critério de mudança de fase. Além disso, o Sujeito 4d precisou retornar a fase anterior por duas sessões entre a segunda e terceira sessões de FR2, devido às taxas de resposta nas duas primeiras sessões nessa contingência terem sido muito baixas. Nas demais fases, os sujeitos de ambos os grupos apresentaram número de sessões semelhantes entre si.

A Figura 4 apresenta os dados individuais dos sujeitos VAR relativos aos valores $\mathrm{U}$ (parte superior), seguidos por MetVAR, porcentagem de reforço e taxa de resposta, nas diferentes fases do estudo. Nas condições em que a variabilidade era critério para reforçamento, os índices $U$ foram os mais altos que nas demais, sem diferenças no desempenho dos sujeitos idosos e jovens. Os valores $U$ de todos os sujeitos se elevaram quando da mudança de Lag 1 para Lag 2, sendo os mais altos índices apresentados em Lag 4, entre 0,6 e 0,85. Portanto, quanto maior a exigência de variação, maior foi variabilidade obtida. Na condição Lag 4', que seguiu ACO, houve retomada dos altos valores $U$ nas primeiras sessões, sendo que os índices da maioria dos sujeitos permaneceram acima dos apresentados em ACO, mas um pouco abaixo dos obtidos sob Lag 4.

Sob FR4, condição na qual variar não era requisito para reforçamento, os animais idosos e jovens mostraram índices U maiores na primeira sessão e queda progressiva nas seguintes (exceção apenas de um animal idoso que aumentou a variabilidade ao longo das sessões e outro que começou e se manteve com índice U baixo). No todo dessa fase, os animais jovens mostraram, no geral, maiores índices U que os idosos. Na condição ACO, que também não exigia variabilidade como critério para reforçamento, mas seguiu uma fase de reforço contingente ao variar, a mesma relação se repetiu: os animais idosos mostraram índices $U$ inferiores aos dos animais jovens, além de queda mais acentuada no decorrer das sessões. Porém, em ambos os conjuntos de sujeitos a variabilidade em ACO foi superior a apresentada em FR4. Os animais idosos começaram a fase ACO mostrando índices U mais elevados sob ACO do que no início de FR4, enquanto os animais jovens apresentaram valores de U no começo de ACO semelhantes às primeiras sessões de FR4, porém sem mostrar a mesma queda ao longo das sessões. Os sujeitos idosos apresentaram maior diversidade dos valores U sob as contingências FR4 e, ACO, enquanto os jovens, a diversidade foi maior apenas em FR4. Os valores $U$ de todos os sujeitos, sob as 
contingências Lag, mostraram-se consistentes entre si, assim como os valores dos jovens sob ACO.
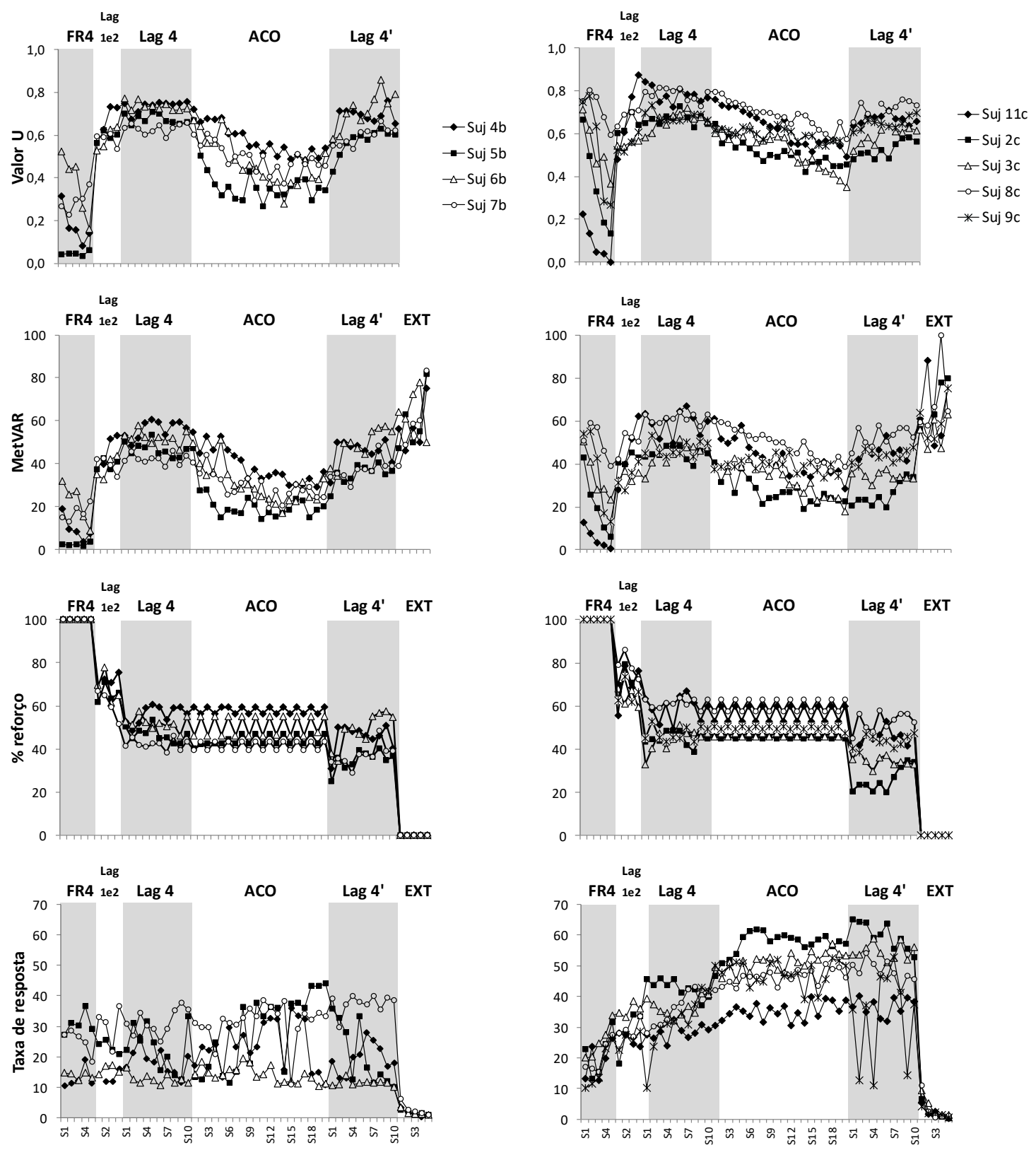

I-VAR

J-VAR

Figura 4 - Valor U, MetVAR, porcentagem de reforço e taxa de resposta dos sujeitos VAR, idosos e jovens (I-VAR e J-VAR, respectivamente), nas sessões válidas de cada fase experimental. São apresentados os dados individuais dos sujeitos, em que os gráficos à esquerda correspondem aos sujeitos Idosos, e os gráficos à direita, aos sujeitos jovens.

Os índices MetVAR estão demonstrados na segunda linha da Figura 4. Eles replicam de forma muito próxima os dados obtidos com os índices U. O dado adicional 
está na condição EXT, sob a qual tanto os sujeitos idosos como os jovens exibiram acentuado e sistemático crescimento do índice MetVAR da primeira à última sessão.

$\mathrm{Na}$ terceira linha da Figura 4 estão apresentadas as porcentagens de reforço obtidos pelos sujeitos VAR. Por características da contingência, sob FR4 e EXT as porcentagens se apresentaram nos valores máximos, superior e inferior, respectivamente. Também em ACO esse dado repete as duas últimas medidas obtidas na fase Lag 4. Portanto, nessa figura o relevante são os dados obtidos sob as contingências VAR, tendo os animais idosos e jovens demonstrado padrões semelhantes entre si: as porcentagens de reforço apresentaram diminuição à medida que a contingência ficou mais exigente, atingindo valores, na maioria das sessões, entre 40 e $60 \%$ sob Lag 4; na condição Lag 4', as porcentagens de reforço foram mais baixas que as obtidas em Lag 4 (em torno de 40\%).

As taxas de resposta dos sujeitos jovens e idosos submetidos à VAR são apresentadas na última linha da Figura 4. Essa variável não se mostrou diretamente sensível as contingências em vigor, tendo tendência crescente ao longo do experimento dentre os animais jovens que, no geral, apresentaram taxas de respostas bem mais elevadas que os idosos, os quais mantiveram taxas relativamente constantes ao longo do experimento. A exceção para os padrões citados é em relação à contingência EXT, que produziu queda acentuada das taxas de resposta de todos, idosos e jovens, chegando a praticamente zero nas últimas sessões.

Os dados dos animais REP seguem mesmo padrão de apresentação na Figura 5. De uma maneira geral, os valores $U$ dos sujeitos idosos e jovens foram semelhantes nas contingências REP e REP', em que os índices apresentaram queda nas primeiras sessões dessas contingências, estabilizando abaixo de 0,10 entre a maioria dos sujeitos idosos, e abaixo de 0,15 entre os sujeitos jovens. A exceção foi o Sujeito 11, idoso, que mostrou valores $U$ cerca de 3,5 vezes mais altos que a média dos demais sujeitos de seu grupo sob REP'.

Nas condições em que variar não era exigência para reforçamento (FR4 e ACO), os sujeitos jovens obtiveram valores $U$ mais altos, comparados aos sujeitos idosos: sob FR4, os valores U da maioria dos sujeitos idosos permaneceram estáveis e abaixo de 0,2 , enquanto que os sujeitos jovens obtiveram valores mais altos, variando entre 0,4 e 0,7 na primeira sessão, e com diminuição desses valores nas sessões subsequentes; sob ACO, a maioria dos sujeitos idosos apresentaram estabilidade nos valores $U$ abaixo de 0,1 durante toda a contingência, e os sujeitos jovens apresentaram aumento dos valores $\mathrm{U}$, estabilizando em torno de 0,25, exceto pelo Sujeito 5 d que permaneceu abaixo de 0,15. 
Nessas condições, os sujeitos jovens apresentaram maior diversidade dos valores U, comparados aos sujeitos idosos. Entre os animais jovens, os Sujeitos $2 \mathrm{~d}$ e $5 \mathrm{~d}$, diferentemente do ocorrido com os animais VAR, tiveram valores U maiores sob FR4 do que sob ACO. Já entre os animais idosos, o Sujeito 11 iniciou a fase FR4 mostrando valor $\mathrm{U}$ de 0,45 , com queda leve nas sessões subsequentes, e sob ACO, apresentou acentuada elevação no valor U nas primeiras sessões e estabilização em torno de 0,5.
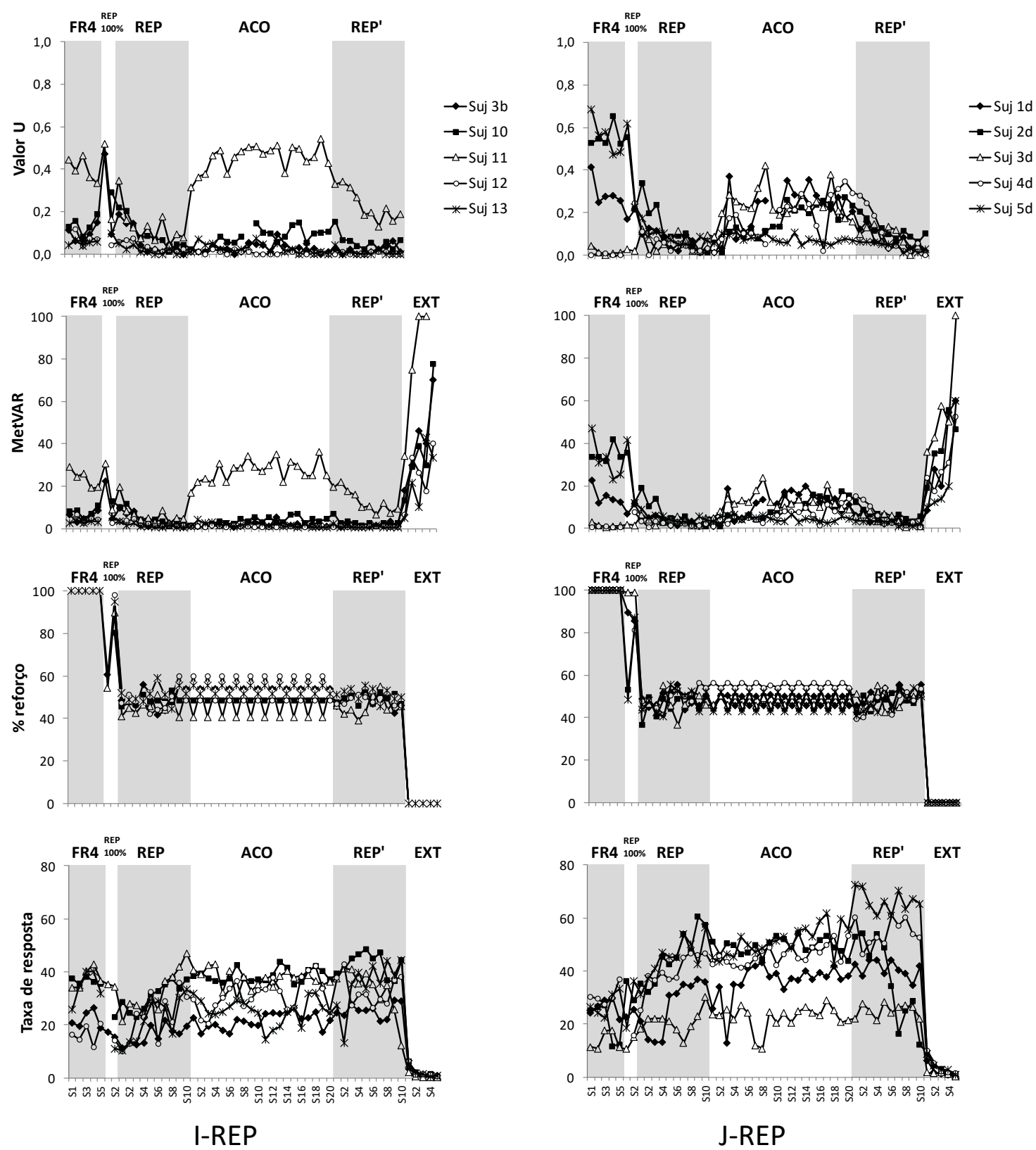

Figura 5- Valor U, MetVAR, porcentagem de reforço e taxa de resposta dos sujeitos REP, idosos e jovens (I-REP e J-REP, respectivamente), nas sessões válidas de cada fase experimental. São apresentados os dados individuais dos sujeitos, em que os gráficos à esquerda correspondem aos sujeitos idosos, e os gráficos à direita, aos sujeitos jovens. 
Na segunda linha da Figura 5 são apresentados os índices MetVAR dos sujeitos idosos e jovens expostos à REP em cada contingência a que foram submetidos. Conforme descrito para os animais VAR, os padrões foram bastante semelhantes aos observados em relação ao valor $\mathrm{U}$, tendo como dado adicional o desempenho em EXT: tanto os sujeitos idosos como os jovens tiveram acentuados aumentos nos índices MetVAR no decorrer das sessões desta contingência. Comparando os índices MetVAR mostrados durante a contingência EXT pelos animais REP e VAR, destaca-se que os índices dos animais REP tiveram elevação de 2,3 a 3,6 vezes (idoso e jovem respectivamente) ao longo das sessões em comparação ao aumento obtido entre os sujeitos VAR de mesma idade. Ou seja, sob EXT, as inclinações das curvas obtidas pelos sujeitos REP foram mais acentuadas que as obtidas pelos sujeitos VAR.

As porcentagens de reforço dos sujeitos idosos e jovens submetidos à REP são exibidas na terceira linha da Figura 5. Essas porcentagens se mantiveram constantes nas fases REP e REP', atingindo o patamar de 50\% permitido pelo procedimento.

As taxas de resposta dos sujeitos idosos e jovens submetidos à REP são mostradas da última linha da Figura 5. Novamente, a taxa de resposta não se mostrou diretamente sensível as contingências em vigor, exceto sob EXT. Assim como entre os animais VAR, os sujeitos jovens mostraram maiores taxas que os idosos a partir da fase REP. Na fase inicial, os idosos mostraram queda das taxas de resposta de FR4 a REP $100 \%$, e a partir de REP, exibiram leve aumento das taxas até REP'. Em contrapartida, os sujeitos jovens tiveram elevação de suas taxas de resposta já a partir de FR4 até REP', com aumento mais acentuado que o observado entre os sujeitos de idosos. Sob EXT, as taxas de todos os sujeitos diminuíram, atingindo valores próximos de zero.

Foram calculadas as porcentagens das sequências selecionadas para reforçamento sob REP (EEEE ou DDDD) nas sessões válidas de todas as fases a que os sujeitos foram submetidos, apresentadas na Figura 6. Sob ACO, os dois conjuntos de sujeitos mostraram padrão muito diferente entre si: com apenas uma exceção, os animais idosos se mantiveram emitindo quase que exclusivamente a sequência anteriormente reforçada, enquanto os jovens foram gradualmente apresentando outras sequências ao longo das sessões sucessivas. Nas sessões experimentais sob REP, ambos os conjuntos de sujeitos se comportaram de forma adaptada à continência, sendo que em EXT ambos mostraram aumento da variação ao longo das sessões. 

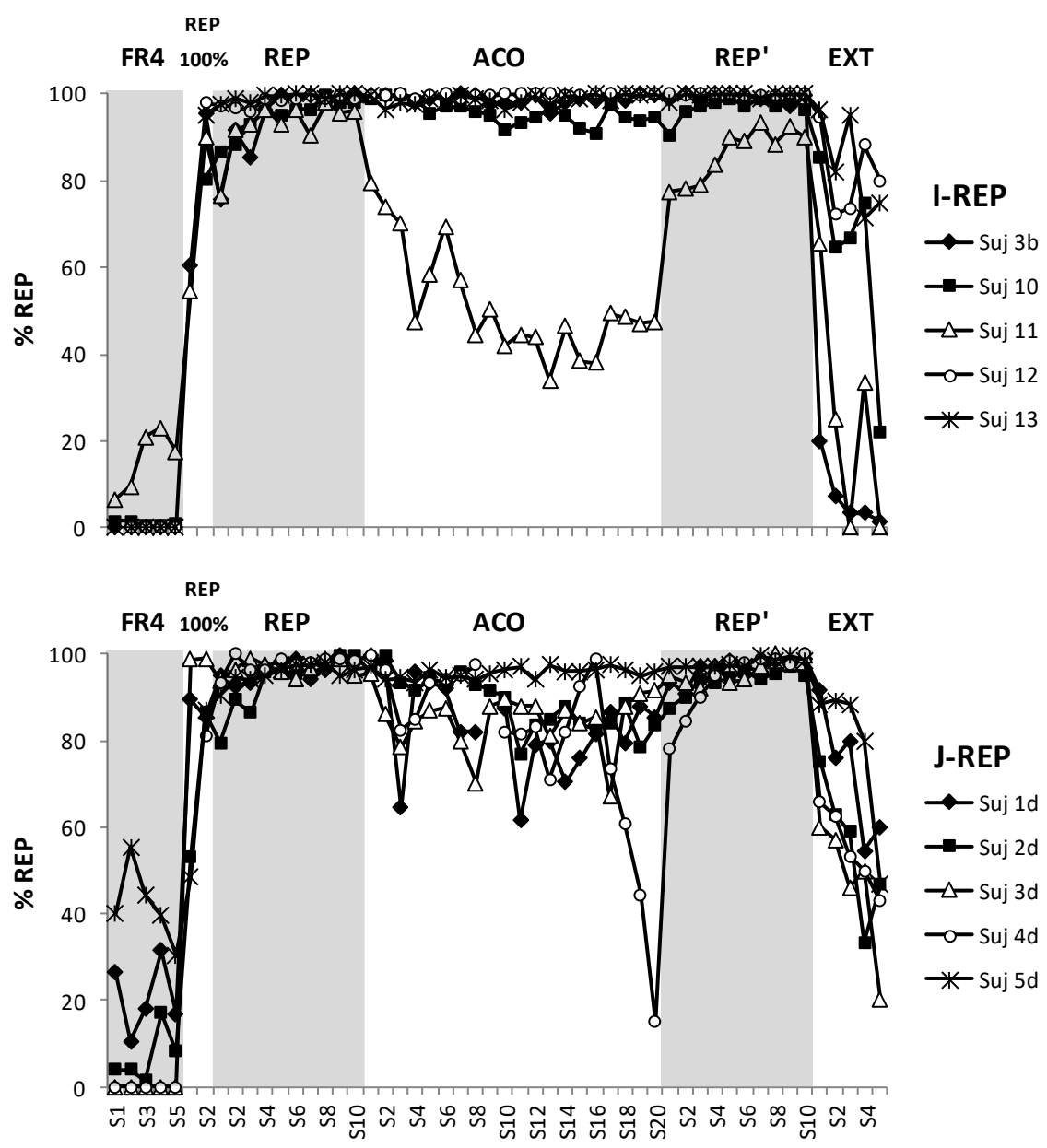

Figura 6 - Porcentagem das sequências selecionadas para reforçamento sob REP nas sessões válidas de cada fase experimental. São apresentados os dados individuais dos sujeitos idosos e jovens submetidos à REP (I-REP e J-REP, respectivamente), em que o gráfico superior corresponde aos sujeitos idosos, e o gráfico inferior, aos sujeitos jovens.

As frequências relativas das sequências emitidas pelos sujeitos VAR, idosos e jovens, são mostradas na Figura 7, na qual o eixo horizontal está ordenado de acordo com as sequências de menor para maior alternação: 0 alt, 1 alt, 2 alt e 3 alt. As distribuições das sequências de EXT serão analisadas posteriormente, e por isso, não foram incluídas. Tanto os sujeitos idosos como os jovens mostraram, em todas as fases, maior frequência de sequências com 0 alt e 1 al. Nas fases em que variar não era exigido, as sequencias de 2alt e 3 alt foram praticamente ausentes, embora tenha havido maior distribuição de sequências na contingência ACO que em FR4. Comparando as últimas sessões destas condições, a maioria dos animais emitiram quase que exclusivamente sequências 0 alt sob FR4. Nas contingências $\operatorname{Lag} 4$ e $\operatorname{Lag} 4$ ', houve maior distribuição das sequências, especialmente na última sessão dessas contingências, porém sendo mantidas maiores as frequências de 0 alt e 1 alt, com algumas emissões sequências 2 alt e 3 alt. 

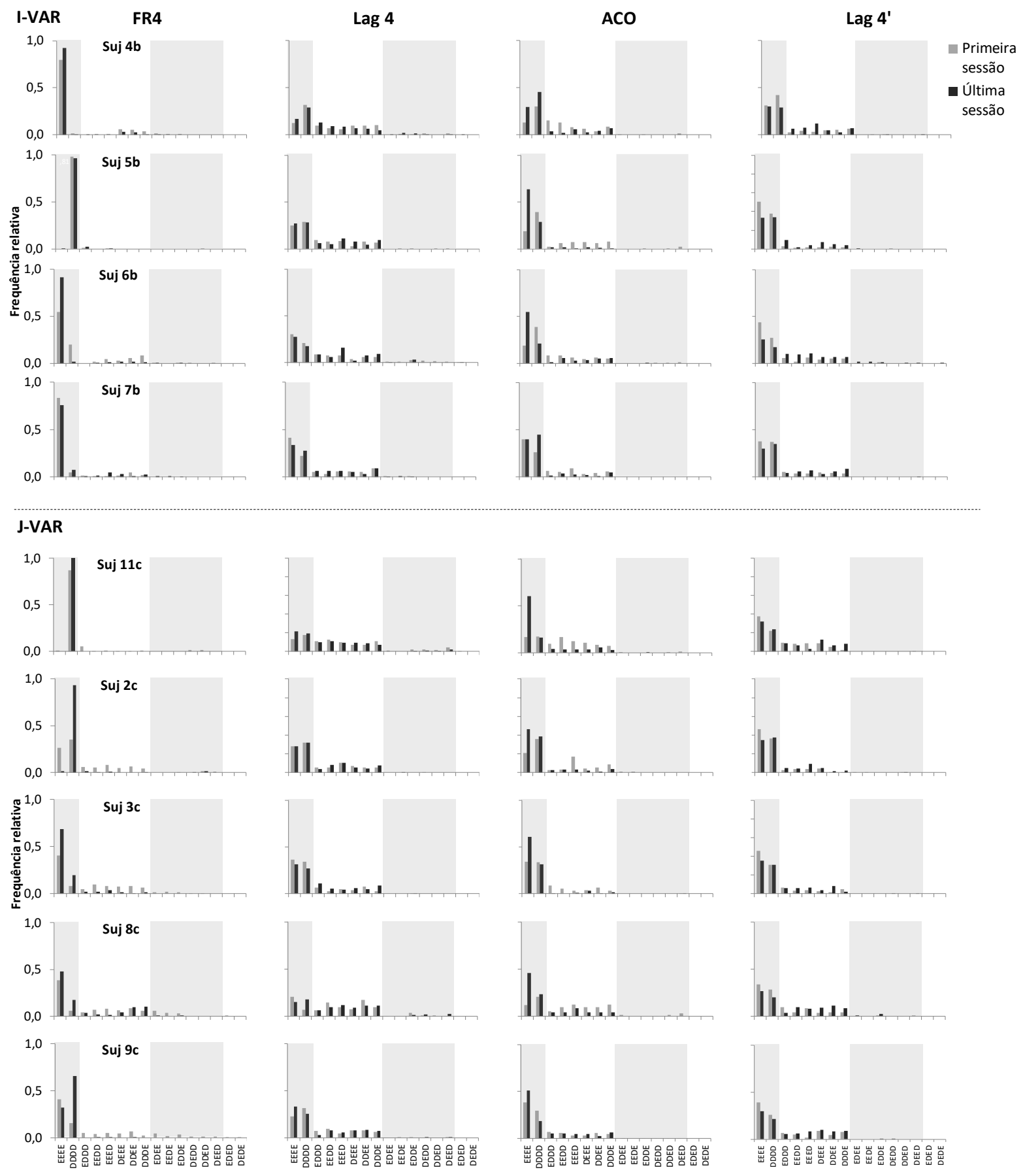

Figura 7 - Distribuição de sequências emitidas por sujeitos VAR, idosos e jovens (I-VAR e JVAR, respectivamente), em cada fase experimental. São apresentadas as frequências relativas das sequências emitidas na primeira e última sessão de cada contingência, tendo como universo 16 sequências possíveis. No eixo horizontal, estão ordenadas sequências agrupadas em função do número de alternações (entre barras exigido para sua emissão: mais à esquerda estão as sequencias com zero alternação, seguidas pelas que exigem uma, duas ou três alternações entre barras). As áreas cinza e branca delimitam os conjuntos de sequências por número de alternação. 
Na Figura 8 são demonstradas as frequências relativas das sequências emitidas pelos sujeitos REP, idosos e jovens, na primeira e na última sessão das contingências FR4, REP, ACO e REP'. A distribuição das sequências não diferiu entre os sujeitos idosos e jovens. Em todas as fases foi mantida maior concentração das sequências 0alt, sendo quase inexistentes as de 2alt e 3 alt. Nas fases de FR4 e ACO houve um pequeno aumento de distribuição dentre as sequências 1alt, e nas fases REP e REP' houve a predominância quase exclusiva da sequência 0 alt, que era condição para reforçamento. 

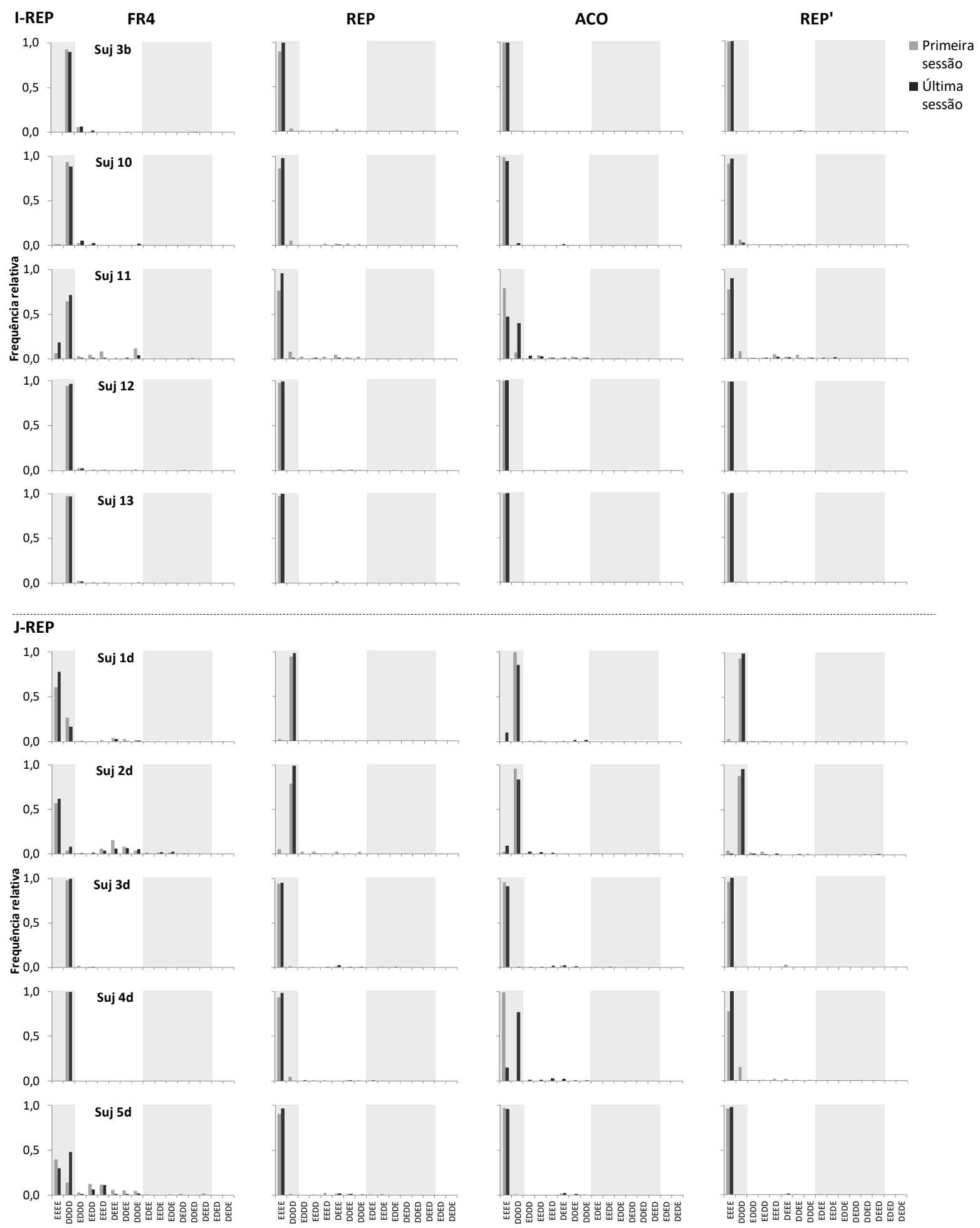

Figura 8 - Distribuição de sequências emitidas por sujeitos dos Grupos I-REP e J-REP em cada fase experimental. São apresentadas as frequências relativas das sequências emitidas na primeira e última sessão de cada contingência, tendo como universo 16 sequências possíveis. No eixo horizontal, estão ordenadas sequências agrupadas em função do número de alternações (entre barras exigido para sua emissão: mais à esquerda estão as sequencias com zero alternação, seguidas pelas que exigem uma, duas ou três alternações entre barras). As áreas cinza e branca delimitam os conjuntos de sequências por número de alternação. 
Nas contingências em que a repetição não foi reforçada foi possível observar algumas pequenas diferenças ente sujeitos idosos e jovens: sob FR4, os sujeitos jovens emitiram mais sequências 1 alt na primeira sessão, e até mesmo sequências 2 alt; já na última sessão, os sujeitos concentraram suas respostas em uma das sequências 0 alt. Sob $\mathrm{ACO}$, a sequência reforçada ainda foi a que teve maior frequência relativa para todos os sujeitos, com exceção do sujeito 4d. Na última sessão de ACO, os sujeitos jovens também emitiram mais sequências 1 alt do que os sujeitos idosos, exceto pelo Sujeito 11, que destoou dos demais animais idosos e distribuiu suas respostas entre duas das sequências 0 alt, principalmente, e entre as sequências 1 alt.

A Figura 9 mostra as médias das frequências relativas das sequências nas últimas cinco sessões válidas de Lag 4' e nas cinco sessões de EXT apresentadas pelos sujeitos VAR, idosos e jovens. Não foram constatadas diferenças entre os sujeitos idosos e jovens. É relevante destacar também que, durante EXT, a distribuição das frequências relativas se manteve similar à de $\operatorname{Lag} 4$ ': as sequências com maior frequência relativa sob Lag 4' continuaram sendo as mais frequentes sob EXT, e aquelas emitidas menos frequentemente sob Lag 4' também foram as menos frequentes sob EXT. 


\section{I-VAR}
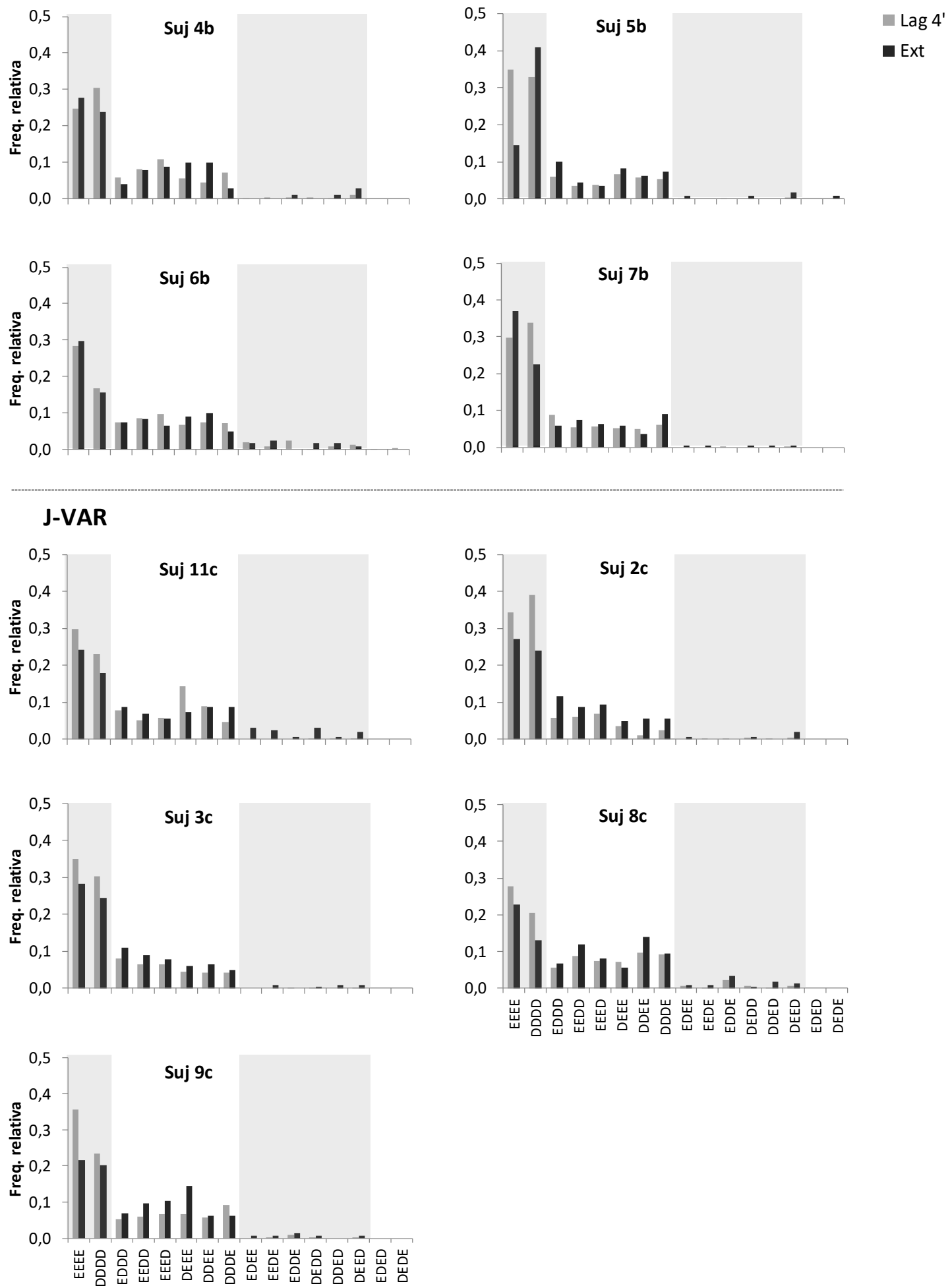

Figura 9 - Distribuição de sequências emitidas pelos sujeitos VAR, idosos e jovens (I-VAR e JVAR, respectivamente), em Lag 4' e EXT. São apresentadas as médias das frequências relativas das sequências emitidas nas cinco últimas sessões de Lag 4' e nas cinco sessões de EXT, tendo como universo 16 sequências possíveis. No eixo horizontal, estão ordenadas sequências agrupadas em função do número de alternações (entre barras exigido para sua emissão: mais à esquerda estão as sequencias com zero alternação, seguidas pelas que exigem uma, duas ou três alternações entre barras). As áreas cinza e branca delimitam os conjuntos de sequências por número de alternação. 
Entretanto, apesar da manutenção da estrutura de distribuição das sequências emitidas pelos sujeitos, verificou-se que houve diminuição das frequências 0 alt entre os sujeitos jovens, e entre a maioria dos sujeitos de idosos ${ }^{10}$, ao mesmo tempo que sequências menos prováveis de serem emitidas sob Lag 4' aumentaram sua frequência relativa sob EXT. Isto é, muitas das sequências 1 alt aumentaram de frequência, e diferentes sequências 2 alt foram emitidas por todos os sujeitos, o que não ocorreu sob Lag 4' - um sujeito idoso teve, ainda, emissão de sequência 3 alt sob EXT. Ao retomar os dados apresentados anteriormente na Figura X1 sobre os índices MetVAR, é possível atribuir o aumento desses índices sob EXT ao aumento das sequências com maior número de alternação.

A Figura 10 mostra essa mesma comparação, porém em relação aos sujeito REP. Os dados mostrados pelos sujeitos idosos e jovens apresentaram o mesmo padrão entre si, sendo possível verificar que a sequência reforçada em REP' permanece como a mais frequente sob EXT, embora sua frequência relativa tenha decrescido. Sob REP', houve raras emissões de sequências diferentes daquela reforçada, sendo nítido o aumento das emissões de sequências variadas e com maior número de alternações sob EXT. Pode-se relacionar o aumento de MetVAR sob EXT, descrito anteriormente, ao aumento na variação das sequências emitidas.

\footnotetext{
${ }^{10}$ Embora tenha ocorrido diminuição nas frequências de uma sequência 0 alt e aumento da outra entre os sujeitos I-VAR, houve diminuição na frequência total das sequências 0 alt de Lag 4' para EXT
} 

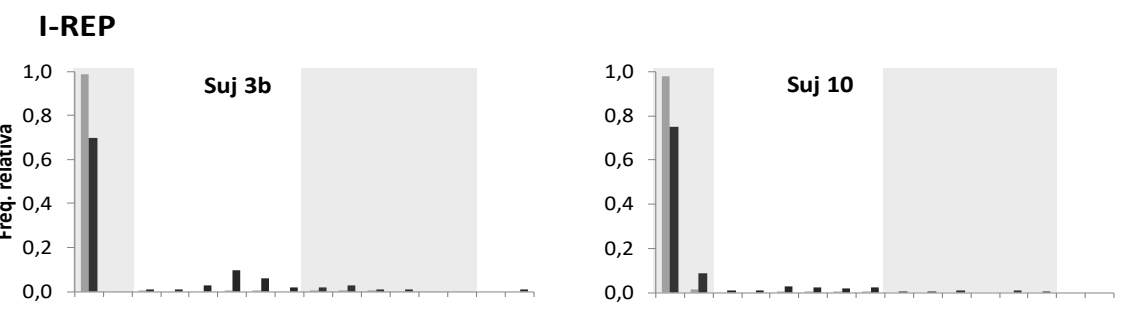

$\square$ REP'
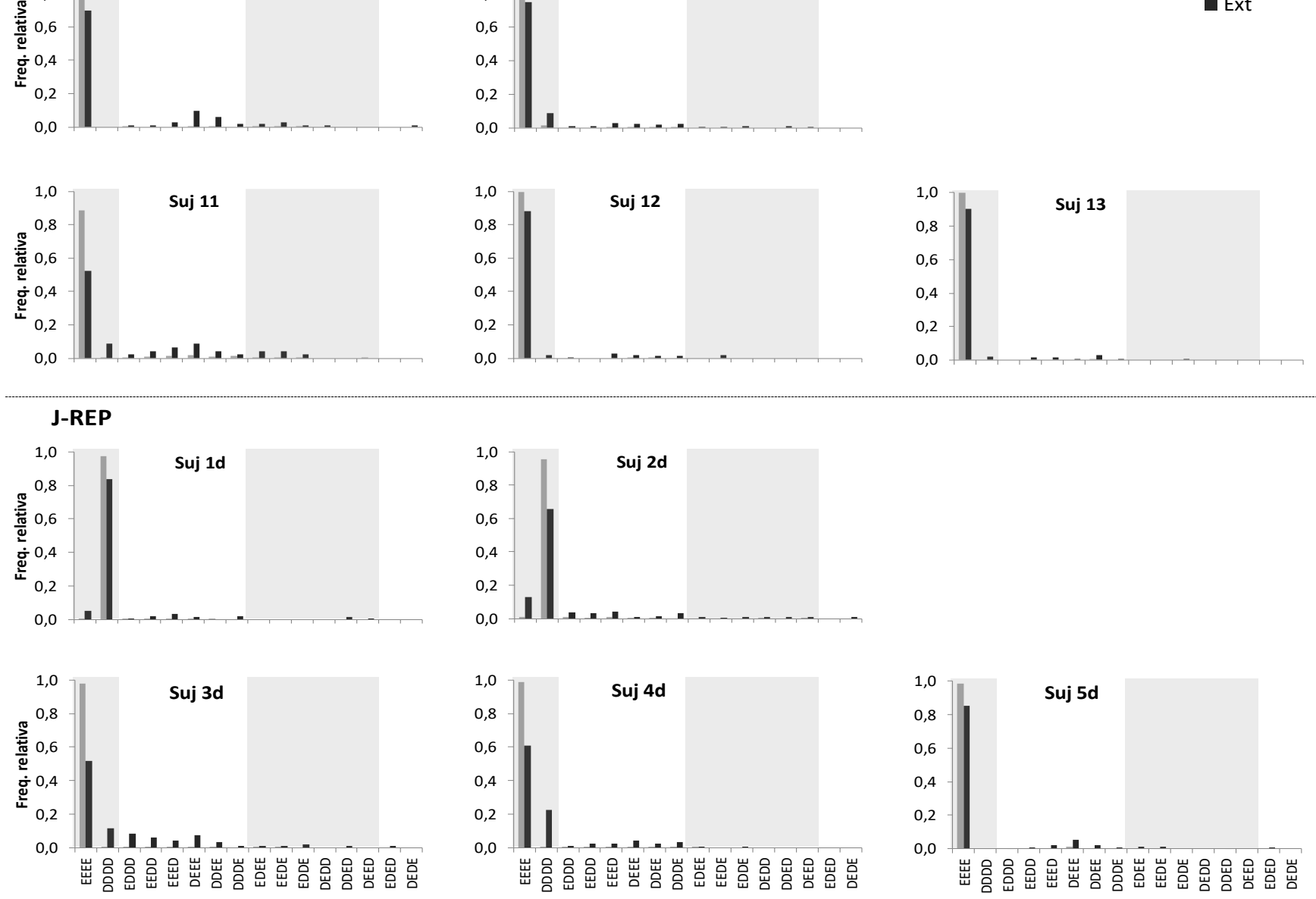

Figura 10 - Distribuição de sequências emitidas pelos sujeitos dos Grupos I-REP e J-REP em Lag 4' e EXT. São apresentadas as médias das frequências relativas das sequências emitidas nas cinco últimas sessões de Lag 4' e nas cinco sessões de EXT, tendo como universo 16 sequências possíveis. No eixo horizontal, estão ordenadas sequências agrupadas em função do número de alternações (entre barras exigido para sua emissão: mais à esquerda estão as sequencias com zero alternação, seguidas pelas que exigem uma, duas ou três alternações entre barras). As áreas cinza e branca delimitam os conjuntos de sequências por número de alternação. 
Os dados sobre distribuição de sequências na EXT complementam (ou esclarecem) a diversidade dos índices MetVAR. Por exemplo, dentre os animais idosos, os Sujeitos 12 e 13, que obtiveram os menores índices MetVAR e maiores porcentagens de sequências reforçadas nas duas últimas sessões de EXT, foram os que apresentaram menor distribuição das sequências, com altas frequências relativas da sequência reforçada na fase anterior, e baixas frequências de outras sequências. Ao mesmo tempo, os demais sujeitos que, nas duas últimas sessões de EXT, apresentaram índices MetVAR elevados e menores porcentagens da sequência reforçada na fase anterior, tiveram distribuição de sequências mais diversa entre as sequências de diferentes alternações. Em relação aos sujeitos jovens, o Sujeito 3d, que teve índice MetVAR de $100 \%$ na última sessão de EXT, é o sujeito com a maior distribuição de sequências. 


\section{DISCUSSÃO}

No presente experimento, os resultados dos sujeitos VAR idosos e jovens replicam em parte os resultados obtidos no Experimento 1. Na condição VAR, os índices de variabilidade dos sujeitos idosos foram semelhantes aos índices obtidos pelo único sujeito idoso a completar o Experimento 1, e os índices dos jovens, em ambos os experimentos, também foram similares. Nesse sentido, os resultados do Experimento 2 confirmam a asserção exposta no experimento anterior de que a idade dos animais não interferiu na variabilidade comportamental operante. Em relação aos resultados nas contingências em que o repetir era reforçado (REP), os animais de ambas as idades obtiveram índices de variabilidade muito baixos e semelhantes entre si, exibindo também altas porcentagens da sequência reforçada. Chama a atenção, que mesmo com frequência muito baixa, ou com nenhuma emissão, em FR4 da sequência selecionada para reforçamento, os animais idosos responderam de maneira eficaz à contingência de repetição em vigor. Assim, pode-se afirmar que não houve diferenças entre os animais jovens e idosos na aprendizagem de uma sequência "fácil" (assim considerada pelo fato de não exigir nenhuma alternação entre barras), e na manutenção de sua emissão em níveis altos, mesmo em esquema com intermitência de reforçamento.

Diferenças nos índices de variabilidade entre os sujeitos idosos e jovens foram encontradas apenas nas contingências FR4 e ACO. Em geral, os sujeitos VAR e REP jovens variaram mais que os sujeitos VAR e REP idosos em ambas as contingências. Antes de qualquer história de reforçamento do variar ou do repetir, sob FR4, quando variar era permitido, mas não exigido, obteve-se que os animais idosos emitiram com maior frequência uma mesma sequência (sem alternação entre barras), ou seja, baixos índices de variação. Já os índices da maioria dos animais jovens foram mais elevados nas primeiras sessões sob FR4 do que os índices dos animais idosos. Especialmente, os sujeitos VAR jovens tiveram índices tão elevados que alcançaram valores similares aos índices obtidos posteriormente nas contingências Lag - com a diferença que, sob FR4, não se mantiveram altos ao longo das sessões. Tal diferença entre idosos e jovens pode ser decorrente da maior atividade motora que os idosos. Como discutido no Experimento 1, ratos idosos apresentam atividade motora reduzida em comparação aos ratos jovens, isso tendo sido descrito em estudos que avaliaram as atividades em campo aberto ou na gaiola-viveiro (Gage et al., 1984; Goodrick, 1966; Hodge et al., 1967). Assim, uma maior atividade motora dos animais jovens pode ter contribuído na alternação entre barras nas primeiras sessões de FR4, enquanto os animais idosos, desde o início, exibiram preferência por 
uma barra. Ao serem expostos por mais tempo à contingência de FR4, em que variar não aumentava a chance de reforçamento, os níveis de variação dos jovens diminuíram.

Após a fase de FR4, as distribuições das sequências apresentadas pelos sujeitos submetidos à REP ou VAR mostraram formatos diferentes, se diferenciando a partir do controle operante exercido, os animais expostos à VAR tiveram maior distribuição de resposta entre sequências diversas, embora seja notável que tenha havido concentração das respostas entre as oito sequências compostas por zero ou uma alternação, compatível com a relativa baixa exigência de variação do Lag 4. Ao contrário, a distribuição dos sujeitos, independentemente da idade, dos animais que passaram por REP concentraram suas respostas em uma única sequência, a que era condição para reforçamento. Esse padrão de concentração em sequência sem alternação se deu também sob ACO. Entretanto, uma diferença pode ser apontada em função da idade dos sujeitos: enquanto a maioria dos sujeitos REP idosos, emitiram, sob ACO, quase que exclusivamente a sequência anteriormente reforçada, os sujeitos REP jovens, na última sessão de ACO, passaram a emitir, em baixa frequência, sequências diversas.

Um sujeito REP idoso apresentou padrão diverso, exibindo um padrão de resposta mais variável que os demais, exceto sob a contingência REP 100\% e REP. Ou seja, apesar de diferir nas condições em que variar ou repetir não interferiam na obtenção do reforço, ele aprendeu e manteve o comportamento de repetir quando este foi critério para reforçamento. Esse dado é semelhante aos de outras pesquisas utilizando ratos idosos que mostraram que alguns animais apresentavam padrões comportamento distintos dos jovens, mas outros apresentavam desempenho bastante semelhante. Pesquisas utilizando sujeitos humanos ou não humanos, relataram maior heterogeneidade dos idosos em algumas tarefas, as quais vem sendo atribuídas a maiores diferenças intragrupo, em relação a aptidões físicas ou história de vida (Baron et al., 1983; Gage et al., 1984; Myerson et al.,2007; Nelson \& Dannefer, 1992).

A história de reforçamento aparentemente influenciou o padrão exibido sob ACO: os níveis de variabilidade foram menores entre os sujeitos que anteriormente foram expostos à REP que quando submetidos à VAR. Esse dado é consistente com o relatado por Hunziker et al. (1998) e Yamada (2012). O aumento da variabilidade em ACO, mostrados pelos animais jovens, previamente expostos a REP, pode ser produto da intermitência do reforçamento aliada à quebra da relação de dependência entre a resposta de repetir e a liberação do reforço. Ainda, ao emitirem sequências diferentes da reforçada anteriormente, algumas dessas sequências podem ter sido seguidas por reforçamento, sendo sua emissão acidentalmente fortalecidas. $\mathrm{O}$ mesmo não se deu com os animais idosos possivelmente em função de sua baixa atividade 
motora. Não havendo exigência de variação, essa atividade reduzida pode favorecer a emissão preferencial das duas sequencias mais "fáceis" (zero alternação entre barras) o que, necessariamente gera menor índice de variação. Portanto, o baixo nível de atividade motora típico dos ratos idosos, somado ao fato de que esses animais tiveram fortalecida a emissão de uma única sequência (sem alternação) sob REP, pode ter contribuído para que eles continuassem emitindo tal sequência frente à nova contingência (ACO).

Os dados mostraram também que, tendo histórico de reforçamento da variabilidade, sob ACO, os índices foram menores dentre os animais idosos. Esses resultados do Experimento 2 não replicam os obtidos por Wells (1999, Experimento 1), que descreveram não haver diferenças nos índices de variabilidade entre os grupos idosos e jovens. na condição ACO. Entretanto, eles replicam os resultados descritos por Neuringer e Huntley (1991), que verificaram que, sob ACO, os índices de variabilidade dos sujeitos adultos (10 meses) foram menores que os dos jovens ( 2 meses). Os animais mais velhos tiveram também taxas de resposta mais altas que os sujeitos mais novos, dado que Neuringer e Huntley (1991) interpretaram como, por terem pesos menores, os ratos jovens teriam atingido o limiar de saciedade mais rapidamente que os sujeitos adultos e, consequentemente, apresentavam taxas de resposta mais baixas. Baseando-se em Neuringer (1991), que identificou relação entre as taxas de resposta mais baixas com níveis de variabilidade mais altos, os autores concluíram que as baixas taxas de resposta dos sujeitos mais jovens, por acarretarem em menor taxa de reforçamento, acabavam por induzir índices de variabilidade mais altos.

Esta relação não foi observada no presente estudo. Os sujeitos VAR idosos, no Experimento 2, apresentaram taxas de resposta mais baixas que os sujeitos VAR jovens, e, sob ACO, índices de variabilidade também menores. Uma maneira de entender esses resultados pode ser analisar a contingência ACO como um procedimento de extinção. Lattal, St. Peter e Escobar (2013) apontaram que a extinção de respostas operantes mantidas por reforçamento positivo pode ocorrer de duas maneiras: (1) pela suspenção completa da liberação de reforços; e (2) pela remoção da dependência resposta-reforço positivo, ou seja, a liberação de reforço ocorre independente da resposta do sujeito. Na contingência ACO, o reforçamento ocorre contingente apenas à emissão de sequência de quatro respostas a duas barras, mas independentemente de sua configuração. Ou seja, como na fase anterior o reforço era contingente à variação das sequências de resposta de pressão a duas barras, sob ACO esta relação de dependência é suspensa. Como já citado anteriormente, pesquisas demonstraram que ratos idosos tendem a extinguir respostas de pressão à barra mais rapidamente do que ratos 
jovens (Goodrick, 1969; Samson et al., 2014). Logo, os resultados obtidos no presente experimento estariam de acordo com estes estudos, podendo tais conclusões serem estendidas à resposta de variar sequências de respostas de pressão a duas barras.

Em relação à EXT, os resultados dos sujeitos VAR, obtidos no segundo experimento, replicam os do Experimento 1, em que após a contingência Lag 4', os índices MetVAR aumentaram progressivamente. Além disso, sequências menos prováveis de serem emitidas sob Lag 4' aumentaram de frequência sob EXT, embora a sequências com maior frequência de emissão em Lag 4' continuassem sendo as mais frequentes sob EXT. Tal replicação é de especial importância para os sujeitos idosos, uma vez que apenas um sujeito havia chegado à EXT no experimento anterior. Assim, é possível concluir que a idade - e a magnitude do reforço - não afetaram diferencialmente os níveis de variabilidade sob EXT após uma contingência de variabilidade operante.

Dado semelhante foi verificado também entre os sujeitos expostos à REP no presente experimento, em que sob EXT, os índices MetVAR exibiram aumento progressivo. Porém, o aumento observado entre os sujeitos REP foi mais acentuado que o dos sujeitos VAR. Este dado está de acordo com Neuringer et al. (2001, Experimento 3). No Experimento 3, Neuringer et al. (2001) reforçaram ratos Long-Evans de quatro meses a emitiram uma única sequência de três respostas a duas barras e uma chave (ECD), com probabilidade de reforçamento de $65 \%$. Sob EXT, os índices MetVAR aumentaram mais de duas vezes que os obtidos sob REP, enquanto que os sujeitos submetidos à VAR tiveram índices até 1,4 vez maior que sob VAR. Em Neuringer et al. (2001), e também no presente trabalho, foi nítido, sob EXT, o aumento de emissões menos prováveis de serem emitidas sob REP.

Retomando a discussão sobre extinção no Experimento 1 a respeito das estratégias apontadas por Neuringer et al. (2001), nomeadas como conservadora e arriscada, para interpretar a distribuição das sequências encontradas na extinção, e a ressurgência e variabilidade comportamental como fenômenos existentes na extinção, abordadas por VillasBôas (2006), podemos entender que, ao mesmo tempo que a extinção tende a reduzir a frequência da sequência anteriormente reforçada sob REP, tal sequência continuará sendo emitida em maior frequência, uma vez que foi fortalecida por uma história de reforçamento anterior. Tal história de repetição construiu um repertório de comportamento mais restrito que sob VAR, em que todas as outras sequências possuem menor probabilidade de serem emitidas sob REP, diferentemente da contingência VAR. Assim, como observado por Maes (2003), Neuringer et al. (2001), Souza (2009) e Villas-Bôas (2006), sequências menos prováveis de 
serem emitidas na contingência de reforçamento anterior aumentam sua frequência de emissões durante a extinção. No caso dos sujeitos que foram submetidos à REP, o universo comportamental de sequências menos prováveis é maior, o que pode contribuir para o maior nível de variação induzida tendo como linha de base a repetição.

Pesquisas, utilizando animais humanos e não-humanos, em que foi exigido para reforçamento a emissão de sequências de respostas, verificaram também que a repetição operante é menos resistente à mudança que a variabilidade operante, tendo como variável independente a extinção (Souza, 2009), alimentação prévia à sessão e liberação de comida nos intervalos entre tentativas (Doughty \& Lattal, 2001), aumento do intervalo entre cada resposta da sequência (Neuringer, 1991), e administração de substâncias, como álcool (Cohen et al., 1990; McElroy \& Neuringer, 1990) e anfetamina (Ward et al., 2006). 


\section{DISCUSSÃO GERAL}

Diante do que foi exposto até aqui, pode-se afirmar que os dados obtidos no atual estudo sugerem que quando a variação e a repetição são padrões comportamentais diretamente reforçados, os níveis de variabilidade não são afetados pela idade dos animais (dentro dos limites aqui testados). O mesmo não ocorre no caso das contingências em que esses padrões não são consequenciados: sob FR4 e ACO, variação ou repetição são permitidas, embora não sejam reforçadas. No Experimento 2, diferenças nos índices de variabilidade entre os sujeitos idosos e jovens foram encontradas nas contingências FR4 e ACO, ou seja, na variabilidade não operante: os sujeitos jovens, VAR e REP, variaram, no geral, mais do que os sujeitos idosos sob FR4 e sob ACO. Além disso, a comparação entre os sujeitos dos Experimentos 1 e 2, sugere que no Experimento 2, além da idade, a magnitude do reforço parece ter produzido diferenças nos índices de variação nas condições em que o reforço independia desse padrão comportamental.

Quanto às diferentes concentrações nas soluções de SAC usadas nos dois experimentos, parece não ter havido efeitos diferenciais sobre a variabilidade operante. Estes resultados aparentemente não estão de acordo com os obtidos por Doughty et al. (2013), que verificaram que a magnitude do reforçador afetou os níveis de variabilidade operante em pombos expostos a um esquema múltiplo: embora os níveis de variabilidade tenham sido maiores quando o critério de reforçamento da variabilidade era mais exigente, os sujeitos apresentaram menores níveis de variabilidade no componente com o reforçador de maior magnitude, nas duas exigências de variação. Os autores concluíram que reforçadores de maior magnitude podem induzir estereotipia, mesmo em uma contingência em que a variabilidade é reforçada. No presente trabalho, essa relação não foi encontrada, sendo que alguns poucos sujeitos jovens que receberam solução de SAC 20\% chegaram a apresentar índices U e MetVAR mais altos que os obtidos pelos sujeitos jovens que receberam solução de SAC $10 \%$.

Contudo, essa diferença nos resultados pode ser devido a diferenças nos procedimentos empregados. A começar pela medida de magnitude do reforço que, em Doughty et al. (2013), correspondeu a tempo de acesso a alimento ( 2 s e 6 s) e aqui foi relativo à concentração da sacarose (10\% e 20\%). Porém, possivelmente ainda mais relevante são as diferenças quanto às contingências empregadas para reforçar a variabilidade: enquanto aqui foi utilizado o Lag 4, Doughty et al. (2013) utilizaram dois esquemas de RDF, ambos exigindo maior variabilidade para liberação do reforço do que o Lag 4 (para uma análise das diferentes exigências de variação 
entre os esquemas RDF e Lag, ver Yamada , 2012). Com esse delineamento, Doughty et al. (2013) concluíram que maior magnitude do reforço diminui os níveis de variabilidade nas duas contingências em que o variar era reforçado. Porém esse efeito foi mais acentuado na condição mais exigente, sendo pouco detectado na condição de menor exigência de variação. Como já discutido no Experimento 1, a contingência $\operatorname{Lag} 4$ não é uma contingência que exige diretamente altos níveis de variação, embora indiretamente essa variabilidade ocorra: dentre um universo contendo 16 opções, basta ao sujeito não repetir as quatro últimas, o que, num extremo, lhe permitiria atender a condição para reforçamento emitindo apenas cinco sequências alternadas entre si. Portanto, ao considerarmos as diferenças do atual estudo como o de Doughty et al. (2013), parece que nossos resultados são compatíveis com os deles: sob Lag 4 o esperado seria não obter a mesma interferência da magnitude do reforço.

Comparando-se ambos os experimentos, pode-se apontar que, entre os animais jovens, os níveis de variabilidade induzida foram maiores no segundo estudo, quando o reforço foi a solução de SAC 20\%. Quanto à diferença observada em ACO, pesquisas indicam que respostas mantidas com reforçamento positivo em esquemas múltiplos apresentam maior resistência à extinção quando o reforçador utilizado é de maior magnitude, tanto tendo como respostas reforçadas tanto o bicar um disco, por pombos (Dulaney \& Bell, 2008; Harper \& McLean, 1992), como o clicar com mouse em estímulos numa tela, por humanos (Cohen, Riley, \& Weigle, 1993; McComas, Hartman, \& Jimenez, 2008; Nevin, 1974). Pesquisas utilizando esquemas simples também encontraram relação direta entre a magnitude do reforço e a resistência à extinção após reforçamento positivo de respostas de correr em uma pista (Likely, Little, \& Mackintosh, 1971; Morris \& Capaldi, 1979; Roberts, 1969; Wagner, 1961) e pressão à barra (Pavlik \& Collier, 1977) e de focinhar (Shull \& Grimes, 2006).

Utilizando procedimento mais semelhante à contingência ACO, Nevin, McLean e Grace (2001) submeteram pombos a um esquema múltiplo com dois componentes VI $150 \mathrm{~s}$ com reforços sendo acesso à comida por $8 \mathrm{~s}$ e por $2 \mathrm{~s}$. A fase seguinte consistiu na liberação a cada $150 \mathrm{~s}$ dos reforços não contingente a qualquer resposta emitida pelos sujeitos. Os resultados demonstraram que o responder mantido pelo reforço de maior magnitude foi mais resistente à mudança. Assim, a diferença obtida no presente estudo, relativas aos níveis de variabilidade entre os sujeitos jovens do Experimento 1 e os sujeitos VAR jovens do Experimento 2, sob ACO, poderia ser explicada por diferenças na resistência à extinção da resposta de variar produzida pela diferença de magnitude do reforço utilizado em cada experimento. A consistência dos índices de variabilidade dos sujeitos VAR jovens parece 
fortalecer essa interpretação, uma vez que, sob ACO, pela variabilidade ser permitida, mas não exigida, tal consistência parece indicar um controle pela a magnitude do reforço sobre os níveis de variação.

É importante considerar que as diferenças nos níveis de variação entre os sujeitos VAR idosos e jovens (Experimento 2), na contingência ACO, pode ser decorrente também de alterações na sensibilidade à magnitude do reforço de acordo com a idade. Como dito na seção de Introdução, foi verificado que ratos machos Wistar apresentam redução do consumo de água e alimento até os 17 meses de idade e estabilização do consumo até os 25 meses (Everitt, 1958). Isso pode ter implicações no valor reforçador também da solução de $\mathrm{SAC}$, visto que o potencial reforçador da SAC vem de suas propriedades gustativas, mas também nutricionais (de Araújo, 2015). Verifica-se pela pesquisa de Everitt (1958) que conforme o rato deixa de crescer e envelhece há uma diminuição da necessidade calórica para o funcionamento do organismo, o que pode reduzir o valor reforçador da SAC nos idosos, uma vez que talvez animais idosos e jovens não estejam no mesmo grau de privação. É possível também questionar se o paladar do animal idoso encontra-se intacto ou se pode ser prejudicado pelo processo de envelhecimento. Entretanto, Mistretta e Baum (1984) apontaram que as alterações no número de papilas gustatórias em ratos Wistar machos são mínimas na medida em que envelhecem. Nesse sentido, os autores entendem que a partir desses dados as alterações no paladar desses ratos devem ser pequenas na velhice. Pode-se supor, portanto, que, nas condições arranjadas no presente estudo, os valores reforçadores da solução de SAC 10\% sejam diferentes entre os animais idosos e jovens, da mesma maneira que para a solução de SAC 20\%, sendo os valores reforçadores dessas soluções menores para os sujeitos idosos.

Tais questões acerca do valor reforçador das soluções de SAC entre os animais idosos e jovens se aplicam também para a análise dos resultados obtidos na contingência FR4. Os índices dos sujeitos jovens do Experimento 2 foram maiores que os dos jovens do Experimento 1. O efeito de diferentes magnitudes do reforço na variabilidade induzida por esquema de reforçamento intermitente foi avaliada por Stebbins (1962). Ratos foram treinados a pressionar uma chave na presença de uma luz, sendo a resposta de soltar a chave reforçada em um esquema de VI 1,5 s. A variabilidade foi mensurada pelo tempo de reação para soltar a chave. Na linha de base (LB), o reforçador utilizado foi uma solução de SAC 20\%. Quando a resposta estava estável, o reforço foi alterado para água por duas sessões. Após essas sessões, o reforçador voltou a ser a solução de SAC $20 \%$ até que a resposta voltou a se estabilizar, sendo a concentração da solução, então, reduzida para 5\%. A variabilidade foi medida a partir da 
frequência relativa dos tempos de reação obtidos em milissegundos. Foi observado que os níveis de variabilidade aumentaram quando a concentração da solução de SAC foi reduzida. Ainda, a diferença nos níveis de variabilidade foi maior quando a solução passou para água comparada com a redução para $5 \%$.

Quanto aos resultados referentes à FR4 no presente trabalho, eles vão de encontro aos obtidos por Stebbins (1962), uma vez que os animais idosos tiveram seus índices inalterados em função da magnitude do reforço, e os sujeitos jovens apresentaram maiores níveis de variabilidade quando consequenciados com reforço de maior magnitude. Considerando as possíveis diferenças no valor reforçador das soluções de SAC $10 \%$ e $20 \%$ entre idosos e jovens, é possível que o fortalecimento das respostas de pressão a cada uma das duas barras tenha sido afetado de acordo com a idade do sujeito e a magnitude do reforço utilizado. O aumento das taxas de respostas dos sujeitos idosos e jovens no Experimento 2, em comparação as exibidas pelos sujeitos no Experimento 1, é um indicativo de que o responder dos animais estiveram mais fortalecidos quando o reforço foi a solução de SAC $20 \%$.

Em suma, os resultados indicam que a existência de diferenças nos níveis de variabilidade induzida não depende apenas da idade dos sujeitos, mas de outras variáveis: a contingência de reforçamento a qual o sujeito está exposto; a magnitude do reforço; e a história de reforçamento anterior. Tais descobertas adicionam informações quanto as variáveis que influenciariam os desempenhos de ratos idosos, indicando que quanto ao nível de variabilidade, sob FR4 e ACO, as soluções de SAC $10 \%$ e $20 \%$ interferem na manutenção da resposta, mas não nos níveis de variabilidade induzida.

A solução de SAC $20 \%$ se mostrou mais eficaz em manter as respostas dos animais idosos, o que possibilitou que todos os sujeitos idosos completassem o experimento e atingissem o critério de passagem de fases em menor número de sessões que no Experimento 1. Apesar disso, os animais idosos, em sua maioria, necessitaram de maior número de sessões para completar todas as fases do Experimento 2 do que os animais jovens, o que está de acordo com os dados apresentados na Discussão do Experimento 1, que ratos idosos necessitam de maior quantidade de treino para atingir os critérios de aprendizagem estipulados (Brushfield et al., 2008; Gallagher \& Burwell, 1989; Frutos et al., 2012; Schoembaum et al., 2002; Stephens et al., 1985). A concentração de $20 \%$ de SAC também facilitou a aquisição da resposta de pressão à barra, visto pelo menor número de sessões na fase de modelagem, e pelo fato de que todos os sujeitos idosos aprenderam tal resposta, o que não ocorreu com a solução SAC $10 \%$. 
Uma variável que se mostrou relevante no desempenho de ratos idosos, e também jovens, foi a história de reforçamento anterior, que produziu, sob ACO, diferenças entre os níveis de variabilidade de sujeitos da mesma idades quando submetidos à VAR e REP. No que se refere à variabilidade induzida por EXT, os resultados obtidos replicaram os resultados demonstrados pela literatura tanto em relação aos sujeitos jovens, como também os idosos. Pode ser interessante, em pesquisas futuras, submeter os ratos idosos à extinção após uma contingência com alta exigência de variação a fim de verificar se o mesmo padrão de declínio, observado em ratos jovens, é verificado como nos estudos de Maes (2003) e Souza (2009).

Em relação especificamente aos sujeitos jovens, os resultados obtidos quanto a solução de SAC $10 \%$ e $20 \%$ produzir níveis diferentes de variabilidade sob FR4 e ACO, acrescenta informações a respeito da influência que diferentes magnitudes podem ter sobre a variabilidade em ACO. Entretanto, quanto à FR4, os dados se contrapõem ao estudo de Stebbins (1962), sendo importante investigar as causas desses resultados divergentes. Na mesma linha, no que se refere à influência de reforçadores de maiores magnitudes reduzindo os níveis de variabilidade operante, verificada por Doughty et al. (2013), poder-se-ia investigar futuramente se, submetendo ratos idosos e jovens a contingências mais exigentes de variação, se a mesma relação ocorreria. Para isso, porém, outra questão, e talvez anterior, seria como os ratos idosos responderiam a contingências cada vez mais exigentes de variação, visto a dificuldade encontrada nas passagens de fase, em que foi necessário adicionar fases intermediárias a cada vez que o critério para reforçamento ficava mais exigente.

A partir dos resultados do presente trabalho, portanto, pode ser importante atentar, em futuros trabalhos, para magnitude do reforçador utilizado na manutenção da resposta de ratos Wistar, uma vez que água, ração, e solução de SAC, entre outros, comumente usados como reforçadores em pesquisas com ratos jovens, podem ter valor reforçador menor para os ratos idosos, sendo necessário compreender de maneira mais aprofundada que implicações isso pode ter na comparação de dados de jovens e idosos num mesmo experimento. Ao mesmo tempo, parece importante investigar também o valor reforçador de tais itens, fazendo uso de procedimentos que meçam diretamente tal variável.

Chama a atenção, ainda, a similaridade dos resultados dos sujeitos jovens do Experimento 1, com solução de SAC $10 \%$ como reforço, e os sujeitos VAR idosos, no Experimento 2, que tiveram como reforço solução de SAC 20\%, tanto nos níveis de variabilidade em todas as fases dos experimentos, especialmente nas fases FR4 e ACO, e quanto aos padrões da curva exibido. Assim, pode-se aventar a hipótese que há uma similaridade no 
valor reforçador da solução de SAC $20 \%$ e 10\%, entre idosos e jovens, respectivamente, sendo relevante investigar futuramente tal questão, além de, se existem necessidades diferentes de privações entre os sujeitos de ambas as idades, devido a diferenças metabólicas ou de paladar entre eles.

Por fim, em relação aos resultados de Wells (1999, Experimento 1), eles foram similares aos obtidos no Experimento 1, com a diferenças de que no presente trabalho, apenas um sujeito idoso completou todas as fases do experimento. Entretanto, essa diferença pode ser decorrente da não exigência de Wells (1999) por uma taxa de resposta mínima para se obter um valor U confiável. Pelo fato da magnitude do reforçador não ter demonstrado produzir diferenças entre jovens e idosos na variabilidade operante, no presente trabalho, esse fator não parece ter comprometido as conclusões finais da autora. Entretanto, pode ter sido, de fato, um dos motivos pelos quais Wells (1999) não replicou os dados de ACO de Neuringer e Huntley (1991).

Rangel (2010), por sua vez, levantou a questão de se os pontos poderiam afetar diferencialmente na variabilidade operante dos participantes jovens e idosos por terem, possivelmente, diferenças no valor reforçador. Este resultado não foi confirmado pelo presente estudo. Os resultados de Lopatto et al. (1998), que não encontrou diferenças entre pessoas jovens e idosas na variabilidade induzida nem na operante, assemelharam-se apenas aos dados obtidos no Experimento 1, quanto à variabilidade induzida, mas foram replicados em relação à variabilidade operante nos dois experimentos. Ainda, uma maior diversidade dos níveis de variabilidade entre os participantes idosos, verificada por Lopatto et al. (1998), não foi constatado no presente estudo, indicado que a história de vida de participantes humanos e a grande amplitude de idades dos idosos, pode ter interferido nos resultados de Lopatto et al. (1998). Ainda, não se deve desconsiderar que a diferença de espécies entre os estudos de Rangel (2010) e Lopatto et al. (1998) podem ser um fator responsável pelas diferenças observadas.

Para concluir, é possível afirmar que apesar das diferenças nos níveis de variação induzida entre idosos e jovens sob algumas condições, qualquer diferença foi suplantada quando os sujeitos foram submetidos à contingência de variação e repetição operantes aqui manipuladas. Estes dados são de extrema relevância, visto que a variabilidade na aquisição de novos comportamentos, na resolução de problemas e na exploração de novos interesses, é habilidade de grande importância para a adaptação dos indivíduos, talvez ainda mais especialmente os idosos, à novos contextos. Os dados aqui obtidos sugerem que o planejamento de intervenções que diretamente reforcem o variar podem ser essenciais para a adaptação dos 
idosos a novos ambientes: a variabilidade operante pode ser estabelecida no indivíduo idoso pelo manejo de contingências específicas, ajudando a compensar possíveis déficits comportamentais e físicos. Tais resultados também fortalecem a afirmação de Wells (1999) de que os déficits comportamentais no idoso devem ser considerados com cautela, evitando vieses nas pesquisas e favorecendo intervenções criativas com esta população. 


\section{REFERÊNCIAS}

Abreu-Rodrigues, J., Hanna, E. S., Mello-Cruz, A. P., Matos, R., \& Delabrida, Z. (2004). Differential effects of midazolam and pentylenetetrazole on behavioral repetition and variability. Behavioural Pharmacology, 15(8), 535-543. doi: 10.1097/00008877200412000-00002

Alexandre, T. S., Corona, L. P., Nunes, D. P., Santos, J. L. F., Duarte, Y. A. O., \& Lebrão, M. L. (2014). Disability in instrumental activities of daily living among older adults: gender differences, Revista de Saúde Pública, 48(3), 378-389. doi:10.1590/S00348910.2014048004754

Algeri, S., Biagini, L., Manfridi, A., \& Pitsikas, N. (1991). Age-related ability of rats kept on a life-long hypoealoric diet in a spatial memory test. Longitudinal observations, Neurobiology of Aging, 12(4), 277-282. doi: http://dx.doi.org/10.1016/0197-4580(91)90003-3

Andreollo, N. A., Santos, E. F., Araújo, M. R., \& Lopes, L. R. (2012). Idade dos ratos versus idade humana: qual é a relação? Arquivos Brasileiros de Cirurgia Digestiva, 25(1), 49-51. doi: http://dx.doi.org/10.1590/S0102-67202012000100011

Antonitis, J. J. (1951). Response variability in the white rat during conditioning, extinction, and reconditioning. Journal of Experimental Psychology, 42(4), 273-281. doi: http://dx.doi.org/10.1037/h0060407

Baltes, M. M., \& Barton, E. M. (1979). Behavioral analysis of aging: a review of the operant model and research, International Journal of Behavioral Development, 2(3), 297-320. doi: 10.1177/016502547900200307

Baltes, P.B. (1987), Theoretical propositions of life-span developmental psychology: on the dynamics between growth and decline. Developmental Psychology, 23(5), 611-626. doi: 10.1037//0012-1649.23.5.611

Barba, L. S. (1997). Variabilidade comportamental aprendida (Dissertação de Mestrado). Instituto de Psicologia, Universidade de São Paulo, São Paulo

Barba, L. S. (2006). Variabilidade comportamental: uma taxonomia estrutural. Acta Comportamentalia, 14(1), 23-46.

Barba, L. S., \& Hunziker, \& M. H. L. (2002). Variabilidade comportamental produzida por dois esquemas de reforçamento. Acta Comportamentalia, 10(1), 5-22.

Baron, A., \& Menich, S.R. (1985). Reaction times of younger and older men: effects of compound samples and a prechoice signal on delayed matching-to-sample performances. Journal of Experimental Analysis of Behavior, 44(1), 1-14. doi: 10.1901/jeab.1985.44-1 
Baron, A., Menich, S. R., \& Perone, M. (1983). Reaction time of younger and older men and temporal contingencies of reinforcement, Journal of Experimental Analysis of Behavior, 40, 275-287. doi: 10.1901/jeab.1983.40-275

Bernardes, A. M. T. (2008). Efeito de enriquecimento ambiental na autoadministração oral de álcool em ratos. (Dissertação de Mestrado). Instituto de Psicologia, Universidade de São Paulo, São Paulo.

Bijou, S. W., \& Baer, D. M. (1980). O desenvolvimento da criança: uma análise comportamental. São Paulo: EPU. Tradução de Rachel R. Kerbauy. Originalmente publicado em 1961.

Boren, J. J., Moerschbaecher, J. M., \& Whyte, A. A. (1978). Variability of reponse location on fixed-ratio and fixed-interval schedules of reinforcement. Journal of the Experimental Analysis of Behavior, 30(1), 63-67. doi: 10.1901/jeab.1978.30-63.

Brushfield, A. M., Luu, T. T., Callahan, B. D., \& Gilbert, P. E. (2008). A comparison of discrimination and reversal learning for olfactory and visual stimuli in aged rats. Behavioral Neuroscience, 122(1), 54-62. doi: http://dx.doi.org/10.1037/0735-7044.122.1.54

Buczek, Y., Lê A. D., Wang, A., Stewart, J. \& Shaham, Y. (1999). Stress reinstates nicotine seeking but not sucrose solution seeking in rats. Psychopharmacology, 144(2), 183-188

Burgio, L. D., \& Burgio, K. L. (1986). Behavioral gerontology: application of behavioral methods to the problems of older adults. Journal of Applied Behavior Analysis, 19(4), 321328. doi: 10.1901/jaba.1986.19-321

Burgio, L., \& Kowalkowski, J. D. (2011). Alive and Well: The State of Behavioral Gerontology in 2011. Behavior Therapy, 42(1), 3-8. doi: 10.1016/j.beth.2010.08.003

Cassado, D. C. (2009). Variabilidade induzida e operante sob contingências de reforçamento negativo (Dissertação de Mestrado). Instituto de Psicologia, Universidade de São Paulo, São Paulo.

Catania, A.C. (1999). Aprendizagem: comportamento, linguagem e cognição. Trad. e revisão de Daisy das Graças de Souza. Porto Alegre: Artmed Editora.

Chaimowicz, F. (2009). Transição Demográfica. In F. Chaimowicz (Ed.), Saúde do idoso. (colaboração de E. M. Barcelos, M. D. S. Madureira e M. T. F. Ribeiro, pp. 16-26). [Versão digital em Adobe Reader]. Recuperado de https://www.nescon.medicina.ufmg.br/biblioteca/imagem/3836.pdf

Cherot, C., Jones, A., \& Neuringer, A. (1996). Reinforced variability decreases with approaches to reinforcers, Journal of Experimental Psychology: Animal Behavior Processes, 22(4), $497-$ 508. doi: http://dx.doi.org/10.1037/0097-7403.22.4.497 
Ciosak, S. I., Braz, E., Costa, M. F. B. N. A., Nakano, N. G. R., Rodrigues, J., Alencar, R. A., \& Rocha, A. C. A. L. (2011). Senescência e Senilidade: novo paradigma na Atenção Básica de Saúde. Revista da Escola Enfermagem da USP, 45(2), 1763-1768. doi: http://dx.doi.org/10.1590/S0080-62342011000800022

Cohen, L., Neuringer, A., \& Rhodes, D. (1990). Effects of ethanol on reinforced variations and repetions by rats under a multiple schedule. Journal of Experimental of Analysis of Behavior, 54(1), 1-12. doi: 10.1901/jeab.1990.54-1

Cohen, S. L., Riley, D. S., \& Weigle, P. A. (1993). Tests of behavior momentum in simple and multiple schedules with rats and pigeons. Journal of the Experimental Analysis of Behavior, 60(2), 255-291. doi:10.1901/jeab.1993.60-255

de Araújo, I.E. (2015). Circuit organization of sugar reinforcement. Pshysiology \& Behavior, 16 Part B (1), 473-477. doi: http://dx.doi.org/10.1016/j.physbeh.2016.04.041

Denney, J., \& Neuringer, A. (1998). Behavioral variability is controlled by discriminative stimuli. Animal Learning \& Behavior, 26(2), 154-162. doi: https://doi.org/10.3758/BF03199208

Derenne, A., \& Baron, A. (2002). Behavior Analysis and the Study of Human Aging. The Behavior Analyst, 25(2), 151-160. doi: 10.1007/bf03392054

Doughty, A. H., \& Lattal, K. A. (2001). Resistance to change of operant variation and repetition, Journal of Experimental Analysis of Behavior, 76(2), 195-215. doi: 10.1901/jeab.2001.76195

Doughty, A. H., Giorno, K. G., \& Miller, H. L. (2013). Effects of reinforcer magnitude on reinforced behavioral variability, Journal of the Experimental Analysis of Behavior, 100(3), 355-369. doi: 10.1002/jeab.50

Dulaney, E.A., \& Bell, M.C. (2008). Resistance to extinction, generalization decrement, and conditioned reinforcement. Behav Processes, 78(2), 253-8. doi: 10.1016/j.beproc.2007.12.006

Eckerman, D. A., \& Lanson, R. N. (1969). Variability of response location for pigeons responding under continuous reinforcement, intermitent reinforcement, and extinction, Journal of Experimental Analysis of Behavior, 12(1), 73-80. doi: 10.1901/jeab.1969.12-73

Everitt, A. V. (1958). The change in food and water consumption and in faeces and urine production in ageing male rats. Gerontologia, 2(1), 21-32. doi: 10.1159/000210719

Ferraro, D. P., \& Branch, K. H. (1968). Variability of response location during regular and partial reinforcement. Psychological Reports, 23(3), 1023-1031. doi: https://doi.org/10.2466/pr0.1968.23.3f.1023 
Fonseca Júnior, A. R. (2015). Variabilidade comportamental reforçada negativamente sob contingência de esquiva (Dissertação de Mestrado). Instituto de Psicologia, Universidade de São Paulo, São Paulo.

Frutos M.G.-S., Pistell P.J., Ingram D.K., \& Berthoud H.R. (2012). Feed efficiency, food choice, and food reward behaviors in young and old Fischer rats. Neurobiology of Aging, 33(1), 206.e41-206.e53. doi: https://doi.org/10.1016/j.neurobiolaging.2010.09.006

Gage, F. H., Dunnett, S. B., \& Björklund, A. (1984). Spatial learning and motor deficits in aged rats, Neurobiology of Aging, 5(1), 43-48. doi: 10.1016/0197-4580(84)90084-8

Gallagher M., \& Burwell R.D. (1989). Relationship of age-related decline across several behavioral domains. Neurobiology of Aging, 10(6), 691-708. doi: https://doi.org/10.1016/0197-4580(89)90006-7

Gehm, T. P. (2013). Reflexões sobre o estudo do desenvolvimento na perspectiva da análise do comportamento (Dissertação de Mestrado). Instituto de Psicologia, Universidade de São Paulo, São Paulo.

Goodrick, C. L. (1966). Activity and exploration as a function of age and deprivation, The Journal of Genetic Psychology: Research and Theory on Human Development, 108(2), 239252. doi: 10.1080/00221325.1966.10532782.

Goodrick, C.L. (1969) Operant Responding of Nondeprived Young and Senescent Male Albino Rats. The Journal of Genetic Psychology: Research and Theory on Human Development, 114(1), 29-40, doi: 10.1080/00221325.1969.10533836

Goyos, C., Rossit, R. A. S., Elias, N. C., Escobal, G., \& Chereguini, P. (2009). Análise do comportamento e o estudo do envelhecimento humano: revisão dos estudos de aplicação. Revista Brasileira de Análise do Comportamento, 5(2), 1-20. doi: http://dx.doi.org/10.18542/rebac.v5i2.927

Grimm, J. W., Fyall, A. M., \& Osincup, D. P. (2005). Incubation of sucrose craving: effects of reduced training and sucrose pre-loading. Physiology \& Behavior, 84(1), 73-79. doi:10.1016/j.physbeh.2004.10.011

Grimm, J. W., Shaham, Y., \& Hope, B. T. (2002). Effect of cocaine and sucrose withdrawal period on extinction behavior, cue-induced reinstatement, and protein levels of the dopamine transporter and tyrosine hydroxylase in limbic and cortical areas in rats. Behavioural Pharmacology, 13(5-6), 379-388.

Harper, D. N., \& McLean, A. P. (1992). Resistance to change and the law of effect. Journal of the Experimental Analysis of Behavior, 57(3), 317-337. doi:10.1901/jeab.1992.57-317 
Herrick, R. M. (1965). Lever displacement under a fixed-ratio schedule and subsequent extinction. Journal of Comparative and Physiological Psychology, 59(2), 263-270. doi: http://dx.doi.org/10.1037/h0021849

Hodge, M. H., Peacock, L. J., \& Hoff, L. A. (1967). The effect of age and food deprivation upon the general activity of the rat, Journal of Genetic Psychology: Research and Theory on Human Development, 111(1), 135-145. doi: 10.1080/00221325.1967.10533755

Hopkinson, J., \& Neuringer, A. (2003). Modifying behavioral variability in moderately depressed students. Behavior Modification, 27(2), 251-264. doi: $10.1177 / 0145445503251605$

Hunziker, M. H. L., Caramori, F. C., da Silva, A. P., \& Barba, L. S. (1998). Efeitos da história de reforçamento sobre a variabilidade comportamental. Psicologia: Teoria e Pesquisa, 14(2), 149-159. doi: http://dx.doi.org/10.1590/S0102-37722002000200004

Hunziker, M. H. L., Saldana, R. L., \& Neuringer, A. (1996). Behavioral variability in SHR and WKY rats as a function of rearing environment and reinforcement contingency. Journal of the Experimental Analysis of Behavior, 65(1), 129-144. doi: https://doi.org/10.1901/jeab.1996.65-129

Hunziker, M. H., \& Moreno, R. (2000). Análise da noção de variabilidade comportamental. Psicologia: Teoria e Pesquisa, 16(2), 135-143. doi: http://dx.doi.org/10.1590/S010237722000000200006

Hunziker, M. H., Lee, V. P. Q., Ferreira, C. C., da Silva, A. P., \& Caramori, F. C. (2002). Variabilidade Comportamental em humanos: Efeitos de regras e contingências. Psicologia: Teoria e Pesquisa, 18(2), 139-147. doi: http://dx.doi.org/10.1590/S010237722002000200004

Instituto Brasileiro de Geografia e Estatística (n.d.). Banco de dados agregados - Censo demográfico e contagem da população. Recuperado de http://www.sidra.ibge.gov.br/cd/cd2010Serie.asp?o=2\&i=P

Jensen, G., Miller, C., \& Neuringer, A. (2012). Truly random operant responding: Results and reasons. In T. R. Zentall \& E. A. Wasserman (Eds.), The Oxford handbook of comparative cognition (pp. 652-673). New York, NY, US: Oxford University Press.

Kobayashi, S., Kametani, H., Ugawa, Y., \& Osanai, M. (1988). Age difference of response strategy in radial maze performance of Fischer-344 rats. Psychology \& Behavior, 42(3), 277 280. doi: https://doi.org/10.1016/0031-9384(88)90082-0 
Lattal, K. A., St. Peter, C., \& Escobar, R. (2013). Operant extinction: Elimination and generation of behavior. In G. J. Madden, W. V. Dube, T. D. Hackenberg, G. P. Hanley, \& K. A. Lattal (Eds.), APA handbook of behavior analysis, Vol. 2. Translating principles into practice (pp. 77-107). Washington, DC, US: American Psychological Association. doi: http://dx.doi.org/10.1037/13938-004

Likely, D., Little, L., \& Mackintosh, N. (1971). Extinction as a function of magnitude and percentage of food or sucrose reward. Canadian Journal of Psychology/Revue Canadienne de Psychologie, 25(2), 130-137 doi: 10.1037/h0082374.

Lopatto, D., Ogier, S. Wickelgren, E.A., Gibbens, C., Smith, A., Sullivan, L., \& Muns, M. (1998). Cautiousness, Stereotypy, and Variability in Older and Younger Adults. Psychological Record. 48(4), 571-589. doi: 10.1007/BF03395290.

Luce, S. C., Christian, W. P., Lipsker, L. E., \& Hall, R. V. (1981). Response cost: A case for specificity. The Behavior analyst, 4(1), 75-80.

Machado, A. (1997). Increasing the variability of response sequences in pigeons by adjusting the frequency of switching between two keys. Jounal of Experimental Analysis of Behavior, 68(1), 1-25. doi: 10.1901/jeab.1997.68-1

Maes, J. (2003). Response stability and variability induced in humans by different feedback contingencies. Learning \& behavior, 31(4), 332-48. doi: 10.3758/BF03195995.

McComas, J., Hartman, E.C., \& Jiménez, A. (2008). Some Effects of Magnitude of Reinforcement on Persistence of Responding. Psychological Record, 58(4), 517-28. doi: 10.1007/BF03395635.

McElroy, E., \& Neuringer, A. (1990). Effects of alcohol on reinforced repetitions and reinforced variation in rats. Psychopharmacology, 102(1), 49-55. doi: https://doi.org/10.1007/BF02245743

Miller, N., \& Neuringer, A. (2000). Reinforcing variability in adolescents with autism. Journal of Applied Behavior Analysis, 33(2), 151-65. doi: 10.1901/jaba.2000.33-151

Mistretta, C. M., \& Baum, B. J. (1984). Quantitative study of taste buds in fungiform and circumvallate papillae of young and aged rats. Journal of Anatomy, 138 (Pt 2), 323-32.

Mook, D. M., \& Neuringer, A. (1994). Different effects of amphetamine on reinforced variations versus repetitions in spontaneously hypertensive rats (SHR). Physiology \& Behavior, 56(5), 939-44. doi: https://doi.org/10.1016/0031-9384(94)90327-1

Mook, D. M., Jeffrey, J., \& Neuringer, A. (1993). Spontaneously hypertensive rats (SRH) readily learn to vary but not to repeat instrumental responding, Behavioral \& Neural Biology, 59(2), 126-35. doi: 10.1016/0163-1047(93)90847-B 
Moraes, E. N. (2008). Processo de envelhecimento e bases da avaliação multidimensional do idoso. In A. P. A. Borges e A. M. C. Coimbra (Orgs.), Envelhecimento e Saúde da Pessoa Idosa (pp. 151-175). Rio de Janeiro, RJ: EAD/ENSP.

Moraes, E. N. (2012). Saúde do Idoso. In E. N. Moraes (Ed.), Atenção à saúde do idoso: aspectos conceituais (pp. 9-22). Brasília, DF: Organização Pan-Americana da Saúde.

Moraes, E. N., Marino, M. C. A., \& Santos, R. R. (2010). Principais Síndromes Geriátricas. Revista Médica de Minas Gerais, 20(1), 54-66.

Morris, M.D. \& Capaldi, E.J. (1979). Extinction responding following partial reinforcement: The effects of number of rewarded trials and magnitude of reward Animal Learning \& Behavior, 7(4), 509-13. doi: https://doi.org/10.3758/BF03209711

Myerson, J., Robertson, S., \& Hale, S. (2007). Aging and intraindividual variability in performance: analysis of response time distributions. Journal of Experimental Analysis of Behavior, 88(3), 319-37. doi: 10.1901/jeab.2007.88-319

Nelson, E. A., \& Dannefer, D. (1992). Aged heterogeneity: fact or fiction? The fate of diversity in gerontological research, The Gerontologist, 32(1), 17-23. doi: 10.1093/geront/32.1.17

Neuringer, A. (1991). Operant variability and repetition as functions of interresponse time. Journal of Experimental Psychology: Animal Behavior Processes, 17(1), 3-12. doi: 10.1037/0097-7403.17.1.3

Neuringer, A. (2002). Operant variability: Evidence, functions, and theory. Psychonomic Bulletin \& Review, 9(4), 672-705. doi: 10.3758/BF03196324

Neuringer, A. (2004). Reinforced Variability in Animals and People: Implications for Adaptive Action. American Psychologist, 59(9), 891-906. doi: http://dx.doi.org/10.1037/0003066X.59.9.891

Neuringer, A. (2009). Operant variability and the power of reinforcement. The Behavior Analyst Today, 10(2), 319-343. doi: http://dx.doi.org/10.1037/h0100673

Neuringer, A., \& Huntley, R. W. (1991). Reinforced variability in rats: Effects of gender, age and contingency. Physiology \& Behavior, 51(1), 145-149. doi: 10.1016/00319384(92)90216-O

Neuringer, A., \& Jensen, G. (2012). The predictably unpredictable operant. Comparative Cognition \& Behavior Reviews, 7, 55-84. doi: 10.3819/ccbr.2012.70004

Neuringer, A., Kornell, N., \& Olufs, M. (2001). Stability and variability in extinction, Journal of Experimental Psychology: Animal Behavior Processes, 27(1), 79-94. doi: 10.1037/00977403.27.1.79 
Nevin J. A. (1974). Response strength in multiple schedules. Journal of the Experimental Analysis of Behavior, 21(3), 389-408. doi:10.1901/jeab.1974.21-389

Nevin, J.A., Mclean, A.P. \& Grace, R.C.(2001). Resistance to extinction: contingency termination and generalization decrement. Animal Learning \& Behavior, 29(2), 176-191. doi: https://doi.org/10.3758/BF03192826

Odum, A. L., Ward, R. D., Barnes, C. A., \& Burke, K. A. (2006). The effects of delayed reinforcement on variability and repetition of response sequences. Journal of the Experimental Analysis of Behavior, 86(2), 159-179. doi: 10.1901/jeab.2006.58-05

Page, S., \& Neuringer, A. (1985). Variability is an operant. Journal of Experimental Psychology: Animal Behavior Processes, 11(3), 429-452. doi: http://dx.doi.org/10.1037/0097-7403.11.3.429

Parahyba, M. I., \& Veras, R. (2008). Diferenciais sociodemográficos no declínio funcional em mobilidade física entre idosos no Brasil. Ciência e Saúde Coletiva, 13(4), 1257-1264. doi://dx.doi.org/10.1590/S1413-81232008000400022

Pavlik, W. B., \& Collier, A. C. (1977). Magnitude and schedule of reinforcement in rats' resistance to extinction-within subjects. The American Journal of Psychology, 90(2), 195205. doi: http://dx.doi.org/10.2307/1422042

Pelleymounter, M. A., Smith, M. Y., \& Gallagher, M. (1987). Spatial learning impairments in aged rats trained with a salient configuration of stimuli, Psychobiology, 15(3), 248-254. doi: $10.3758 / \mathrm{BF} 03327276$

Perone, M. (2018). How I learned to stop worrying and love replication failures. Perspectives on Behavior Science, 42(1), 91-108.doi: 10.1007/s40614-018-0153-x.

Rangel, P. C. N. (2010). Variabilidade comportamental: uma comparação entre pessoas jovens e idosas (Tese de Doutorado). Instituto de Psicologia Universidade de Brasília, Brasília.

Ribes, E. (1996). Some Thoughts onde the nature of a theory of benhavior development and its application. In Bijou, S.M., \& Ribes, E. (Org.), New Directions in Behavior Development (pp. 35-46. Okland, CA: Context Press.

Roberts, W. A. (1969). Resistance to extinction following partial and consistent reinforcement with varying magnitudes of reward. Journal of Comparative and Physiological Psychology, 67(3), 395-400. doi: http://dx.doi.org/10.1037/h0026795.

Rodríguez, R. M., \& Hunziker, M. H. L. (2008). Behavioral variability: A unified notion and some criteria for experimental analysis. Revista Mexicana de Análisis de la Conducta, 34(2), 135-145.

Rowe, J. W., \& Kahn, R. L. (1998). Successful Aging. New York, NY: Dell Trade Paperback. 
Samelo, M. J. (2008). Investigação sobre desamparo aprendido em humanos (Dissertação de Mestrado). Instituto de Psicologia, Universidade de São Paulo, São Paulo.

Samelo, M. J. (2012). Desamparo aprendido e imunização em humanos: avaliação metodológica/conceitual e uma proposta experimental (Tese de Doutorado). Instituto de Psicologia, Universidade de São Paulo, São Paulo.

Samson, R. D., Venkatesh, A., Patel, D. H., Lipa, P., \& Barnes, C. A. (2014). Enhanced performance of aged rats in contingency degradation and instrumental extinction tasks. Behavioral neuroscience, 128(2), 122-133. doi:10.1037/a0035986

Santos, J. L. F., Lebrão, M. L., Duarte, Y. A. O., \& Lima, F. D. (2008). Functional performance of the elderly in instrumental activities of daily living: an analysis in the municipality of São Paulo, Brazil. Cadernos de Saúde Pública, 24(4), 879-886. doi: http://dx.doi.org/10.1590/S0102-311X2008000400019

Schaefer, H. H., \& Steinhorst, R. A. (1959). The effect of changing the schedule of reinforcement upon duration of responding, Journal of Experimental Analysis of Behavior, 2(4), 335-341. doi: 10.1901/jeab.1959.2-335

Schoenbaum, G., Nugent, S., Saddoris, M. P., \& Gallagher, M. (2002). Teaching old rats new tricks: Age-related impairments in olfactory reversal learning. Neurobiology of Aging, 23(4), 555-564. doi: http://dx.doi.org/10.1016/S0197-4580(01)00343-8

Schoenfeld W. N. (1968). On the difference in resistance to extinction following regular and periodic reinforcement. Journal of the Experimental Analysis of Behavior, 11(3), 259-261. doi:10.1901/jeab.1968.11-259

Schwartz B. (1980). Development of complex, stereotyped behavior in pigeons. Journal of the Experimental Analysis of Behavior, 33(2), 153-166. doi:10.1901/jeab.1980.33-153

Shalev U., Morales M., Hope B., Yap J., \& Shaham Y. (2001). Time-dependent changes in extinction behavior and stress-induced reinstatement of drug seeking following withdrawal from heroin in rats. Psychopharmacology, 156(1), 98-107. doi: 10.1007/s002130100748

Shull, R. L., \& Grimes, J. A. (2006). Resistance to extinction following variable-interval reinforcement: Reinforcer rate and amount. Journal of the Experimental Analysis of Behavior, 85(1), 23-39. http://dx.doi.org/10.1901/jeab.2006.119-04/

Sidman, M. (1976). Táticas da pesquisa científica: Avaliação dos dados experimentais na psicologia (M. E. Paiva, Trad.). São Paulo, SP: Brasiliense. (Original publicado em 1960)

Skinner, B. F. (1966). Phylogeny and ontogeny of behavior. Science, 153(3741), 1205-1213. doi: $10.1126 /$ science.153.3741.1205 
Skinner, B. F. (1981). Selection by consequences. Science, 213(4507), 501-504. doi: 10.1126/science.7244649

Skinner, B. F., \& Vaughan, M. E. (1985). Viva bem a velhice. São Paulo, SP: Summus Editorial.

Soares, P. G., Costa, C. E., Aló, R. M., Luiz, A., \& Cunha, T. R. L. (2017). Custo da resposta: Como tem sido definido e estudado? Perspectivas em Análise do Comportamento, 8(2), 258268. https://dx.doi.org/10.18761/PAC.2017.020

Souza, A. S. (2009). Aquisição e resistência a mudança dos operantes variar e repetir (Tese de Doutorado. Instituto de Psicologia, Universidade de Brasília, Brasília.

Stebbins, W. C. (1962). Response latency as a function of amount of reinforcement. Journal of the Experimental Analysis of Behavior, 5(3), 305-307. doi:10.1901/jeab.1962.5-305

Stebbins, W. C., \& Lanson, R. N. (1962). Response latency as a function of reinforcement schedule. Journal of the Experimental Analysis of Behavior, 5(3), 299-304. doi:10.1901/jeab.1962.5-299

Stephens, D. N., Weidmann, R., Quartermain, D., \& Sarter, M. (1985) Reversal learning in senescent rats. Behavioural Brain Research, 17(3), 193-202. doi: https://doi.org/10.1016/0166-4328(85)90043-9

Tomanari, G., Pine, A., \& Silva, M. T. (2003). Ratos wistar sob regimes rotineiros de restrição hídrica e alimentar. Revista Brasileira De Terapia Comportamental E Cognitiva, 5(1), 57 71. https://doi.org/10.31505/rbtcc.v5i1.91

Tremont, P.J. (1984). Variability of force and interresponse time under random interval reinforcement schedules. Behavioural Processes 9(4), 413-420. doi: https://doi.org/10.1016/0376-6357(84)90026-3

Van Praag, H., Shubert, T., Zhao, C., \& Gage, F. H. (2005). Exercise Enhances Learning and Hippocampal Neurogenesis in Aged Mice. The Journal of Neuroscience, 25(38), 8680-8685. doi: 10.1523/JNEUROSCI.1731-05.2005

Villas-Bôas, A. A. (2006). Efeitos do procedimento de extinção sobre o responder de ratos: sequências de respostas como operante (Dissertação de Mestrado). Instituto de Psicologia, Universidade de São Paulo, São Paulo.

Vogel, R., \& Annau, Z. (1973). An operant discrimination task allowing variability of reinforced response patterning. Journal of the Experimental Analysis of Behavior, 20(1), 16. doi:10.1901/jeab.1973.20-1

Wagner, A. R. (1961). Effects of amount and percentage of reinforcement and number of acquisition trials on conditioning and extinction. Journal of Experimental Psychology, 62(3), 234-242. doi: http://dx.doi.org/10.1037/h0042251 
Wagner, K., \& Neuringer, A. (2006). Operant variability when reinforcement is delayed. Learning \& Behavior, 34(2), 111-123. doi: 10.3758/BF03193187

Ward, R. D., Bailey, E. M., \& Odum, A. L. (2006). Effects of D-anphetamine and ethanol on variable and repetitive key-peck sequence in pigeons. Journal of Experimental Analysis of Behavior, 86(3), 285-305. doi: https://doi.org/10.1901/jeab.2006.17-06

Wells, M. (1999). Teaching an old rat new tricks: The effects of age on behavioral variability (Unpublished undergraduate thesis). Reed College, Portland, Oregon.

Winocur, G. (1998). Environmental Influences on Cognitive Decline in Aged Rats, Neurobiology of Aging, 19(6), 589-597. doi: http://dx.doi.org/10.1016/S01974580(98)00107-9

Yamada, M. T. (2007). Manutenção e extinção da variabilidade comportamental em função de diferentes contingências de reforçamento (Dissertação de Mestrado). Instituto de Psicologia, Universidade de São Paulo, São Paulo.

Yamada, M. T. (2012). Variabilidade comportamental como função de diferentes contingências de reforçamento e sua ordem de apresentação (Tese de doutorado). Instituto de Psicologia, Universidade de São Paulo, São Paulo.

Zuccolo, P. F., Ávila, R., Nakano, E. Y., Litvoc, J., Lopes, M. A., \& Bottino, C. M.C. (2012). Instrumental activity of daily living performance in healthy and cognitively intact seniors from a Brazilian sample and its relation to age and other socio-demographic variables, International Psychogeriatrics, 24(5), 784-793. doi: 10.1017/S104161021100250X 